\title{
Ordenação das páginas do Google - "Page Rank"
}

\author{
Mariana Pereira de Melo
}

\author{
DisSERTAÇÃO APRESENTADA \\ $\mathrm{AO}$ \\ Instituto De Matemática e Estatística \\ DA \\ UnIVERSIDAde DE SÃo PAUlO \\ PARA \\ OBTENÇÃO DO TÍTULO \\ $\mathrm{DE}$ \\ Mestre em CiênCIAS
}

\author{
Programa: Estatística \\ Orientador: Profa. Dra. Cláudia Peixoto
}

Durante o desenvolvimento deste trabalho o autor recebeu auxílio financeiro do CNPq

São Paulo, maio de 2009 


\section{Ordenação das páginas do Google - "Page Rank"}

Este exemplar corresponde à redação

final da dissertação devidamente corrigida

e defendida por Mariana Pereira de Melo

e aprovada pela Comissão Julgadora.

Banca Examinadora:

- Profa. Dra. Cláudia Monteiro Peixoto - IME-USP.

- Prof. Dr. Marcelo Finger - IME-USP.

- Prof. Dr. Ronaldo Garcia - UNICAMP. 


\section{Agradecimentos}

Primeiramente, devo agradecer a minha orientadora, Prof. Dra. Cláudia Peixoto, que sempre demonstrou acreditar em meu potencial, pela orientação e grande dedicação e, principalmente, pelo ótimo convívio desde o início da minha graduação. Com suas argumentações científicas e suas sugestões, tive a oportunidade de enriquecer meu conhecimento.

Um agradecimento especial deve ser feito ao meu querido marido, André, por sua extrema paciência, pelo seu amor, por sempre estar disposto a me ajudar em qualquer situação, inclusive neste trabalho e, principalmente, pelo seu apoio que me conforta e me deixa mais forte para superar meus desafios.

Agradeço aos meus familiares que sempre acreditaram e torceram por em mim. Em especial, aos meus pais, Ada e Gerson, que me deram não somente a vida, mas principalmente educação e condições de estudo e que, junto com minha irmã, Mayara, de diferentes maneiras me ajudaram muito a concluir esta etapa da minha vida. Obrigada por compreenderem todos os momentos de ausência e por todo o apoio que me deram, sempre acreditando e me fazendo acreditar que sou capaz.

Devo agradecer ao Prof. Dr. Adilson Simonis, que sugeriu o tema desta dissertação, pela amizade e apoio, acreditando também no meu potencial.

Ao meus verdadeiros amigos, de década, e alguns mais recentes que, apesar de minha ausência, estão sempre em meu pensamento.

Não posso esquecer de uma pessoa muito especial, a quem sempre recorro nos momentos mais difíceis, me confortando e me dando forças para continuar lutando, meu anjo da guarda e padrinho, José Pereira, sempre presente.

Meus agradecimentos à entidade financiadora deste projeto, CNPQ, que possibilitou a realização de meu trabalho.

Este trabalho é dedicado a todas estas pessoas, especiais e essenciais em minha vida. 



\section{Resumo}

Grande parte do sucesso do Google provém do algoritmo Page Rank, que avalia quantitativamente a importância de cada página na web. Esta ordenação é obtida através do vetor estacionário de uma matriz estocástica específica, utilizando o Método das Potências. A velocidade de convergência deste método será avaliada em detalhe, já que se trata de uma resposta imediata da pesquisa do usuário.

A fim de entender as diferentes situações que o modelo pode enfrentar, diversas simulações são apresentadas neste trabalho. Em particular, estamos interessados nos fatores que influenciam a velocidade de convergência. Para tanto, o número de páginas total e de cada conjunto fechado, bem como o número de conjuntos fechados e de nós pendentes foram estudados.

Palavras-chave: Cadeias de Markov, Page-Rank, Velocidade de Convergência, Distribuição Estacionária. 



\section{Abstract}

Great part of Google's success comes from the Page Rank algorithm, wich quantitatively evaluates the importance of each page on the web. This sort is achieved through a specifc stochastic matrix stationary vector, using the Power Method. The convergency speed of this method will be evaluated in details, since this is a imediate response for the user search.

In order to understand the diferent situations the model can confront, several simulations are shown in this work. In particular, we are interested in the factors which influences the convergency speed.

For that, the total and inside each closed set number of pages and also the closed sets and dangling nodes numbers were studied.

Keywords: Markov Chains, Page-Rank, Convergence Speed, Stationary Distribution. 



\section{Sumário}

Lista de Tabelas $\quad$ ix

1 Introdução 1

1.1 Considerações Preliminares . . . . . . . . . . . . . . . . . . . . . . 1

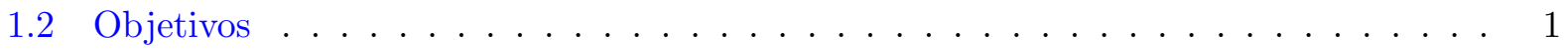

1.3 Organização do Trabalho . . . . . . . . . . . . . . . . . . 2

2 Cadeias de Markov $\quad 3$

2.1 Cadeias de Markov . . . . . . . . . . . . . . . . . . . . . . . . 3

2.2 Definições e Propriedades . . . . . . . . . . . . . . . . . . . . . . 4

2.3 Distribuição Estacionária . . . . . . . . . . . . . . . . . . 6

2.4 Método das Potências . . . . . . . . . . . . . . . . . . . . 15

3 Matriz Google $\quad 17$

3.1 Page Rank - Determinação da Importância da Página . . . . . . . . . . . . . . . 17

3.2 Utilização do Método das Potências ～. . . . . . . . . . . . . . . . . . . . . 19

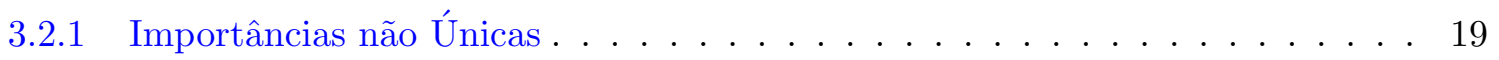

3.2 .2 Nós Pendentes . . . . . . . . . . . . . . . . . . . . . . . 19

3.3 Modificação Sugerida . . . . . . . . . . . . . . . . . . . . . . . . 21

4 Simulação $\quad 29$

4.1 Quantidade de Links por Página . . . . . . . . . . . . . . . . . . . . 29

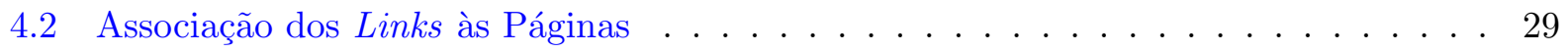

4.3 Resultados . . . . . . . . . . . . . . . . . . . . 30

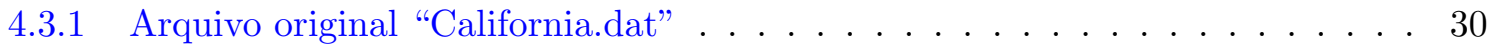

4.3 .2 Arquivo original "Epa.dat" . . . . . . . . . . . . . . . 33

4.3.3 Influência dos Fatores na Velocidade de Convergência . . . . . . . . . . . . . 35

A Número Médio de Iterações $\quad 39$

B Comparação entre $\alpha=0,85$ e $\alpha=0,99$

$\begin{array}{ll}\text { Referências Bibliográficas } & 67\end{array}$ 



\section{Lista de Tabelas}

4.1 Número de iterações para cada valor de $\alpha$, número de páginas que possuem mesma posição com $\alpha_{1}$ e $\alpha_{2}$ e distância média quando houve alteração. . . . . . . . . . . . . 31

4.2 Ordenação das trinta primeiras páginas quando $\alpha=0,85$ e suas respectivas posições

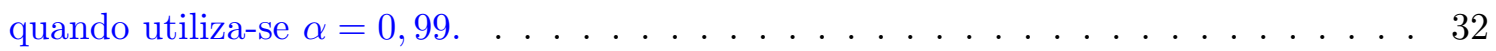

4.3 Ordenação das trinta primeiras páginas quando $\alpha=0,85$ e suas respectivas posições quando utiliza-se $\alpha=0,99 . \ldots \ldots \ldots \ldots \ldots$

4.4 Número de iterações para cada valor de $\alpha$, número de páginas que possuem mesma posição com $\alpha_{1}$ e $\alpha_{2}$ e distância média quando houve alteração. . . . . . . . . . . . . 33

4.5 Ordenação das trinta primeiras páginas quando $\alpha=0,85$ e suas respectivas posições quando utiliza-se $\alpha=0,99 \ldots \ldots \ldots \ldots \ldots \ldots$

4.6 Ordenação das trinta primeiras páginas quando $\alpha=0,85$ e suas respectivas posições quando utiliza-se $\alpha=0,99 . \ldots \ldots \ldots \ldots \ldots \ldots \ldots$

A.1 Número médio de iterações para $\alpha=0,85$ e $\alpha=0,99$ e seus respectivos intervalos de confiança, variando o tamanho do grupo fechado, a existência do Grupo de Ligação e o número de Nós Pendentes, para um total de 1.000 páginas nos conjuntos fechados. . . . . . . . . . . . . . . . . 40

A.2 Número médio de iterações para $\alpha=0,85$ e $\alpha=0,99$ e seus respectivos intervalos de confiança, variando o tamanho do grupo fechado, a existência do Grupo de Ligação e o número de Nós Pendentes, para um total de 10.000 páginas nos conjuntos fechados. . . . . . . . . . . . . . . 41

A.3 Número médio de iterações para $\alpha=0,85$ e $\alpha=0,99$ e seus respectivos intervalos de confiança, variando o tamanho do grupo fechado, a existência do Grupo de Ligação e o número de Nós Pendentes, para um total de 100.000 páginas nos conjuntos fechados. . . . . . . . . . . . . . . . 42

A.4 Número médio de iterações para $\alpha=0,85$ e $\alpha=0,99$ e seus respectivos intervalos de confiança, variando o tamanho do grupo fechado, a existência do Grupo de Ligação e o número de Nós Pendentes, para grupos fechados com até 750 páginas. . . . . . . . . . . . . . . . . . . 43 
A.5 Número médio de iterações para $\alpha=0,85$ e $\alpha=0,99$ e seus respectivos intervalos de confiança, variando o tamanho do grupo fechado, a existência do Grupo de Ligação e o número de Nós Pendentes, , para grupos fechados com até 7.500 páginas. . . . . . . . . . . . . . . . . . . . . . 44

A.6 Número médio de iterações para $\alpha=0,85$ e $\alpha=0,99$ e seus respectivos intervalos de confiança, variando o tamanho do grupo fechado, a existência do Grupo de Ligação e o número de Nós Pendentes, , para grupos fechados com até 75.000 páginas. . . . . . . . . . . . . . . . . . . . 45

A.7 Número médio de iterações para $\alpha=0,85$ e $\alpha=0,99$ e seus respectivos intervalos de confiança, variando o tamanho do grupo fechado, para grupos fechados de 1.000 e 10.000 páginas. . . . . . . . . . . . . . . . . . 46

A.8 Número médio de iterações para $\alpha=0,85$ e $\alpha=0,99$ e seus respectivos intervalos de confiança, variando o tamanho do grupo fechado, para grupos fechados de 500 a 2.000 páginas. . . . . . . . . . . . . . . . . . . . 47

A.9 Número médio de iterações para $\alpha=0,85$ e $\alpha=0,99$ e seus respectivos intervalos de confiança, variando o tamanho do grupo fechado, para grupos fechados de 5.000 a 20.000 páginas. . . . . . . . . . . . . . . . 48

A.10 Número médio de iterações para $\alpha=0,85$ e $\alpha=0,99$ e seus respectivos intervalos de confiança, variando o tamanho do grupo fechado, para um total de 500, 5.000 e $\mathbf{5 0 . 0 0 0}$ páginas nos conjuntos fechados. . . . . . . . . 49

A.11 Número médio de iterações para $\alpha=0,85$ e $\alpha=0,99$ e seus respectivos intervalos de confiança, variando o tamanho do grupo fechado, para combinações de grupos fechados de 50 e 500 páginas e 450 e 500 páginas.

A.12 Número médio de iterações para $\alpha=0,85$ e $\alpha=0,99$ e seus respectivos intervalos de confiança, variando o tamanho do grupo fechado, para combinações de grupos fechados de 500 e 5.000 páginas e 4.500 e 5.000 páginas. 51

A.13 Número médio de iterações para $\alpha=0,85$ e $\alpha=0,99$ e seus respectivos intervalos de confiança, variando o tamanho do grupo fechado, para combinações de grupos fechados de diversos tamanhos. . . . . . . . . . . . . . 52

B.1 Número médio de iterações para $\alpha=0,85$ e $\alpha=0,99$, número médio de páginas com diferentes posições, média do Desvio Médio e média do Desvio Máximo, variando o tamanho do grupo fechado, a existência do Grupo de Ligação e o número de Nós Pendentes, para um total de 1.000 páginas nos conjuntos fechados. . . . . . . . . . . . . . . . . 54 
B.2 Número médio de iterações para $\alpha=0,85$ e $\alpha=0,99$, número médio de páginas com diferentes posições, média do Desvio Médio e média do Desvio Máximo, variando o tamanho do grupo fechado, a existência do Grupo de Ligação e o número de Nós Pendentes, para um total de 10.000 páginas nos conjuntos fechados. . . . . . . . . . . . . . . 55

B.3 Número médio de iterações para $\alpha=0,85$ e $\alpha=0,99$, número médio de páginas com diferentes posições, média do Desvio Médio e média do Desvio Máximo, variando o tamanho do grupo fechado, a existência do Grupo de Ligação e o número de Nós Pendentes, para um total de 100.000 páginas nos conjuntos fechados. . . . . . . . . . . . . . . . 56

B.4 Número médio de iterações para $\alpha=0,85$ e $\alpha=0,99$, número médio de páginas com diferentes posições, média do Desvio Médio e média do Desvio Máximo, variando o tamanho do grupo fechado, a existência do Grupo de Ligação e o número de Nós Pendentes, para grupos fechados com até 750 páginas. . . . . . . . . . . . . . . . . . . . . 57

B.5 Número médio de iterações para $\alpha=0,85$ e $\alpha=0,99$, número médio de páginas com diferentes posições, média do Desvio Médio e média do Desvio Máximo, variando o tamanho do grupo fechado, a existência do Grupo de Ligação e o número de Nós Pendentes, para grupos fechados

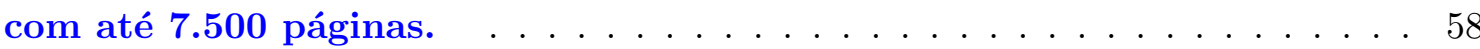

B.6 Número médio de iterações para $\alpha=0,85$ e $\alpha=0,99$, número médio de páginas com diferentes posições, média do Desvio Médio e média do Desvio Máximo, variando o tamanho do grupo fechado, a existência do Grupo de Ligação e o número de Nós Pendentes, para grupos fechados com até 75.000 páginas. . . . . . . . . . . . . . . . . . . . . . . 59

B.7 Número médio de iterações para $\alpha=0,85$ e $\alpha=0,99$, número médio de páginas com diferentes posições, média do Desvio Médio e média do Desvio Máximo, variando o tamanho do grupo fechado, para grupos fechados de 1.000 e 10.000 páginas. . . . . . . . . . . . . . . . . . . 60

B.8 Número médio de iterações para $\alpha=0,85$ e $\alpha=0,99$, número médio de páginas com diferentes posições, média do Desvio Médio e média do Desvio Máximo, variando o tamanho do grupo fechado, para grupos fechados de 500 a 2.000 páginas.

B.9 Número médio de iterações para $\alpha=0,85$ e $\alpha=0,99$, número médio de páginas com diferentes posições, média do Desvio Médio e média do Desvio Máximo, variando o tamanho do grupo fechado, para grupos fechados de 5.000 a 20.000 páginas 
B.10 Número médio de iterações para $\alpha=0,85$ e $\alpha=0,99$, número médio de páginas com diferentes posições, média do Desvio Médio e média do Desvio Máximo, variando o tamanho do grupo fechado, para um total de 500, 5.000 e 50.000 páginas nos conjuntos fechados. . . . . . . . . . . 63

B.11 Número médio de iterações para $\alpha=0,85$ e $\alpha=0,99$, número médio de páginas com diferentes posições, média do Desvio Médio e média do Desvio Máximo, variando o tamanho do grupo fechado, para combinações de grupos fechados de 50 e 500 páginas e 450 e 500 páginas. . . . . . . . . 64

B.12 Número médio de iterações para $\alpha=0,85$ e $\alpha=0,99$, número médio de páginas com diferentes posições, média do Desvio Médio e média do Desvio Máximo, variando o tamanho do grupo fechado, para combinações de grupos fechados de 500 e $\mathbf{5 . 0 0 0}$ páginas e 4.500 e $\mathbf{5 . 0 0 0}$ páginas. . . . . 65

B.13 Número médio de iterações para $\alpha=0,85$ e $\alpha=0,99$, número médio de páginas com diferentes posições, média do Desvio Médio e média do Desvio Máximo, variando o tamanho do grupo fechado, para combinações de grupos fechados de diversos tamanhos. . . . . . . . . . . . . . 66 


\section{Capítulo 1}

\section{Introdução}

\subsection{Considerações Preliminares}

Quando o Google entrou no ar, por volta dos anos 90, uma característica que o diferenciou dos demais mecanismos de busca foi que suas listas de resultados sempre apresentavam as páginas de forma ordenada, ou seja, as mais relevantes no topo da lista. Já com outros mecanismos de busca, este ranqueamento não era feito de forma eficiente.

Grande parte do sucesso do Google provém do algoritmo Page Rank, que avalia quantitativamente a importância de cada página na web, promovendo um ranqueamento das páginas, obtido a partir da ordenação do vetor estacionário da matriz Google. Desse modo, quando são feitas buscas através do Google, as páginas que encontram-se no topo apresentam conteúdo supostamente mais útil e satisfatório ao usuário.

Devido a proeminência do Google como mecanismo de busca, seu sistema de ordenação teve uma profunda influência no desenvolvimento e estruturação da internet, e em quais tipos de informação e serviços são mais acessados frequentemente.

Esta dissertação trata a etapa em que é avaliada a importância de cada página, de forma que, quando o usuário faz uma busca e o subconjunto de dados com a informação desejada é encontrado, as páginas mais importantes sejam apresentadas nas primeiras posições da lista de resultados.

\subsection{Objetivos}

O primeiro objetivo é apresentar o algoritmo Page-Rank de forma detalhada retomando a teoria de Cadeias de Markov.

Em seguida, devido a importância do tempo de convergência do algoritmo, um estudo detalhado de vários fatores que possam influenciar na velocidade de convergência será feito. Em particular, características da Cadeia de Markov envolvida será estudada, tais como sua dimensão, número de conjuntos fechado, etc. Para este último, diversas simulações foram realizadas e os resultados encontram-se no Apêndice. 


\subsection{Organização do Trabalho}

No Capítulo 2 são apresentados uma revisão de Cadeias de Markov contemplando algumas definições e propriedades úteis para a compreensão do algoritmo, bem como o Método das Potências para a obtenção dos autovalores e autovetores de uma matriz, com o objetivo de prover embasamento teórico para o entendimento do Page-Rank.

O algoritmo de ordenação Page-Rank encontra-se no Capítulo 3.

O Capítulo 4 contém um estudo sobre a velocidade de convergência do algoritmo, além das conclusões deste trabalho.

Nos Apêndices A e B encontram-se os resultados das simulações. 


\section{Capítulo 2}

\section{Cadeias de Markov}

Neste capítulo será apresentada uma revisão sobre Cadeias de Markov, abragendo alguns tópicos fundamentais ao entendimento deste trabalho. As definições e os teoremas aqui citados encontramse em [4], [5], [6], [7], [8] e [9].

\subsection{Cadeias de Markov}

Seja $(\Omega, F, P)$ um espaço de probabilidade. Considere a sequência de variáveis aleatórias $\left\{X_{n}\right\}_{n \geq 0}$ assumindo valores num espaço de estados finito $\vartheta .\left\{X_{n}\right\}_{n \geq 0}$ é uma Cadeia de Markov discreta se para qualquer sequência de estados $x_{0}, x_{1}, \ldots, x_{n}, x_{n+1} \in \vartheta$

$$
P\left[X_{n+1}=x_{n+1} \mid X_{n}=x_{n}, X_{n-1}=x_{n-1}, \ldots, X_{0}=x_{0}\right]=P\left[X_{n+1}=x_{n+1} \mid X_{n}=x_{n}\right] .
$$

De acordo com a definição acima, uma Cadeia de Markov é uma sequência de variáveis aleatórias tais que, para qualquer instante $n, X_{n+1}$ é condicionalmente independente de $X_{0}, \ldots, X_{n-1}$ dado $X_{n}$, ou seja, o próximo estado do processo é independente do passado, uma vez que o estado presente é conhecido.

Este estudo ficará restrito aos casos em que a cadeia é estacionária (homogênea), ou seja, onde a probabilidade condicional

$$
P\left[X_{n+1}=j \mid X_{n}=i\right]=P\left[X_{n+k+1}=j \mid X_{n+k}=i\right]=p(i, j), \quad i, j \in \vartheta
$$

é independente do momento em que ocorre.

A probabilidade $p(i, j)$ é chamada de probabilidade de transição da Cadeia de Markov.

Considere $\left\{X_{n}\right\}_{n \geq 0}$ uma Cadeia de Markov estacionária, discreta e com espaço de estados finito $\vartheta=\{1,2, \ldots, n\}$. Chama-se $\mathbf{P}$ a matriz de transição utilizada para expressar as probabilidades de transição, associando-se a i-ésima linha e coluna de $\mathbf{P}$ com o i-ésimo estado de $\vartheta$.

A matriz $\mathbf{P}$ é expressa do seguinte modo:

$$
\mathbf{P}=\left(\begin{array}{cccc}
p(1,1) & p(1,2) & \ldots & p(1, n) \\
p(2,1) & p(2,2) & \ldots & p(2, n) \\
\vdots & \vdots & \vdots & \vdots \\
p(n, 1) & p(n, 2) & \ldots & p(n, n)
\end{array}\right)
$$


Esta matriz tem as seguintes propriedades:

(i) $p(i, j) \geq 0$, para $\forall i, j \in \vartheta$;

(ii) $\sum_{j} p(i, j)=1, \forall i \in \vartheta$.

Definição: Qualquer matriz quadrada que satisfaça as condições (i) e (ii) acima será uma matriz estocástica.

\subsection{Definições e Propriedades}

\section{Estado recorrente}

Seja $\left\{X_{n}\right\}_{n \geq 0}$ uma Cadeia de Markov discreta com espaço de estados $\vartheta$ e matriz de transição $\mathbf{P}$. Dado que o estado inicial da cadeia é $i$, considere $T_{i}$ o tempo do primeiro retorno e $N_{i}$ o número total de retornos.

O estado $i$ é chamado recorrente se

$$
P\left\{T_{i}<\infty \mid X_{0}=i\right\}=1
$$

caso contrário, se $P\left\{T_{i}=\infty \mid X_{0}=i\right\}>0$, então $i$ é chamado estado transiente.

Utilizaremos a notação $P_{i}\left\{T_{i}<\infty\right\}=P\left\{T_{i}<\infty \mid X_{0}=i\right\}$ a partir daqui.

Além disso, um estado recorrente $j$ é chamado nulo se

$$
E_{j}\left\{T_{j}\right\}=\infty
$$

caso contrário, é chamado recorrente positivo.

Denota-se por

$$
f_{i, k}^{(n)}=P\left(X_{n}=k, X_{n-1} \neq k, \ldots, X_{2} \neq k, X_{1} \neq k \mid X_{0}=i\right),
$$

a probabilidade de que a primeira visita ao estado $k$, partindo de $i$, ocorra no $n$-ésimo passo.

Assim,

$$
f_{i, k}=\sum_{n=1}^{\infty} f_{i, k}^{(n)}
$$

é a probabilidade que a cadeia visite $k$, iniciando de $i$.

Temos que:

(a) $k$ é recorrente se $f_{k, k}=1$, e se isto ocorre então $E_{i}\left(N_{k}\right)=\infty$;

(b) $k$ é transiente se $f_{k, k}<1$, e se isto ocorre então $E_{i}\left(N_{k}\right)<\infty$, pois,

$$
P_{i}\left(N_{k}=n\right)=f_{i, k}\left(f_{k, k}\right)^{n-1}\left(1-f_{k, k}\right) .
$$


Deste modo,

$$
E_{i}\left(N_{k}\right)=\sum_{n=1}^{\infty} n \times f_{i, k}\left(f_{k, k}\right)^{n-1}\left(1-f_{k, k}\right)=\frac{f_{i, k}}{1-f_{k, k}} .
$$

Assim, se $f_{k, k}=1$ então $E_{i}\left(N_{k}\right)=\infty$ e se $f_{k, k}<1, E_{i}\left(N_{k}\right)<\infty$.

\section{Conjunto fechado}

Considere um subconjunto $C$ do espaço de estados $\vartheta$. Este conjunto é dito fechado se $p(i, k)=0$ para todo $i \in C$ e $k \notin C$.

Se um conjunto fechado consiste de um único estado, este será chamado estado absorvente, ou seja, o estado $k$ é absorvente se e somente se $p(k, k)=1$.

Uma Cadeia de Markov é chamada irredutível se não existirem conjuntos fechados não vazios exceto o próprio $\vartheta$. Se $\vartheta$ tem um subconjunto fechado próprio, a cadeia é chamada redutível.

\section{Estados Intercomunicantes}

Dois estados, $i$ e $j$, são ditos intercomunicantes se, para algum $n \geq 0, p^{(n)}(i, j)>0$ e para algum $m \geq 0, p^{(m)}(j, i)>0$, ou seja, nesta cadeia é possível ir de $i$ para $j$ em $n$ passos e de $j$ para $i$ em $m$ passos. Os inteiros $m$ e $n$ não precisam ser iguais.

Teorema 2.1: Uma Cadeia de Markov será irredutível se e somente se todos os pares de estados são intercomunicantes.

\section{Prova:}

$(\Longrightarrow)$ Assuma que a cadeia seja irredutível e defina $C_{j}=\left\{i: p^{(n)}(i, j)=0\right.$ para todo $\left.n \geq 0\right\}$, isto é, $C_{j}$ é o conjunto de todos os estados a partir dos quais o estado $j$ não pode ser alcançado.

O conjunto $C_{j}$ é um subconjunto fechado de $\vartheta$ e para provar isto é necessário mostrar que se $i \in$ $C_{j}$ e $k \notin C_{j}$, então $p(i, k)=0$. Contudo, se $k \notin C_{j}$ então para algum $m \geq 0$ segue que $p^{(m)}(k, j)>0$. Se $p(i, k)$ for positivo, então $p^{(m+1)}(i, j)=\sum_{l \in \vartheta} p(i, l) \times p^{(m)}(l, j) \geq p(i, k) \times p^{(m)}(k, j)>0$, o que implica $i \notin C_{j}$. Esta contradição leva-nos a concluir que $p(i, k)=0$ para todo $i \in C_{j}, k \notin C_{j}$. Logo, $C_{j}$ é fechado.

O único subconjunto fechado não-vazio de uma cadeia irredutível é o próprio $\vartheta$. Deste modo, $C_{j}=\vartheta$ ou $C_{j}=\emptyset$. Entretanto, como $j \notin C_{j}$ pois $p^{(0)}(j, j)=1$, temos que $C_{j}=\emptyset$, o que significa que $j$ pode ser alcançado a partir de todos os estados. Como $j$ foi escolhido de forma arbitrária, conclui-se que todos os estados são intercomunicantes.

$(\Longleftarrow)$ Assuma que todos os estados sejam intercomunicantes e que $\chi$ seja um conjunto fechado não-vazio de $\vartheta$. Se $j \in \chi$, então para um estado arbitrário $i \in \vartheta$ existe um $n_{i}$ tal que $p^{\left(n_{i}\right)}(j, i)>0$. Como o estado $i$ pode ser alcançado a partir do estado $j \in \chi$, segue que $i \in \chi$. Mas $i$ foi escolhido de forma arbitrária em $\vartheta$, assim $\chi=\vartheta$. Logo, a cadeia é irredutível. 


\section{Período de um estado ou de uma cadeia}

Um estado recorrente $j$ é chamado periódico de período $\delta$ se $\delta \geq 2$ é o maior inteiro para o qual

$$
P_{j}\left\{T_{j}=n \delta \text { para algum } n \geq 1\right\}=1 \text {; }
$$

caso contrário, $j$ é chamado aperiódico.

\subsection{Distribuição Estacionária}

Devido a própria flutuação especificada por sua matriz de transição, não é possível que a sequência $\left\{X_{n}\right\}_{n \geq 0}$ convirja para determinado estado em particular. Porém, sujeita a certas condições, é possível que ela se estabilize.

Nota-se que a existência de uma distribuição limite para $X_{n}$, quando $n \rightarrow \infty$, está estritamente ligada a existência da distribuição estacionária.

O vetor $\pi$ é denominado distribuição estacionária de uma cadeia se possuir entradas $(\pi(k)$ : $k \in \vartheta)$ tal que

(a) $\pi(i) \geq 0$ para todo $i \in \vartheta$, e $\sum_{i \in \vartheta} \pi(i)=1$;

(b) $\pi^{\prime}=\pi^{\prime} \mathbf{P}$, onde dizemos que $\pi(j)=\sum_{i} \pi(i) p(i, j)$ para todo $j \in \vartheta$.

Temos que $\pi^{\prime} \mathbf{P}^{n}=\pi^{\prime}$, para todo $n \geq 0$, pois,

$$
\pi^{\prime}=\pi^{\prime} \mathbf{P}=\pi^{\prime} \mathbf{P}^{1}=\left(\pi^{\prime} \mathbf{P}\right) \mathbf{P}^{1}=\ldots=\pi^{\prime} \mathbf{P}^{n-2}=\left(\pi^{\prime} \mathbf{P}\right) \mathbf{P}^{n-2}=\pi^{\prime} \mathbf{P}^{n-1}=\left(\pi^{\prime} \mathbf{P}\right) \mathbf{P}^{n-1}=\pi^{\prime} \mathbf{P}^{n}
$$

A distribuição estacionária é um estado de equilíbrio da cadeia. Se, o estado inicial for escolhido segundo $\pi$, então todos os instantes seguintes também terão distribuição $\pi$, mostrando que a cadeia é estacionária com o passar do tempo; neste caso, $\pi$ é também a distribuição limite de $X_{n}$ quando $n \rightarrow \infty$, pois

$$
P_{\pi}\left(X_{1}=i\right)=\sum_{u \in \vartheta} P_{\pi}\left(X_{1}=i, X_{0}=u\right)=\sum_{u \in \vartheta} P\left(X_{1}=i \mid X_{0}=u\right) \pi(u)=\sum_{u \in \vartheta} p(u, i) \pi(u)=\pi(i)
$$

Teorema 2.2: Suponha que $P$ seja irredutível, aperiódica e que tenha distribuição estacionária $\pi$. Então, $\lim _{n \rightarrow \infty} p^{(n)}(i, j)=\pi(j)$.

Os lemas a seguir serão utilizados na demonstração do Teorema 2.2.

Lema 2.1: Considere $T_{j}^{k}$ o tempo necessário para fazer $k$ visitas ao estado $j$. Para $k \geq 1$, 
$P_{i}\left(T_{j}^{k}<\infty\right)=f_{i, j}\left(f_{j, j}\right)^{k-1}$

Prova: A fim de fazer $k$ visitas a $j$, primeiro temos que ir do estado inicial $i$ a $j$ e então retornar $k-1$ vezes de $j$ para $j$. A propriedade de Markov implica que a probabilidade de todos os eventos ocorrerem é o produto de suas probabilidades. Logo,

$$
P_{i}\left(T_{j}^{k}<\infty\right)=f_{i, j}\left(f_{j, j}\right)^{k-1}
$$

Lema 2.2: Sendo $i$ o estado inicial da cadeia, então:

$$
E_{i}\left(N_{j}\right)=\frac{f_{i, j}}{1-f_{j, j}}, \forall i, j, \in \vartheta
$$

Prova: O valor esperado de qualquer variável aleatória $N$ com valores inteiros não negativos, pode ser calculado por:

$$
E_{i}\left(N_{j}\right)=\sum_{k=1}^{\infty} P_{i}\left(N_{j} \geq k\right)
$$

Como $P_{i}\left(N_{j} \geq k\right)=P_{i}\left(T_{j}^{k}<\infty\right)$, temos pelo Lema 2.1 que:

$$
E_{i}\left(N_{j}\right)=f_{i, j} \sum_{k=1}^{\infty}\left(f_{j, j}\right)^{k-1}=\frac{f_{i, j}}{1-f_{j, j}} .
$$

Lema 2.3: Considere $\pi(\cdot)$ a distribuição estacionária de uma cadeia irredutível e $j \in \vartheta$ tal que $\pi(j)>0$. Então $j$ é recorrente.

Prova: Considere $i$ o estado inicial da cadeia e $N_{j}$ o número de visitas a $j$. Temos que:

$$
N_{j}=\sum_{n=1}^{\infty} 1_{\left\{X_{n}=j\right\}} .
$$

Tomando a esperança dos dois lados,

$$
\begin{gathered}
E_{i}\left(N_{j}\right)=\sum_{n=1}^{\infty} p^{(n)}(i, j) \Rightarrow \sum_{i \in \vartheta} \pi(i) E_{i}\left(N_{j}\right)=\sum_{i \in \vartheta} \pi(i) \sum_{n=1}^{\infty} p^{(n)}(i, j) \\
\Rightarrow \sum_{i \in \vartheta} \pi(i) E_{i}\left(N_{j}\right)=\sum_{n=1}^{\infty} \sum_{i \in \vartheta} \pi(i) p^{(n)}(i, j)=\sum_{n=1}^{\infty} \pi(j)=\infty,
\end{gathered}
$$

pois $\pi(j)>0$. 
De acordo com o Lema $2.2, E_{i}\left(N_{j}\right)=f_{i, j} /\left(1-f_{j, j}\right)$, portanto

$$
\infty=\sum_{i} \pi(i) \frac{f_{i, j}}{1-f_{j, j}} \leq \frac{1}{1-f_{j, j}}
$$

A segunda inequação segue do fato de que $f_{i, j} \leq 1$ e de que $\pi$ é uma medida de probabilidade. Concluímos que $f_{j, j}=1$, ou seja, $j$ é recorrente.

Retornando a demonstração do Teorema 2.2:

Prova: Considere $\vartheta^{2}=\vartheta \times \vartheta$ e defina a matriz de transição $\mathbf{P}^{*}$ em $\vartheta^{2}$ por

$$
p^{*}((i, j),(k, l))=p(i, k) \times p(j, l)
$$

ou seja, cada coordenada move-se independentemente. O primeiro passo é verificar se $\mathbf{P}^{*}$ é irredutível e, para isso, é necessário que a cadeia seja aperiódica. Como $\mathbf{P}$ é irredutível, existem $M, N$ tais que $p^{(M)}(i, k)>0$ e $p^{(N)}(j, l)>0$. Como $k$ e $l$ tem período 1 , existe $Z$ tal que, $p^{(M+Z)}(k, k)>0$ e $p^{(N+Z)}(l, l)>0$, assim:

$$
p^{*(M+N+Z)}((i, j),(k, l))>0
$$

O segundo passo é observar que como as duas coordenadas são independentes, então $\pi^{*}(i, j)=$ $\pi(i) \pi(j)$ define uma distribuição estacionária para $\mathbf{P}^{*}$ e, de acordo com o Lema 2.3, todos os estados de $\mathbf{P}^{*}$ são recorrentes. Denote $\left(X_{n}, Y_{n}\right)$ a cadeia em $\vartheta \times \vartheta$ e considere $T$ o primeiro instante em que as duas coordenadas são iguais, isto é, $T=\min \left\{n \geq 0: X_{n}=Y_{n}\right\}$. A partir de $T$ os dois processos seguem o mesmo caminho. Seja $V_{(i, i)}=\min \left\{n \geq 0: X_{n}=Y_{n}=i\right\}$ o tempo da primeira visita a $(i, i)$. Como $\mathbf{P}^{*}$ é irredutível e recorrente, $V_{(i, i)}<\infty$ com probabilidade 1 e, como $T \leq V_{(i, i)}$, devemos ter $T<\infty$.

Utilizando a técnica de acoplamento e considerando que $X_{0}=i$ e $Y_{0}$ com distribuição estacionária $\pi$, temos:

$$
\begin{aligned}
P_{i}\left(X_{n}=j\right) & =P_{i}\left(X_{n}=j, T \leq n\right)+P_{i}\left(X_{n}=j, T>n\right) \\
& =P_{\pi}\left(Y_{n}=j, T \leq n\right)+P_{i}\left(X_{n}=j, T>n\right) \\
& \leq P_{\pi}\left(Y_{n}=j\right)+P_{i}\left(X_{n}=j, T>n\right) \Rightarrow \\
P_{i}\left(X_{n}=j\right)-P_{\pi}\left(Y_{n}=j\right) & \leq P_{i}\left(X_{n}=j, T>n\right)
\end{aligned}
$$

e similarmente, $P_{\pi}\left(Y_{n}=j\right)-P_{i}\left(X_{n}=j\right) \leq P_{\pi}\left(Y_{n}=j, T>n\right)$.

Assim,

$$
\left|P_{i}\left(X_{n}=j\right)-P_{\pi}\left(Y_{n}=j\right)\right| \leq P_{i}\left(X_{n}=j, T>n\right)+P_{\pi}\left(Y_{n}=j, T>n\right)
$$


e, somando para todo $j$, temos

$$
\begin{gathered}
\sum_{j \in \vartheta}\left|P_{i}\left(X_{n}=j\right)-P_{\pi}\left(Y_{n}=j\right)\right| \leq 2 \times P(T>n) \\
\sum_{j \in \vartheta}\left|p^{(n)}(i, j)-\pi(j)\right| \leq 2 P(T>n) \rightarrow 0
\end{gathered}
$$

Teorema 2.3: Seja $\left\{X_{n}\right\}_{n \geq 0}$ uma Cadeia de Markov irredutível, aperiódica e com distribuição estacionária $\pi$. Então:

$$
E_{i}\left(T_{i}\right)=1 / \pi(i), \quad \forall i \in \vartheta
$$

O Teorema a seguir será utilizado para a demonstração do Teorema 2.3.

Teorema 2.4: Seja $\left\{X_{n}\right\}_{n \geq 0}$ uma Cadeia de Markov, $N_{i}^{(n)}=\sum_{m=1}^{n} 1_{\left\{X_{k}^{(m)}=i\right\}}$ o número total de visitas ao estado $i$ no instante $n$ e $G^{(n)}(k, i)=\sum_{m=1}^{n} p^{(m)}(k, i), i, k \in \vartheta$.

Assim, $E_{k}\left(N_{i}^{(n)}\right)=G^{n}(k, i)$. Temos que:

$$
\lim _{n \rightarrow \infty} \frac{G^{(n)}(k, i)}{n}=\frac{1}{E_{i}\left(T_{i}\right)}
$$

Prova: Considere o caso no qual $i$ é um estado transiente. Pela definição, temos que $E_{i}\left(N_{i}^{(n)}\right)<$ $\infty$, assim $\lim _{n \rightarrow \infty} N_{i}^{(n)}<\infty$ e, consequentemente, $N_{i}^{(n)} / n \rightarrow 0$ quando $n \rightarrow \infty$. Por outro lado, transiência implica $P_{i}\left(T_{i}=\infty\right)>0$, então $E_{i}\left(T_{i}\right)=\infty$ e $1 / E_{i}\left(T_{i}\right)=0$.

Para o caso recorrente, suponha que iniciemos no estado $i$. Seja $R_{i}^{k}=\min \left\{n \geq 1: N_{i}^{(n)}=k\right\}$ o instante do k-ésimo retorno a $i$. Considere também $W_{i}^{1}=R_{i}^{1}=T_{i}$ e, para $k \geq 2$, seja $W_{i}^{k}=$ $R_{i}^{k}-R_{i}^{k-1}$ o tempo de espera entre a $(k-1)$-ésima e a $k$-ésima visita a $i$.

As variáveis aleatórias $W_{i}^{1}, W_{i}^{2}, \ldots$ são independentes e identicamente distribuídas e, consequentemente, possuem mesma média $E_{i}\left(W_{i}^{1}\right)=E_{i}\left(T_{i}\right)$.

De acordo com a Lei Forte dos Grandes Números, temos que:

$$
\lim _{k \rightarrow \infty} \frac{W_{i}^{1}+W_{i}^{2}+\ldots+W_{i}^{k}}{k}=E_{i}\left(T_{i}\right),
$$

com probabilidade 1 , ou seja,

$$
\lim _{k \rightarrow \infty} \frac{R_{i}^{k}}{k}=E_{i}\left(T_{i}\right)
$$

com probabilidade 1 . 
Seja $r=N_{i}^{(n)}$, isto é, no tempo $n$ a cadeia fez exatamente $r$ visitas a $i$. Então a $r$-ésima visita a $i$ ocorre durante ou antes do tempo $n$ e a $(r+1)$-ésima visita ocorre depois do tempo $n$. Deste $\operatorname{modo}, R_{i}^{N_{i}^{(n)}} \leq n<R_{i}^{N_{i}^{(n)}+1} \mathrm{e}$,

$$
\frac{R_{i}^{N_{i}^{(n)}}}{N_{i}^{(n)}} \leq \frac{n}{N_{i}^{(n)}}<\frac{R_{i}^{N_{i}^{(n)}}+1}{N_{i}^{(n)}+1} \times \frac{N_{i}^{(n)}+1}{N_{i}^{(n)}} .
$$

Quando $n \rightarrow \infty$, temos $\frac{N_{i}^{(n)}+1}{N_{i}^{(n)}}$ convergindo para 1 e $n / N_{i}^{(n)}$ limitado entre dois valores que convergem para $E_{i}\left(T_{i}\right)$, logo,

$$
\lim _{n \rightarrow \infty} \frac{n}{N_{i}^{(n)}}=E_{i}\left(T_{i}\right) \Rightarrow \lim _{n \rightarrow \infty} \frac{G^{(n)}(k, i)}{n}=\frac{1}{E_{i}\left(T_{i}\right)}
$$

Retornando a demonstração do Teorema 2.3:

Prova: Do Teorema 2.4, segue que

$$
\lim _{n \rightarrow \infty} \frac{G^{(n)}(k, i)}{n}=\frac{1}{E_{i}\left(T_{i}\right)}
$$

Suponha $\pi(\cdot)$ a distribuição estacionária. De acordo com a equação 2.2 , temos que $G^{(n)}(k, i)=$ $E_{k}\left(N_{i}^{(n)}\right)=\sum_{m=1}^{n} p^{(m)}(k, i)$

Pela definição, sabemos que $\sum_{k \in \vartheta} \pi(k) p^{(m)}(k, i)=\pi(i)$. Somando para todo $m=1,2, \ldots, n$ e dividindo por $n$, encontramos $\sum_{k \in \vartheta} \frac{\pi(k) \sum_{m=1}^{n} p^{(m)}(k, i)}{n}=\pi(i)$.

\section{Resultado: Teorema da Convergência Dominada}

Seja $a(x)$ números não negativos com soma finita e $b_{n}(x)$, tal que $\left|b_{n}(x)\right| \leq 1$ e $\lim _{n \rightarrow \infty} b_{n}(x)=$ $b(x), x \in \vartheta$ e $n \geq 1$. Então:

$$
\lim _{n \rightarrow \infty} \sum_{x \in \vartheta} a(x) b_{n}(x)=\sum_{x \in \vartheta} a(x) b(x)
$$

Deste modo,

$$
\pi(i)=\lim _{n \rightarrow \infty} \sum_{k \in \vartheta} \frac{\pi(k) \sum_{m=1}^{n} p^{(m)}(k, i)}{n}=\lim _{n \rightarrow \infty} \sum_{k \in \vartheta} \frac{\pi(k) G^{(n)}(k, i)}{n}=\sum_{k \in \vartheta} \frac{\pi(k)}{E_{i}\left(T_{i}\right)}=\frac{1}{E_{i}\left(T_{i}\right)} \sum_{k \in \vartheta} \pi(k)=\frac{1}{E_{i}\left(T_{i}\right)}
$$




\section{Teorema 2.5 (Teorema da Razão de Doeblin):}

Sejam $i, j, k$ e $l$ quaisquer estados de uma cadeia irredutível e recorrente.

Então,

$$
\lim _{N \rightarrow \infty} \frac{\sum_{n=0}^{N} p^{(n)}(i, j)}{\sum_{n=0}^{N} p^{(n)}(k, l)} \text { existe. }
$$

Prova: Primeiro serão considerados dois casos especiais e, a partir destes, o caso geral será deduzido.

Sendo $f_{i, j}^{(n)}$ a probabilidade de que a primeira visita ao estado $j$ iniciando do estado $i$ ocorra no instante $n$, considere $g_{i, j}^{(n)}$ a probabilidade de visitar o estado $j$ no instante $n$ sem retornar ao estado $i$, isto é,

$$
g_{i, j}^{(n)}=P\left[X_{n}=j, X_{n-1} \neq i, X_{n-2} \neq i, \ldots, X_{1} \neq i \mid X_{0}=i\right] .
$$

Seja $f_{i, j}=\sum_{n=1}^{\infty} f_{i, j}^{(n)}$ e $g_{i, j}=\sum_{n=1}^{\infty} g_{i, j}^{(n)}$.

Caso 1: Considere $k=l=j \neq i$. Temos que

$$
\sum_{n=0}^{N} p^{(n)}(i, j)=\sum_{n=0}^{N} \sum_{m=0}^{n} f_{i, j}^{(n-m)} p^{(m)}(j, j)
$$

Usando o Teorema de Fubini para justificar a troca da ordem do somatório, temos:

$$
\sum_{n=0}^{N} p^{(n)}(i, j)=\sum_{m=0}^{N} \sum_{n=m}^{N} f_{i, j}^{(n-m)} p^{(m)}(j, j)=\sum_{m=0}^{N} p^{(m)}(j, j) \sum_{p=0}^{N-m} f_{i, j}^{(p)}
$$

Dividindo ambos os lados por $\sum_{n=0}^{N} p^{(n)}(j, j)$ obtemos

$$
\frac{\sum_{n=0}^{N} p^{(n)}(i, j)}{\sum_{n=0}^{N} p^{(n)}(j, j)}=\frac{\sum_{m=0}^{N} p^{(m)}(j, j) \sum_{p=0}^{N-m} f_{i, j}^{(p)}}{\sum_{n=0}^{N} p^{(n)}(j, j)} .
$$

Como todos os estados são recorrentes, por (2.1) temos que $E_{j}\left(N_{j}\right)=\sum_{n=0}^{\infty} p^{(n)}(j, j)=\infty$ e assim

$$
\frac{p^{(n)}(j, j)}{\sum_{m=0}^{n} p^{(m)}(j, j)} \rightarrow 0 \text { quando } n \rightarrow \infty
$$

Resultado: Seja $\left\{a_{n}\right\}_{n=0}^{\infty}$ uma sequência de números não-negativos nos quais $\frac{a_{n}}{\sum_{k=0}^{n} a_{k}} \rightarrow 0$ quando 
$n \rightarrow \infty$ e seja $\left\{b_{n}\right\}_{n=0}^{\infty}$ uma sequência de números convergindo para $b$. Então,

$$
\frac{b_{0} a_{n}+b_{1} a_{n-1}+\ldots+b_{n} a_{0}}{\sum_{k=0}^{n} a_{k}} \rightarrow b, \text { quando } n \rightarrow \infty
$$

Com base no resultado acima, podemos concluir que

$$
\lim _{N \rightarrow \infty} \frac{\sum_{n=0}^{N} p^{(n)}(i, j)}{\sum_{n=0}^{N} p^{(n)}(j, j)}=\sum_{p=0}^{\infty} f_{i, j}^{(p)}=f_{i, j}=1
$$

desde que a cadeia seja irredutível e recorrente.

Caso 2: Considere $k=l=i$.

Usando o Teorema de Fubini novamente, temos:

$$
\begin{gathered}
\sum_{n=0}^{N} p^{(n)}(i, j)=\sum_{n=0}^{N} \sum_{m=0}^{n} p^{(m)}(i, i) g_{i, j}^{(n-m)}= \\
=\sum_{m=0}^{N} p^{(m)}(i, i) \sum_{n=m}^{N} g_{i, j}^{(n-m)}=\sum_{m=0}^{N} p^{(m)}(i, i) \sum_{p=0}^{N-m} g_{i, j}^{(p)} .
\end{gathered}
$$

Dividindo ambos os lados por $\sum_{n=0}^{N} p^{(n)}(i, i)$ obtemos

$$
\frac{\sum_{n=0}^{N} p^{(n)}(i, j)}{\sum_{n=0}^{N} p^{(n)}(i, i)}=\frac{\sum_{m=0}^{N} p^{(m)}(i, i) \sum_{p=0}^{N-m} g_{i, j}^{(p)}}{\sum_{n=0}^{N} p^{(n)}(i, i)}
$$

Tomando $N \rightarrow \infty$ e aplicando o resultado acima, vemos que o limite é $g_{i, j}$.

O caso geral é obtido tomando-se produtos de razões como nos Casos 1 e 2 e utilizando-se do fato de que, quando os limites existem, o limite de um produto é o produto dos limites. Em particular,

$$
\frac{\sum_{n=0}^{N} p^{(n)}(i, j)}{\sum_{n=0}^{N} p^{(n)}(k, l)}=\frac{\sum_{n=0}^{N} p^{(n)}(i, j)}{\sum_{n=0}^{N} p^{(n)}(j, j)} \times \frac{\sum_{n=0}^{N} p^{(n)}(j, j)}{\sum_{n=0}^{N} p^{(n)}(j, l)} \times \frac{\sum_{n=0}^{N} p^{(n)}(j, l)}{\sum_{n=0}^{N} p^{(n)}(l, l)} \times \frac{\sum_{n=0}^{N} p^{(n)}(l, l)}{\sum_{n=0}^{N} p^{(n)}(k, l)}
$$

O seguinte teorema mostra que qualquer Cadeia de Markov irredutível e recorrente tem uma distribuição invariante, embora essa distribuição não seja necessariamente finita.

Teorema 2.6: No caso de uma Cadeia de Markov irredutível e recorrente, o sistema de equações 


$$
\pi(j)=\sum_{k=1}^{\infty} \pi(k) p(k, j)
$$

possui solução $\pi(j)=g_{i, j}$, onde $i$ é arbitrário, sendo $g_{i, j}$ definido na demonstração do Teorema 2.5. Quaisquer duas soluções não-negativas para esta equação diferem somente por uma constante multiplicativa.

Prova: Considere

$$
\sum_{j=1}^{\infty} g_{i, j} p(j, k)=\sum_{j=1}^{\infty} \sum_{n=1}^{\infty} g_{i, j}^{(n)} p(j, k)=\sum_{n=1}^{\infty} \sum_{j=1}^{\infty} g_{i, j}^{(n)} p(j, k)
$$

onde $\sum_{j \neq i} g_{i, j}^{(n)} p(j, k)$ representa a probabilidade de visitar o estado $k$ no tempo $n+1$ sem retornar ao estado $i$. Note que quando $j=i$, a quantidade $g_{i, i}^{(n)}$ é igual $f_{i, i}^{(n)}$ pois ambos representam a probabilidade de retornar à $i$ pela primeira vez no tempo $n$. Assim, para qualquer cadeia recorrente, temos $\sum_{n=1}^{\infty} g_{i, i}^{(n)}=1$. Além disso, note que $p(i, j)=g_{i, j}^{(1)}$.

Podemos simplificar $\sum_{n=1}^{\infty} \sum_{j=1}^{\infty} g_{i, j}^{(n)} p(j, k)$ do seguinte modo:

$$
\sum_{n=1}^{\infty} \sum_{j=1}^{\infty} g_{i, j}^{(n)} p(j, k)=\sum_{n=1}^{\infty} g_{i, k}^{(n+1)}+p(i, k) \sum_{n=1}^{\infty} g_{i, i}^{(n)}=\sum_{n=1}^{\infty} g_{i, k}^{(n+1)}+p(i, k)=g_{i, k} .
$$

Consequentemente, $\left\{g_{i, j}\right\}_{j=1}^{\infty}$ satisfaz o sistema de equações (2.3).

Para mostrar que quaisquer duas soluções não nulas e não-negativas para (2.3) diferem apenas por uma constante, considere $\left\{\pi^{*}(j)\right\}$ uma solução. Como a solução é não-nula, existe um estado $k$ tal que $\pi^{*}(k)>0$. Note que como $\pi^{*}(j)=\sum_{i=1}^{\infty} \pi^{*}(i) p(i, j)$, então $\pi^{*}(j)=\sum_{i=1}^{\infty} \pi^{*}(i) p^{(n)}(i, j)$ para todo $n \geq 1$. Além disso, pela irredutibilidade sabemos que existe algum $n_{0}$ tal que $p^{\left(n_{0}\right)}(k, j)$ é estritamente positivo, desse modo $\pi^{*}(j)=\sum_{i=1}^{\infty} \pi^{*}(i) p^{\left(n_{0}\right)}(i, j) \geq \pi^{*}(k) p^{\left(n_{0}\right)}(k, j)>0$. Assim, uma solução não-nula e não-negativa para (2.3) deve ser, de fato, uma solução estritamente positiva.

Sabemos que $\pi(j)=g_{i, j}$ é uma solução positiva para (2.3). Considere $\left\{\pi^{*}(j)\right\}$ qualquer outra solução positiva. Defina $r_{i, j}=\frac{\pi^{*}(j)}{\pi^{*}(i)} p(j, i)$. Temos que $\left\{r_{i, j}\right\}$ é uma matriz de probabilidade de transição para uma cadeia irredutível e recorrente.

Dos Casos 1 e 2 do teorema da Razão de Doeblin, temos que

$$
1 \leftarrow \frac{\sum_{n=1}^{N} r_{j, i}^{(n)}}{\sum_{n=1}^{N} r_{i, i}^{(n)}}=\frac{\pi^{*}(i)}{\pi^{*}(j)} \frac{\sum_{n=1}^{N} p_{i, j}^{(n)}}{\sum_{n=1}^{N} p_{i, i}^{(n)}} \rightarrow \frac{\pi^{*}(i)}{\pi^{*}(j)} g_{i, j}
$$

Portanto, $\pi^{*}(j)=\pi^{*}(i) g_{i, j}=\pi^{*}(i) \pi(j)$, para $j=1,2, \ldots$ Assim $\pi^{*}(j)$ é uma constante múltipla de $\pi(j)$. 
Logo, podemos concluir que qualquer Cadeia de Markov irredutível e recorrente tem uma única distribuição invariante.

Corolário 2.1: Seja $\mathbf{P}$ uma matriz de transição para uma Cadeia de Markov $\left\{X_{n}\right\}_{n \geq 0}$, então a multiplicidade do autovalor 1 é igual ao número de subconjuntos fechados irredutíveis da cadeia.

Prova: A matriz $\mathbf{P}$ pode ser reescrita em forma de blocos, com cada bloco $\mathbf{P}_{i}, i=1,2, \ldots, m$, correspondendo a um subconjunto fechado irredutível de $\vartheta$ e o último bloco, $\mathbf{Q}$, correspondendo aos estados transientes. Isto é,

$$
\mathbf{P}=\left(\begin{array}{ccccc}
\mathbf{P}_{1} & 0 & \ldots & 0 & 0 \\
0 & \mathbf{P}_{2} & \ldots & 0 & 0 \\
\vdots & \vdots & & \vdots & \vdots \\
0 & 0 & \ldots & \mathbf{P}_{m} & 0 \\
\mathbf{R}_{1} & \mathbf{R}_{2} & \ldots & \mathbf{R}_{m} & \mathbf{Q}
\end{array}\right)
$$

Cada um desses blocos $\mathbf{P}_{i}$ corresponde ao espaço de estados $\vartheta_{i}$ para uma cadeia irredutível e recorrente. Além disso, existe um autovetor $\pi_{i}=\left(0 \ldots 0, \pi_{1}^{(i)}, \pi_{2}^{(i)}, \ldots, \pi_{n_{i}}^{(i)}, 0, \ldots, 0\right)$ com entradas positivas nas coordenadas correspondendo a $\vartheta_{i}$ e zero nas demais com $\pi_{i} \mathbf{P}=\pi_{i}$ para $i=1,2, \ldots, m$. Sendo os $\vartheta_{i}$ 's disjuntos por construção, os $\pi_{i}$ 's tem entradas positivas nas coordenadas não sobrepostas, assim elas são linearmente independentes. Consequentemente a multiplicidade do autovalor 1 é pelo menos igual ao número de subconjuntos fechados irredutíveis de $\vartheta$.

A fim de mostrar que a multiplicidade é no máximo o número de subconjuntos fechados irredutíveis de $\vartheta$, tomamos $\pi^{*}$ como sendo um autovetor arbitrário de $\mathbf{P}$ correspondendo ao autovalor 1 sendo que $\pi^{*}$ pode ser escrito como uma combinação linear dos $\pi_{i}$ 's $, i=1,2, \ldots, m$. Se $\pi^{*} \mathbf{P}=\pi^{*}$, então $\pi^{*} \mathbf{P}^{(k)}=\pi^{*}$ para todo $k=1,2, \ldots$ e assim $\sum_{i=1}^{n^{3}} \pi_{i}^{*} p^{(k)}(i, j)=\pi_{j}^{*}$, para todo $k$.

Se $j$ é um estado transiente, então $\lim _{k \rightarrow \infty} p^{(k)}(i, j)=0$ e assim todas as coordenadas de $\pi^{*}$ correspondendo aos estados transientes são zero. A equação $\sum_{i=1}^{n} \pi_{i}^{*} p(i, j)=\pi_{j}^{*}$ pode agora ser reescrita somando somente os estados recorrentes, da seguinte forma

$$
\sum_{k=1}^{m} \sum_{i \in \vartheta_{k}} \pi_{i}^{*} p(i, j)=\pi_{j}^{*} \text { para } j \in \cup_{k=1}^{m} \vartheta_{k}
$$

Se $i$ e $j$ pertencem a subconjuntos fechados distintos, então $p(i, j)=0$ e $\sum_{i \in C_{k}} \pi_{i}^{*} p(i, j)=\pi_{j}^{*}$ para $j \in C_{k}, k=1,2, \ldots, m$.

Pelo Teorema 2.4, para uma cadeia irredutível e recorrente, a equação $\sum_{i \in C_{k}} \pi_{i}^{*} p(i, j)=\pi_{j}^{*}$ tem 
uma única solução. Daqui obtemos $\pi^{*}=\sum_{k=1}^{m} a_{k} \pi_{k}^{*}$.

Deste modo, a multiplicidade do autovalor 1 é igual ao número de subconjuntos fechados irredutíveis de $\vartheta$.

A seguir será apresentado o Método das Potências para se obter a distribuição estacionária, já que é o autovetor associado ao maior autovalor de $\mathbf{P}$.

\subsection{Método das Potências}

O Método das Potências é um método iterativo utilizado para obtenção do autovalor dominante e seu correspondente autovetor.

Atribui-se uma aproximação inicial arbitrária para o autovetor correspondente ao autovalor dominante que é sucessivamente melhorada até que a precisão requerida seja encontrada. A convergência para o autovalor dominante é simultaneamente obtida.

Os métodos iterativos são mais proveitosos no tratamento de matrizes de grandes dimensões e esparsas, obtendo-se boas estimativas para os seus autovetores.

\section{Método das Potências}

Considere $A$ uma matriz de dimensão $n \times \mathrm{x} n$ com $n$ autovalores $\lambda_{i}, i=1,2, \ldots, n$ que satisfazem $\left|\lambda_{1}\right|>\left|\lambda_{2}\right| \geq\left|\lambda_{3}\right| \geq \ldots \geq\left|\lambda_{n}\right|$, e $n$ correspondentes autovetores $\nu_{j}$, para $j=1, \ldots, n$, linearmente independentes e normalizados.

Um vetor $x_{0}$ pode ser expresso pela combinação linear:

$$
x_{0}=\alpha_{1} \nu_{1}+\alpha_{2} \nu_{2}+\ldots+\alpha_{n} \nu_{n}=\sum_{i=1}^{n} \alpha_{i} \nu_{i}
$$

onde $\alpha_{i}$, para $i=1, \ldots, n$, são escalares nem todos iguais a 0 .

O método iterativo é dado por:

$$
x_{k}=A x_{k-1}, \text { para } k=1,2,3, \ldots
$$

Deste modo,

$$
x_{k}=A x_{k-1}=A^{2} x_{k-2}=\ldots=A^{k} x_{0}=\sum_{i=1}^{n} \alpha_{i} \lambda_{i}^{k} \nu_{i} .
$$

Como $\alpha_{1}, \alpha_{2}, \ldots, \alpha_{r}$ são diferentes de zero, o termo do lado direito da equação 2.5 é governado pelos termos $\sum_{i=1}^{r} \alpha_{i} \lambda_{i}^{k} \nu_{i}$. Em particular, se $r=1$, assumimos que $\alpha_{1} \neq 0$ e temos

$$
x_{k}=\lambda_{1}^{k}\left\{\alpha_{1} \nu_{1}+\sum_{i=2}^{n} \alpha_{i}\left(\frac{\lambda_{i}}{\lambda_{1}}\right)^{k} \nu_{i}\right\}=\lambda_{1}^{k}\left\{\alpha_{1} \nu_{1}+\epsilon_{k}\right\} .
$$

Para $k$ suficientemente grande, $\epsilon_{k}$ é um vetor com elementos muito pequenos. O vetor $x_{k}$ é uma aproximação para o autovetor não normalizado $\nu_{1}$, e é exato se $\left\|\epsilon_{k}\right\|$ for suficientemente pequeno. 
Esta observação é a base para a simplicidade do cálculo do autovalor dominante no método das potências.

Como

$$
x_{k+1}=\lambda_{1}^{k+1}\left\{\alpha_{1} \nu_{1}+\epsilon_{k+1}\right\},
$$

Segue, para qualquer $i$, que:

$$
\frac{\left(x_{k+1}\right)_{i}}{\left(x_{k}\right)_{i}}=\lambda_{1} \frac{\alpha_{1}\left(x_{1}\right)_{i}+\left(\epsilon_{k+1}\right)_{i}}{\alpha_{1}\left(x_{1}\right)_{i}+\left(\epsilon_{k}\right)_{i}} \rightarrow \lambda_{1} \text { quando } k \rightarrow \infty
$$

onde $\left(x_{k}\right)_{i}$ denota a i-ésima componente de $x_{k}$.

\section{Velocidade de Convergência}

A velocidade de convergência irá depender das constantes $\alpha_{i}$, mas mais essencialmente das razões $\left|\frac{\lambda_{2}}{\lambda_{1}}\right|,\left|\frac{\lambda_{3}}{\lambda_{1}}\right|, \ldots,\left|\frac{\lambda_{n}}{\lambda_{1}}\right|$, e quanto menor essas razões mais rápida será a convergência. Em particular, se $\left|\frac{\lambda_{2}}{\lambda_{1}}\right|$ é próximo de 1 , a convergência torna-se muito lenta. 


\section{Capítulo 3}

\section{Matriz Google}

\subsection{Page Rank - Determinação da Importância da Página}

A importância de uma página na web será denominada "importância" e seu cálculo é feito considerando-se a quantidade de referências (links) que esta página recebe em toda a rede, pois parte-se do princípio de que as páginas incluem links apenas para outras com conteúdo confiável e informações valiosas. A "importância" da página $k$ será dada por $\pi(k), \pi(k)>0$ e $\pi(j)>\pi(k)$ indica que a página $j$ é mais importante que a página $k$.

Nossa primeira abordagem será tomar $\pi(k)$ como o número de links para a página $k$. Considere o exemplo a seguir:

Exemplo 1:

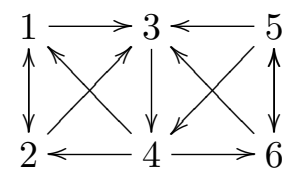

Assim, temos $\pi(1)=2, \pi(2)=2, \pi(3)=4, \pi(4)=2, \pi(5)=1$ e $\pi(6)=2$. Portanto, a página 3 é a mais importante, seguida pelas páginas 1, 2, 4 e 6 . A página 5 é a menos importante, pois recebeu a menor quantidade de links.

Nesta abordagem, um link vindo de uma página importante tem o mesmo peso de um link vindo de uma página menos importante. Para um algoritmo de ranqueamento, é interessante que um link para a página $k$ vindo de uma página importante impulsione sua importância mais do que um link vindo de uma página menos importante.

No exemplo, as páginas 1, 2, 4 e 6 recebem dois links. A página 4 recebe links das páginas 5 e 3, sendo esta última aparentemente mais importante, pois recebe 4 links. Deste modo, a importância da página 4 deveria ser maior que a importância das páginas 1, 2 e 6.

Outro ponto é que uma página com diversos links para outras páginas representará uma grande influência. Logo, para que uma única página não tenha influência demais simplesmente fazendo links para inúmeras outras páginas, dividiremos sua importância pelo número total de links. Com este ajuste, se a página $j$ possuir $n_{j}$ links, um dos quais para a página $k$, então adicionaremos $\pi(j) / n_{j}$ à importância da página $k$.

Considere $L_{k} \subset\{1,2, \ldots, n\}$ o conjunto de páginas que possuem um link para a página $k$. A 
importância da página $k$ será:

$$
\pi(k)=\sum_{j \in L_{k}} \frac{\pi(j)}{n_{j}}
$$

onde $n_{j}$ é o número de links da página $j$. Vale salientar que dois links com mesma página de origem e destino serão considerados como um só.

Remodelando o problema de forma matemática, considere a matriz hyperlink $H=\left[H_{i j}\right]$ na qual a entrada da i-ésima linha e j-ésima coluna é dada por:

$$
H_{i j}= \begin{cases}1 / n_{j} & \text { se } j \in L_{i}, \\ 0 & \text { caso contrário. }\end{cases}
$$

Observe que todas as entradas de $H$ são não-negativas e a soma de cada coluna é 1, a menos que a página correspondente não tenha links.

Podemos escrever a matriz hyperlink do exemplo como segue:

$$
\mathbf{H}=\left(\begin{array}{cccccc}
0 & 1 / 2 & 0 & 1 / 3 & 0 & 0 \\
1 / 2 & 0 & 0 & 1 / 3 & 0 & 0 \\
1 / 2 & 1 / 2 & 0 & 0 & 1 / 3 & 1 / 2 \\
0 & 0 & 1 & 0 & 1 / 3 & 0 \\
0 & 0 & 0 & 0 & 0 & 1 / 2 \\
0 & 0 & 0 & 1 / 3 & 1 / 3 & 0
\end{array}\right)
$$

Considere agora o vetor $\pi=(\pi(1), \pi(2), \ldots, \pi(n))$, cujas entradas são as importâncias de todas as páginas (Page Rank). Por 3.1, temos que:

$$
\pi=H \pi
$$

Deste modo, $\pi$ é o autovetor da matriz $H$ correspondente ao autovalor 1 .

No exemplo, calculando $\pi$ obtemos o seguinte resultado: $\pi(1)=0,1646, \pi(2)=0,1646, \pi(3)=$ $0,2351, \pi(4)=0,2458, \pi(5)=0,0742$ e $\pi(6)=0,1157$.

Comparando este resultado com o obtido inicialmente pela simples contagem de links recebidos, note que a página 3 não é a mais importante. Isto ocorre porque ela está ligada apenas à página 4 , lançando assim toda a sua importância para esta página. Como a página 4 também é linkada pela página 5 , esta torna-se a mais importante.

Observe que podemos considerar a matriz hyperlink $H$ como uma matriz de probabilidade de transição transposta de uma Cadeia de Markov, portanto o vetor de importâncias também pode ser visto como a distribuição estacionária desta cadeia. 
Como já mencionado, uma particularidade da matriz $H$ é sua dimensão, com cerca de 25 bilhões de linhas e colunas. Porém, a maioria das entradas de $H$ são nulas. Em média, cada página tem 10 links, assim, apenas 10 das 25 bilhões de entradas em cada linha não são nulas.

Cada entrada do vetor $\pi$ pode ser interpretada como a importância relativa de cada página, permitindo assim, comparar a importância de quaisquer duas páginas. O vetor $\pi$ deve ser sempre normalizado, para que a soma de todas as popularidades seja 1.

Para encontrar o vetor $\pi$ de uma matriz $H$ utiliza-se o Método das Potências, que foi apresentado a Seção 2.4 .

\subsection{Utilização do Método das Potências}

O uso de (3.1) para ordenar as páginas pode encontrar algumas dificuldades. Nesta seção discutiremos duas questões: importâncias não únicas e nós pendentes ([1] e [2]).

\subsubsection{Importâncias não Únicas}

De acordo com o Corolário 2.1, temos que a multiplicidade do autovalor 1 é igual ao número de subconjuntos fechados irredutíveis da cadeia. Desta forma, uma Cadeia de Markov irredutível possuirá apenas um autovalor igual a 1 e, consequentemente, um único autovetor correspondente que, neste contexto, equivale à unicidade do vetor de importâncias. Considere o exemplo a seguir:

Exemplo 2 ([2]):

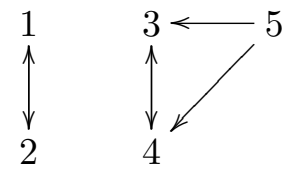

Um possível par de vetores é: $\pi=[1 / 2,1 / 2,0,0,0]^{T}$ e $\pi^{*}=[0,0,1 / 2,1 / 2,0]^{T}$. Além disso, qualquer combinação linear destes dois vetores resulta em outro vetor estacionário, não sendo possível assim identificar qual destes deve ser usado como o vetor de importâncias.

Na Seção 3.3 será apresentada uma modificação na matriz $H$ para resolver este problema.

\subsubsection{Nós Pendentes}

Exemplo 3:

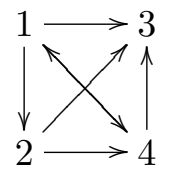


A matriz de transição é dada por:

$$
\mathbf{H}=\left(\begin{array}{cccc}
0 & 0 & 0 & 1 / 2 \\
1 / 3 & 0 & 0 & 0 \\
1 / 3 & 1 / 2 & 0 & 1 / 2 \\
1 / 3 & 1 / 2 & 0 & 0
\end{array}\right)
$$

com vetor estacionário $\pi=[0,0,0,0]^{T}$.

Neste caso, as importâncias de todas as páginas são zero, o que não nos diz nada sobre a importância relativa dessas quatro páginas. O problema é que a página 3 não tem links. Consequentemente, ela toma um pouco da importância das demais páginas a cada processo iterativo, mas não passa isso adiante para nenhuma outra página. Páginas sem links são chamadas de nós pendentes.

Se navergarmos aleatoriamente, em algum ponto certamente vamos ficar presos em um nó pendente. Uma solução, para continuar caminhando, é escolher a próxima página uniformemente em relação ao total de páginas. Isto tem o efeito de modificar a matriz $H$ pela substituição da coluna de zeros, correspondente ao nó pendente, por uma coluna na qual cada registro é $1 / n$, sendo $n$ o total de páginas. Denotaremos esta nova matriz por $S$.

No Exemplo 3, a matriz $S$ é dada por:

$$
\mathbf{S}=\left(\begin{array}{cccc}
0 & 0 & 1 / 4 & 1 / 2 \\
1 / 3 & 0 & 1 / 4 & 0 \\
1 / 3 & 1 / 2 & 1 / 4 & 1 / 2 \\
1 / 3 & 1 / 2 & 1 / 4 & 0
\end{array}\right)
$$

com vetor estacionário $\pi=[0.2,0.2,0.4,0.2]^{T}$.

Note que a matriz $S$ é obtida a partir de $H$ de um modo simples. Se $A$ é a matriz cujos registros são todos zeros, exceto para as colunas correspondente aos nós pendentes, nos quais cada entrada é $1 / n$, então $S=H+A$.

Mesmo que todas as páginas possuam links vindos de outras páginas, é possível termos importâncias nulas atribuídas a algumas destas páginas. Isto ocorre pois a cadeia analisada não é irredutível, ou seja, existe um conjunto de links que torna possível a entrada em determinado grupo de páginas, porém não há links que permitam a saída deste grupo, como é o caso do próximo exemplo:

Exemplo 4:

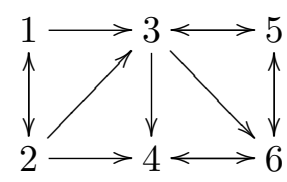


A matriz de transição é dada por:

$$
\mathbf{H}=\left(\begin{array}{cccccc}
0 & 1 / 3 & 0 & 0 & 0 & 0 \\
1 / 2 & 0 & 0 & 0 & 0 & 0 \\
1 / 2 & 1 / 3 & 0 & 0 & 1 / 2 & 0 \\
0 & 1 / 3 & 1 / 3 & 0 & 0 & 1 / 2 \\
0 & 0 & 1 / 3 & 0 & 0 & 1 / 2 \\
0 & 0 & 1 / 3 & 1 & 1 / 2 & 0
\end{array}\right)
$$

com vetor estacionário $\pi=[0,0,0.12,0.24,0.24,0.40]^{T}$.

Na Seção seguinte uma modificação será sugerida para resolver este problema.

\subsection{Modificação Sugerida}

Para encontrar uma nova matriz que seja primitiva e irredutível, iremos modificar a forma que nosso navegador aleatório se move através da web. Neste caso, o movimento do navegador aleatório é determinado por $S$ : ou ele segue um dos links da página atual ou, se a página não tiver links, ele escolhe aleatoriamente qualquer outra página para se mover $([1])$.

Deve-se primeiro escolher um parâmetro $\alpha$ entre 0 e 1 . Com probabilidade $\alpha$, ele é guiado por $S$ e com probabilidade $1-\alpha$, ele escolhe a próxima página uniformemente.

Denotando por $E$ a matriz $n \times n$ cujas entradas são todas 1, obtemos a matriz Google:

$$
G=\alpha S+(1-\alpha) \frac{1}{n} E
$$

onde $0 \leq \alpha \leq 1$. Para $\alpha \in[0,1]$ a matriz $G$ é coluna-estocástica e para $\alpha \in(0,1]$, a solução da equação $\pi P=\pi$ é única. Assim, $G$ tem um único vetor estacionário $\pi$ que pode ser encontrado usando o Método das Potências.

O papel do parâmetro $\alpha$ é importante. Note que se $\alpha=1$, então $G=S$ e trabalharemos com a estrutura original de hyperlinks. Se $\alpha=0$, então $G=1 / n$ e, neste caso, considera-se que há um link entre quaisquer duas páginas, perdendo a estrutura original da web.

Claramente, gostaríamos de manter $\alpha$ próximo a 1 de forma que a estrutura original seja ponderada fortemente no cálculo. Entretanto, há outra consideração: lembre-se que a taxa de convergência do Método das Potências é governada pela magnitude do segundo maior autovalor $\left|\lambda_{2}\right|$. De acordo com a demonstração a seguir, para a matriz Google temos $\left|\lambda_{2}\right|=\alpha$. Isso significa que, quando próximo a 1, a convergência do Método das Potências será muito lenta.

Com o objetivo de satisfazer esses dois interesses concorrentes, os criadores do Page Rank escolheram $\alpha=0,85$, e afirmaram que 50 a 100 interações são suficientes para a obtenção de uma boa aproximação para $\pi([1])$. 
Teorema $3.1([3]):\left|\lambda_{i}\right| \leq 1$, para $\forall i=1, \ldots, n$.

Considere $A$ uma matriz coluna-estocástica dada por:

$$
\mathbf{A}=\left(\begin{array}{lll}
a_{11} & a_{12} & a_{13} \\
a_{21} & a_{22} & a_{23} \\
a_{31} & a_{32} & a_{33}
\end{array}\right),
$$

onde a soma de cada coluna é 1 . Seja $e$ o vetor com todos os elementos iguais a 1 da forma $e^{T}=\left(\begin{array}{lll}e_{1} & e_{2} & e_{3}\end{array}\right)=\left(\begin{array}{lll}1 & 1 & 1\end{array}\right)$, então:

$$
e^{T} A=e^{T} \text { ou } A^{T} e=e
$$

A equação acima indica que a soma dos elementos de cada linha de $A^{T}$ é igual a $1, \operatorname{logo}$ $\left\|A^{T}\right\|_{\infty}=\max _{1 \leq i \leq N} \sum_{j=1}^{N}\left\|a_{i j}\right\|=1$.

Considerando $\rho(A)=\max _{1 \leq i \leq N}\left|\lambda_{i}(A)\right|$, isto é, $\rho(A)$ é a magnitude máxima dos autovalores de $\mathrm{A}$, temos as seguintes propriedades matriciais:

1) $\rho(A) \leq\|A\|_{\infty}$

Denote os autovalores de $A$ por $\lambda_{i}$ e os correspondentes autovetores não-nulos por $x_{i}$, temos:

$$
\begin{gathered}
A x_{i}=\lambda_{i} x_{i} \Longrightarrow\left|\lambda_{i}\right|\left\|x_{i}\right\|=\left\|\lambda_{i} x_{i}\right\|=\left\|A x_{i}\right\| \leq\|A\|\left\|x_{i}\right\| \Longrightarrow \\
\left|\lambda_{i}\right| \leq\|A\| \Longrightarrow\left|\lambda_{i}\right| \leq \sum_{j=1}^{N}\left\|a_{i j}\right\| \Longrightarrow \\
\max _{1 \leq i \leq N}\left|\lambda_{i}\right| \leq \max _{1 \leq i \leq N} \sum_{j=1}^{N}\left\|a_{i j}\right\| \Longrightarrow \rho(A) \leq\|A\|_{\infty} .
\end{gathered}
$$

2) $\rho(A)=\rho\left(A^{T}\right)$

Os autovalores de $A^{T}$ são, por definição, os valores de $\lambda$ para os quais o conjunto de equações

$$
A^{T} y=\lambda y
$$

tem uma solução não-trivial. Deste modo, resolvendo a equação $\operatorname{det}\left(A^{T}-\lambda I\right)=0$, obtemos todos os autovalores de $A^{T}$ e, sabendo-se que $\operatorname{det}(A)=\operatorname{det}\left(A^{T}\right)$, temos:

$$
\operatorname{det}\left(A^{T}-\lambda I\right)=\operatorname{det}\left(A^{T}-\lambda I\right)^{T}=\operatorname{det}(A-\lambda I)
$$

Assim, os autovalores de $A^{T}$ e de $A$ são os mesmos, pois as duas matrizes possuem a mesma equação característica. Os autovetores são, em geral, diferentes. 
Consequentemente, $\rho(A)=\max _{1 \leq i \leq N}\left|\lambda_{i}(A)\right|=\max _{1 \leq i \leq N}\left|\lambda_{i}\left(A^{T}\right)\right|=\rho\left(A^{T}\right)$.

Voltando à demonstração e utilizando as duas propriedades acima, temos:

$$
\rho\left(A^{T}\right)=\rho(A) \leq\|A\|_{\infty}=\max _{1 \leq i \leq N} \sum_{j=1}^{N}\left\|a_{i j}\right\|=1 .
$$

Deste modo, podemos concluir que o autovalor de $A$ de maior valor absoluto é igual a 1 , isto é, $\rho(A)=\max _{1 \leq i \leq N}\left|\lambda_{i}(A)\right| \leq 1$.

Corolário 3.1: $\left|\lambda_{2}\right|=\alpha$.

A demonstração deste Corolário será dividida em duas etapas expostas nos Teoremas abaixo:

Teorema 3.2: Seja $S$ uma matriz coluna estocástica de ordem $n, \alpha$ um número real no qual $0 \leq \alpha \leq 1$ e $E$ uma matriz de ordem $n$ com todas as entradas iguais a 1 .

Considere a matriz Google

$$
G=\left[\alpha S+(1-\alpha) \frac{1}{n} E\right]^{T} .
$$

Seu segundo autovalor será $\left|\lambda_{2}\right| \leq \alpha$.

Prova:

Caso 1: $\alpha=0$

Se $\alpha=0$, a equação (3.2) se reduz a $G=\frac{1}{n} E^{T}$. Como $E$ é uma matriz com posto 1 , então $\lambda_{2}=0$.

Caso 2: $\alpha=1$

Se $\alpha=1$, a equação (3.2) se reduz a $G=S^{T}$. Como $S$ é uma matriz coluna estocástica, de acordo com o Teorema 3.1, conclui-se que $\left|\lambda_{2}\right| \leq 1$.

Caso 3: $0<\alpha<1$

Esta prova será feita através de uma série de lemas, dados a seguir:

Lema 3.2.1: O módulo do segundo autovalor de $G$ é menor que $1 \Rightarrow\left|\lambda_{2}\right|<1$.

Prova: Considere $\left\{X_{n}\right\}_{n \geq 0}$ uma Cadeia de Markov correspondendo a $G$, com espaço de estados $\vartheta$. De acordo com o Corolário 2.1, o número de subconjuntos fechados irredutíveis de $\left\{X_{n}\right\}_{n \geq 0}$ é igual a multiplicidade do autovalor 1. Deste modo, se $\left\{X_{n}\right\}_{n \geq 0}$ possuir apenas um subconjunto fechado irredutível, então possuirá apenas um autovalor igual a 1 e, consequentemente, $\left|\lambda_{2}\right|<1$. 
A seguir será mostrado que existe um único subconjunto fechado irredutível da Cadeia de Markov correspondendo a $G$.

Prova: Considere $\chi$ um conjunto fechado não vazio do espaço de estados $\vartheta$. Pela definição, devemos ter $p(i, j)=0$, para todo $x_{i} \in \chi$ e $x_{j} \notin \chi$. Na matriz Google, todas as probabilidades de transição são positivas, pois a todas adiciona-se o valor $(1-\alpha) \frac{1}{n}$.

Deste modo, como $p(i, j)>0$ para $\forall i, j \in 1, \ldots, n$, conclui-se que $\chi$ é composto por todos os estados da cadeia, isto é, $\chi=\vartheta$. Logo, $\left\{X_{n}\right\}_{n \geq 0}$ possui apenas um subconjunto fechado irredutível.

Lema 3.2.2: O segundo autovetor $x_{2}$ de $G$ é ortogonal a $e \Rightarrow e^{T} x_{2}=0$.

Prova: $G$ é uma matriz linha estocástica de ordem $n$ que pode ser vista como a matriz de transição para uma Cadeia de Markov com $n$ estados. Além disso, temos que $G^{T} e=e$, ou seja, o primeiro autovetor de $G^{T}$ é $e$.

Considere o seguinte teorema: Seja $x_{i}$ é o autovetor de $A$ correspondendo ao autovalor $\lambda_{i}$ e $y_{j}$ o autovetor de $A^{T}$ correspondendo a $\lambda_{j}$, então $x_{i}^{T} y_{j}=0$ se $\lambda_{i} \neq \lambda_{j}$, ([5]).

Deste modo, o segundo autovetor $x_{2}$ de $G$ é ortogonal ao primeiro autovetor $e$ de $G^{T}$, ou seja, $e^{T} x_{2}=0$.

Lema 3.2.3: $\eta^{T} x_{2}=0$, sendo $\eta=\frac{1}{n} e$.

Prova: Como $\eta=\frac{1}{n} e$, então $\eta^{T}=\frac{1}{n} e^{T}$. Deste modo, $\eta^{T} x_{2}=\frac{1}{n} e^{T} x_{2}$. De acordo com o Lema 3.2.2, $e^{T} x_{2}=0$. Consequentemente, $\eta^{T} x_{2}=0$.

Lema 3.2.4: O segundo autovetor $x_{2}$ de $G$ deve ser um autovetor $y_{i}$ de $S^{T}$, e o correspondente autovalor é $\gamma_{i}=\lambda_{2} / \alpha$.

Prova: Denotando o i-ésimo autovalor de $G$ como $\lambda_{i}$ e o correspondente autovetor como $x_{i}$ temos:

$$
G x_{i}=\lambda_{i} x_{i}
$$

Da equação (3.2) temos:

$$
\alpha S^{T} x_{2}+(1-\alpha) \eta^{T} x_{2}=\lambda_{2} x_{2}
$$


Do Lema 3.2.3, segue que:

$$
\alpha S^{T} x_{2}=\lambda_{2} x_{2}
$$

Dividindo ambos os lados por $\alpha$ :

$$
S^{T} x_{2}=\frac{\lambda_{2}}{\alpha} x_{2}
$$

Se $y_{i}=x_{2}$ e $\gamma_{i}=\frac{\lambda_{2}}{\alpha}$, reescrevemos a equação (3.6) da seguinte forma:

$$
S^{T} y_{i}=\gamma_{i} y_{i}
$$

Consequentemente, $x_{2}$ é também um autovetor de $S^{T}$, e a relação entre os autovalores de $G$ e $S^{T}$ que correspondem ao autovalor $x_{2}$ é dada por:

$$
\lambda_{2}=\alpha \gamma_{i}
$$

Para finalizar a demonstração do Teorema 3.2, temos pelo Lema 3.2.4 que $\lambda_{2}=\alpha \gamma_{i}$. Pelo Teorema 3.1, como $S$ é uma matriz coluna-estocástica então $\left|\gamma_{i}\right| \leq 1$. Consequentemente, $\left|\lambda_{2}\right| \leq \alpha$.

Teorema 3.3: Se $S$ tiver ao menos dois subconjuntos fechados irredutíveis (como é o caso da matriz hyperlink), então o segundo autovalor de $G$ é dado por $\lambda_{2}=\alpha$.

\section{Prova:}

Caso 1: $\alpha=0$

Se $\alpha=0$, a partir de (3.2) temos que $G=\frac{1}{n} E^{T}$. Como $E$ é uma matriz com posto 1 , então $\lambda_{2}=0$.

Caso 2: $\alpha=1$

Se $\alpha=1$, a equação (3.2) reduz-se a $G=S^{T}$. Como $S$ é uma matriz coluna estocástica e com o Teorema 3.1, conclui-se que $\left|\lambda_{2}\right| \leq 1$.

Caso 3: $0<\alpha<1$

Esta prova será feita através de dois lemas, dados a seguir: 
Lema 3.3.1: Um autovetor $y_{i}$ de $S^{T}$ que é ortogonal a $e$ é um autovetor $x_{i}$ de $G$. A relação entre esses autovalores é $\lambda_{i}=\alpha \gamma_{i}$.

Prova: Temos que $e^{T} y_{i}=0$. Consequentemente,

$$
\eta^{T} y_{i}=\frac{1}{n} e^{T} y_{i}=0
$$

Denotando o i-ésimo autovalor de $S^{T}$ como $\gamma_{i}$ e o correspondente autovetor como $y_{i}$, temos:

$$
S^{T} y_{i}=\gamma_{i} y_{i}
$$

Das equações (3.2), (3.9) e (3.10),

$$
G y_{i}=\alpha S^{T} y_{i}+(1-\alpha) \eta^{T} y_{i}=\alpha S^{T} y_{i}=\alpha \gamma_{i} y_{i}
$$

Logo, $G y_{i}=\alpha \gamma_{i} y_{i}$.

Lema 3.3.2: Existe $\lambda_{i}=\alpha$, para algum $i$.

Prova: Seja $x_{i}$ um autovetor de $S$ ortogonal a $e$.

Do Corolário 2.1, a multiplicidade do autovalor 1 é igual ao número de subconjuntos fechados irredutíveis de $S$. Assumindo que $S$ tenha ao menos dois subconjuntos fechados irredutíveis, podemos encontrar dois autovetores linearmente independentes $y_{1}$ e $y_{2}$ de $S^{T}$ correspondendo ao autovalor dominante 1 .

Seja,

$$
\begin{aligned}
& k_{1}=y_{1}^{T} e \\
& k_{2}=y_{2}^{T} e
\end{aligned}
$$

Se $k_{1}=0$ temos $x_{i}=y_{1}$, se $k_{2}=0$ temos $x_{i}=y_{2}$ e se $k_{1}, k_{2}>0$, então $x_{i}=\frac{y_{1}}{k_{1}}-\frac{y_{2}}{k_{2}}$. Note que $x_{i}$ é um autovetor de $S^{T}$ com autovalor 1 e ortogonal a $e$. De acordo com o Lema 3.3.1, temos que um vetor $x_{i}$ de $S^{T}$ que é ortogonal a $e$ é um autovetor $z_{i}$ de $G$. Sendo que o autovalor de $S^{T}$ correspondente a $x_{i}$ é $\gamma_{i}$ e o autovalor de $G$ correspondente a $z_{i}$ é $\alpha \gamma_{i}$, como $\gamma_{i}=1$, então o autovalor correspondente a $G$ é $\alpha$. 
Retornando à demonstração do Corolário 3.1, do Teorema 3.2 temos $\lambda_{2} \leq \alpha$ e do Teorema 3.3, conclui-se que existe $\lambda_{i}=\alpha$, para algum $i$.

Deste modo, $\lambda_{2}=\alpha$. 



\section{Capítulo 4}

\section{Simulação}

A velocidade de convergência do Método das Potências deve ser avaliada em detalhes, já que se trata de uma resposta imediata da pesquisa do usuário.

A fim de entender as diferentes situações que o modelo pode enfrentar, diversas simulações são apresentadas neste capítulo. Em particular, estamos interessados nos fatores que influenciam a velocidade de convergência.

As páginas podem pertencer a três grupos distintos: fechados, de ligação e de nós pendentes.

O conjunto fechado é composto por páginas intercomunicantes. As páginas que pertencem ao conjunto de ligação possuem links para o conjunto fechado e para o conjunto de nós pendentes, porém estas páginas não recebem links. Já o conjunto de nós pendentes é composto pelas páginas que não possuem links de saída.

\subsection{Quantidade de Links por Página}

O primeiro passo das simulações é atribuir a cada página dos conjuntos fechados e de ligação a quantidade de links que ela possuirá. Isto foi feito considerando que a quantidade de links apresenta o comportamento de uma Distribuição Uniforme $\{2,5\}$. Aqui, a cada página foi atribuída uma quantidade de links aleatória entre 2 e 5.

A escolha dos parâmetros desta distribuição foi baseada na análise de dois bancos de dados ("Califórnia.dat" e "Epa.dat") construídos a partir da seleção de 200 páginas resultantes de uma pesquisa com a palavra Califórnia e da seleção de 200 páginas com link para www.epa.gov, ambos disponíveis em http://www.cs.cornell.edu/Courses/cs685/2002fa/, onde temos 90,56\% e 91,73\%, respectivamente, das páginas com até (inclusive) 5 links.

\subsection{Associação dos Links às Páginas}

O segundo passo é atribuir a cada link uma página. As páginas foram numeradas de 1 a $T$ (total de páginas). Denota-se $T_{\min }$ o menor número e $T_{\max }$ o maior número entre as páginas de cada conjunto.

Esta atribuição segue uma Distribuição Normal, que foi escolhida acreditando-se que há uma concentração de links em determinadas páginas. Adotou-se em todos os casos que $60 \%$ dos destinos 
concentram-se em $10 \%$ das páginas do conjunto.

Para gerar a distribuição Normal utilizou-se a transformação de Box-Muller: Sejam $U_{1}$ e $U_{2}$ valores independentes gerados pela distribuição Uniforme contínua no intervalo $(0,1)$. Então:

$$
\begin{aligned}
& Z_{1}=\sqrt{-2 \times \ln \left(U_{1}\right)} \cos \left(2 \pi U_{2}\right) \\
& Z_{2}=\sqrt{-2 \times \ln \left(U_{1}\right)} \operatorname{sen}\left(2 \pi U_{2}\right)
\end{aligned}
$$

são normais padronizadas independentes. Descartou-se o valor $Z_{2}$, sendo apenas $Z_{1}$ utilizado para a geração da página de destino, obtida através do seguinte cálculo:

$$
\text { Página de destino }=\mu+Z_{1} \times \sigma
$$

sendo $\mu$ a média $\left(T_{\min }+\frac{T_{\max }-T_{\min }}{2}\right)$ e $\sigma$ o desvio padrão da distribuição normal.

Quando a página de destino gerada estiver fora do conjunto de páginas analisado, ou seja, quando seu valor for inferior a menor ou superior a maior página do conjunto fechado, então ela é descartada e uma nova geração é feita. Outro descarte ocorre quando a página de destino gerada já tenha sido atribuída à página de origem em questão, deste modo uma página nunca terá dois links para um mesmo destino.

Após a atribuição de todas as páginas de destino, calcula-se o vetor estacionário através do Método das Potências. A metodologia deste cálculo está exposta no Capítulo 2.

\subsection{Resultados}

A fim de compararmos o peso da matriz $H$ na ordenação das páginas utilizaremos o vetor de importâncias obtido com $\alpha=0,99$ como referência.

A seguir são apresentados os resultados dos tempos de convergência dos arquivos "California.dat" e "Epa.dat", quando variamos o valor de $\alpha$ em $\{0,85 ; 0,90 ; 0,95 ; 0,99\}$. A precisão utilizada para os cálculos foi de $10^{-8}$.

\subsubsection{Arquivo original "California.dat"}

A seguir será apresentado o número de iterações para cada valor de $\alpha$, o número de páginas que possuem mesma posição com $\alpha_{1}=\{0,85 ; 0,90 ; 0,95\}$ e $\alpha_{2}=0,99$ e a média das distâncias

entre estas posições $\left(\frac{1}{n} \sum_{i=1}^{n}\left|\phi^{\left(\alpha_{2}\right)}(i)-\phi^{\left(\alpha_{1}\right)}(i)\right|\right)$, onde $\phi^{(\alpha)}(i)$ é a posição da $i$-ésima página após a ordenação decrescente do vetor de importâncias, para determinado valor de $\alpha$. 
Tabela 4.1: Número de iterações para cada valor de $\alpha$, número de páginas que possuem mesma posição com $\alpha_{1}$ e $\alpha_{2}$ e distância média quando houve alteração.

\begin{tabular}{|c|c|c|c|}
\hline Califórnia.dat & $\begin{array}{c}\alpha_{1}=0,85 \\
\alpha_{2}=0,99\end{array}$ & $\begin{array}{c}\alpha_{1}=0,90 \\
\alpha_{2}=0,99\end{array}$ & $\begin{array}{c}\alpha_{1}=0,95 \\
\alpha_{2}=0,99\end{array}$ \\
\hline Número de iterações com $\alpha_{1}$ & 95 & 146 & 297 \\
\hline Número de iterações com $\alpha_{2}$ & 1.511 & 1.511 & 1.511 \\
\hline Número de páginas que não estão na mesma posição * & 1.961 & 1.901 & 1.806 \\
\hline Média das distâncias das posições * & 6,624 & 4,227 & 1,860 \\
\hline
\end{tabular}

* Referência: $\alpha=0,99$.

O arquivo "California.dat" possui 9.664 páginas. Como a ordenação das páginas "mais próximas da realidade" é obtida com $\alpha=0,99$, nota-se que, ao utilizarmos $\alpha=0,85$, em torno de $20 \%$ das páginas não estão na mesma posição. A distância em relação ao valor de referência é, em média, de 6,624 posições. Já utilizando $\alpha=0,95$, há uma pequena redução na quantidade de páginas que não estão na posição de referência, porém o mais significante é que as distâncias caem, em média, para 1,860 posições.

A seguir estão identificadas as trinta primeiras páginas obtidas a partir da ordenação do vetor de importâncias com $\alpha=0,85$, apresentando a quantidade de links, a importância e a posição de cada página, quando $\alpha=0,85$ e $\alpha=0,99$. Além disso, calculou-se o módulo da diferença entre estas posições. 
Tabela 4.2: Ordenação das trinta primeiras páginas quando $\alpha=0,85$ e suas respectivas posições quando utiliza-se $\alpha=0,99$.

\begin{tabular}{|c|c|c|c|c|c|c|}
\hline $\begin{array}{c}\text { Identificação } \\
\text { da Página }\end{array}$ & $\begin{array}{l}\text { Qtde. } \\
\text { Links }\end{array}$ & $\begin{array}{c}\text { Importância } \\
\text { com } \alpha=0,85\end{array}$ & $\begin{array}{c}\text { Posição } \\
\operatorname{com} \alpha=0,85\end{array}$ & $\begin{array}{c}\text { Importância } \\
\text { com } \alpha=0,99\end{array}$ & $\begin{array}{c}\text { Posição } \\
\operatorname{com} \alpha=0,99\end{array}$ & $\begin{array}{c}\mid \text { Diferença| } \\
\text { das Posições }\end{array}$ \\
\hline 1488 & 1 & 0,006231 & 1 & 0,064208 & 1 & 0 \\
\hline 4391 & 1 & 0,006085 & 2 & 0,064142 & 2 & 0 \\
\hline 66 & 13 & 0,004773 & 3 & 0,004314 & 18 & 15 \\
\hline 6427 & 0 & 0,004622 & 4 & 0,003031 & 21 & 17 \\
\hline 4823 & 17 & 0,004531 & 5 & 0,003781 & 19 & 14 \\
\hline 2078 & 0 & 0,004342 & 6 & 0,002707 & 24 & 18 \\
\hline 0 & 17 & 0,004197 & 7 & 0,003427 & 20 & 13 \\
\hline 1489 & 1 & 0,003965 & 8 & 0,039611 & 3 & 5 \\
\hline 1617 & 3 & 0,003645 & 9 & 0,002717 & 23 & 14 \\
\hline 2408 & 1 & 0,003635 & 10 & 0,039373 & 4 & 6 \\
\hline 17 & 1 & 0,003572 & 11 & 0,030439 & 5 & 6 \\
\hline 1806 & 0 & 0,003166 & 12 & 0,001971 & 28 & 16 \\
\hline 997 & 1 & 0,003141 & 13 & 0,030193 & 6 & 7 \\
\hline 41 & 3 & 0,002998 & 14 & 0,002946 & 22 & 8 \\
\hline 211 & 1 & 0,002987 & 15 & 0,029848 & 7 & 8 \\
\hline 1862 & 1 & 0,002931 & 16 & 0,002660 & 25 & 9 \\
\hline 1863 & 0 & 0,002931 & 17 & 0,002660 & 26 & 9 \\
\hline 1083 & 0 & 0,002757 & 18 & 0,002090 & 27 & 9 \\
\hline 1079 & 3 & 0,002752 & 19 & 0,001835 & 30 & 11 \\
\hline 126 & 0 & 0,002718 & 20 & 0,001889 & 29 & 9 \\
\hline 8051 & 1 & 0,002595 & 21 & 0,029579 & 8 & 13 \\
\hline 7755 & 5 & 0,002459 & 22 & 0,001725 & 31 & 9 \\
\hline 32 & 13 & 0,002238 & 23 & 0,001724 & 32 & 9 \\
\hline 1660 & 0 & 0,002169 & 24 & 0,001566 & 33 & 9 \\
\hline 2475 & 0 & 0,002153 & 25 & 0,001526 & 35 & 10 \\
\hline 9 & 0 & 0,002123 & 26 & 0,001341 & 37 & 11 \\
\hline 102 & 0 & 0,001947 & 27 & 0,001344 & 36 & 9 \\
\hline 6 & 1 & 0,001890 & 28 & 0,017878 & 9 & 19 \\
\hline 2217 & 1 & 0,001855 & 29 & 0,001266 & 38 & 9 \\
\hline 1661 & 6 & 0,001796 & 30 & 0,001563 & 34 & 4 \\
\hline
\end{tabular}

Um resumo da análise das cem primeiras páginas obtidas a partir da ordenação do vetor de importâncias com $\alpha=0,85$, comparando-se suas respectivas posições quando $\alpha=0,99$ é apresentado abaixo. Na primeira coluna tem-se a quantidade de páginas analisadas. Deste modo, foram analisadas inicialmente as dez primeiras páginas, a seguir, as vinte primeiras páginas, e assim por diante, até a análise das cem primeiras páginas. Na segunda coluna tem-se o número de páginas que apresentaram a mesma posição nas duas ordenações e, na terceira coluna, o número de páginas onde a diferença entre as duas ordenações $(\alpha=0,85$ e $\alpha=0,99)$ foi de até cinco posições. A quarta coluna refere-se à diferença média entre as posições das páginas analisadas e a quinta coluna, à diferença máxima. Na sexta coluna estão identificadas as posições obtidas quando $\alpha=0,85$ e $\alpha=0,99$ no caso onde obteve-se esta diferença máxima. 
Tabela 4.3: Ordenação das trinta primeiras páginas quando $\alpha=0,85$ e suas respectivas posições quando utiliza-se $\alpha=0,99$.

\begin{tabular}{|c|c|c|c|c|c|}
\hline $\begin{array}{c}\text { Total de } \\
\text { Páginas }\end{array}$ & $\begin{array}{c}\text { N.Páginas na } \\
\text { mesma posição }\end{array}$ & $\begin{array}{c}\text { N.Páginas com até } 5 \\
\text { posições de deslocamento }\end{array}$ & $\begin{array}{c}\text { Deslocamento } \\
\text { Médio }\end{array}$ & $\begin{array}{c}\text { Deslocamento } \\
\text { Máximo }\end{array}$ & $\begin{array}{c}\text { Posição } \alpha=0,85 / \text { Posição } \\
\alpha=0,99 \text { no desloc.máximo }\end{array}$ \\
\hline 10 & 2 & 3 & 10,20 & 18 & $06 / 24$ \\
\hline 20 & 2 & 3 & 9,70 & 18 & $06 / 24$ \\
\hline 30 & 2 & 4 & 9,87 & 19 & $28 / 09$ \\
\hline 40 & 2 & 4 & 11,08 & 21 & $37 / 58$ \\
\hline 50 & 2 & 5 & 12,34 & 37 & $58 / 11$ \\
\hline 60 & 2 & 6 & 13,83 & 40 & $64 / 14$ \\
\hline 70 & 2 & 6 & 14,46 & 53 & $75 / 13$ \\
\hline 80 & 2 & 7 & 14,91 & 60 & $75 / 15$ \\
\hline 90 & 3 & 9 & 15,08 & 60 & $75 / 15$ \\
\hline 100 & 3 & 10 & 16,15 & 60 & \\
\hline
\end{tabular}

De acordo com as Tabelas (4.2) e (4.3), apenas as duas primeiras páginas permanecem na mesma posição quando varia-se o parâmetro $\alpha$, sendo que estas apresentam importâncias bem maiores que as demais. Além disso, identifica-se um deslocamento médio e máximo bastante elevado.

\subsubsection{Arquivo original "Epa.dat"}

As mesmas análises da seção anterior foram feitas para o arquivo "Epa.dat".

A seguir será apresentado o número de iterações para cada valor de $\alpha$, o número de páginas que possuem mesma posição com $\alpha_{1}=\{0,85 ; 0,90 ; 0,95\}$ e $\alpha_{2}=0,99$ e a média das distâncias entre estas posições quando houve variação.

Tabela 4.4: Número de iterações para cada valor de $\alpha$, número de páginas que possuem mesma posição com $\alpha_{1}$ e $\alpha_{2}$ e distância média quando houve alteração.

\begin{tabular}{|c|c|c|c|}
\hline Epa.dat & $\alpha_{1}=0,85$ & $\alpha_{1}=0,90$ & $\alpha_{1}=0,95$ \\
& $\alpha_{2}=0,99$ & $\alpha_{2}=0,99$ & $\alpha_{2}=0,99$ \\
\hline Número de iterações com $\alpha_{1}$ & 81 & 123 & 246 \\
\hline Número de iterações com $\alpha_{2}$ & 1.238 & 1.238 & 1.238 \\
\hline Número de páginas que não estão na mesma posição* & 1.930 & 1.799 & 1.469 \\
\hline Média das distâncias das posições* & 8,856 & 5,432 & 1,965 \\
\hline
\end{tabular}

* Referência: $\alpha=0,99$.

O arquivo "Epa.dat" possui 4.772 páginas. Nota-se que, ao utilizarmos $\alpha=0,85$, em torno de $40 \%$ das páginas não estão na mesma posição. A distância em relação ao valor de referência é, em média, de 8,856 posições. Já utilizando $\alpha=0,95$, há uma pequena redução na quantidade de páginas que não estão na posição de referência, porém o mais significante é que a distância cai, em média, para 1,965 posições.

A seguir estão identificadas as trinta primeiras páginas obtidas a partir da ordenação do vetor de importâncias com $\alpha=0,85$, apresentando a quantidade de links, a importância e a posição de cada página, quando $\alpha=0,85$ e $\alpha=0,99$. Além disso, calculou-se o módulo da diferença entre 
estas posições.

Tabela 4.5: Ordenação das trinta primeiras páginas quando $\alpha=0,85$ e suas respectivas posições quando utiliza-se $\alpha=0,99$.

\begin{tabular}{|c|c|c|c|c|c|c|}
\hline $\begin{array}{c}\text { Identificação } \\
\text { da Página }\end{array}$ & $\begin{array}{l}\text { Qtde. } \\
\text { Links }\end{array}$ & $\begin{array}{c}\text { Importância } \\
\text { com } \alpha=0,85\end{array}$ & $\begin{array}{c}\text { Posição } \\
\operatorname{com} \alpha=0,85\end{array}$ & $\begin{array}{c}\text { Importância } \\
\text { com } \alpha=0,99\end{array}$ & $\begin{array}{c}\text { Posição } \\
\operatorname{com} \alpha=0,99\end{array}$ & $\begin{array}{c}\mid \text { Diferença } \mid \\
\text { das Posições }\end{array}$ \\
\hline 1247 & 1 & 0,019116 & 1 & 0,194546 & 1 & 0 \\
\hline 2838 & 1 & 0,018932 & 2 & 0,194391 & 2 & 0 \\
\hline 967 & 0 & 0,006302 & 3 & 0,004125 & 8 & 5 \\
\hline 708 & 0 & 0,005561 & 4 & 0,004251 & 7 & 3 \\
\hline 287 & 0 & 0,005123 & 5 & 0,004314 & 6 & 1 \\
\hline 221 & 0 & 0,004115 & 6 & 0,002610 & 12 & 6 \\
\hline 2175 & 1 & 0,003960 & 7 & 0,002853 & 9 & 2 \\
\hline 1576 & 0 & 0,003747 & 8 & 0,002737 & 11 & 3 \\
\hline 275 & 11 & 0,003654 & 9 & 0,002810 & 10 & 1 \\
\hline 2799 & 0 & 0,003634 & 10 & 0,002575 & 13 & 3 \\
\hline 710 & 0 & 0,003409 & 11 & 0,002128 & 17 & 6 \\
\hline 4249 & 1 & 0,003354 & 12 & 0,002182 & 16 & 4 \\
\hline 1321 & 7 & 0,003339 & 13 & 0,002363 & 14 & 1 \\
\hline 4477 & 1 & 0,003163 & 14 & 0,028444 & 3 & 11 \\
\hline 1194 & 1 & 0,003150 & 15 & 0,002283 & 15 & 0 \\
\hline 4313 & 2 & 0,002864 & 16 & 0,028254 & 4 & 12 \\
\hline 1231 & 1 & 0,002769 & 17 & 0,001708 & 20 & 3 \\
\hline 839 & 0 & 0,002528 & 18 & 0,001655 & 21 & 3 \\
\hline 942 & 1 & 0,002516 & 19 & 0,001899 & 19 & 0 \\
\hline 2040 & 5 & 0,001974 & 20 & 0,001478 & 22 & 2 \\
\hline 46 & 8 & 0,001946 & 21 & 0,001447 & 23 & 2 \\
\hline 4673 & 0 & 0,001946 & 22 & 0,001277 & 26 & 4 \\
\hline 790 & 0 & 0,001941 & 23 & 0,001282 & 25 & 2 \\
\hline 2827 & 1 & 0,001871 & 24 & 0,014396 & 5 & 19 \\
\hline 1508 & 1 & 0,001868 & 25 & 0,001178 & 30 & 5 \\
\hline 45 & 0 & 0,001808 & 26 & 0,001082 & 33 & 7 \\
\hline 87 & 8 & 0,001795 & 27 & 0,001120 & 32 & 5 \\
\hline 1028 & 8 & 0,001736 & 28 & 0,001191 & 28 & 0 \\
\hline 251 & 0 & 0,001715 & 29 & 0,001048 & 35 & 6 \\
\hline 3840 & 0 & 0,001681 & 30 & 0,001155 & 31 & 1 \\
\hline
\end{tabular}

Um resumo da análise das cem primeiras páginas obtidas a partir da ordenação do vetor de importâncias com $\alpha=0,85$, comparando-se suas respectivas posições quando $\alpha=0,99$ é apresentado abaixo. Esta tabela segue o mesmo formato descrito na seção anterior. 
Tabela 4.6: Ordenação das trinta primeiras páginas quando $\alpha=0,85$ e suas respectivas posições quando utiliza-se $\alpha=0,99$.

\begin{tabular}{|c|c|c|c|c|c|}
\hline $\begin{array}{c}\text { Total de } \\
\text { Páginas }\end{array}$ & $\begin{array}{c}\text { N.Páginas na } \\
\text { mesma posição }\end{array}$ & $\begin{array}{c}\text { N.Páginas com até } 5 \\
\text { posições de deslocamento }\end{array}$ & $\begin{array}{c}\text { Deslocamento } \\
\text { Médio }\end{array}$ & $\begin{array}{c}\text { Deslocamento } \\
\text { Máximo }\end{array}$ & $\begin{array}{c}\text { Posição } \alpha=0,85 / \text { Posição } \\
\alpha=0,99 \text { no desloc.máximo }\end{array}$ \\
\hline 10 & 2 & 8 & 2,40 & 6 & $06 / 12$ \\
\hline 20 & 4 & 14 & 3,30 & 12 & $16 / 04$ \\
\hline 30 & 5 & 18 & 3,90 & 19 & $24 / 05$ \\
\hline 40 & 5 & 21 & 4,53 & 19 & $24 / 05$ \\
\hline 50 & 6 & 24 & 4,88 & 19 & $55 / 05$ \\
\hline 60 & 6 & 25 & 5,88 & 21 & $65 / 34$ \\
\hline 70 & 6 & 26 & 6,77 & 27 & $65 / 38$ \\
\hline 80 & 6 & 27 & 7,26 & 27 & $65 / 38$ \\
\hline 90 & 6 & 29 & 7,61 & 27 & $65 / 38$ \\
\hline 100 & 6 & 31 & 7,99 & 27 & \\
\hline
\end{tabular}

De acordo com as Tabelas (4.5) e (4.6), das primeiras dez páginas, apenas as duas primeiras estão na mesma posição nas duas ordenações, ou seja, a maioria das páginas apresentam diferentes posições quando altera-se o parâmetro $\alpha$. Nota-se que a diferença média é menor no conjunto de dados Epa.dat, comparado com o resultado obtido em Califórnia.dat.

\subsubsection{Influência dos Fatores na Velocidade de Convergência}

Conforme já dito, há interesse em verificar a influência do parâmetro $\alpha$, do número de páginas total e dentro de cada conjunto fechado, do número de conjuntos fechados e dos nós pendentes no número de iterações necessárias para a convergência.

Considere $\pi^{(n)}(i)$ a importância da $i$-ésima página na $n$-ésima iteração. O número de iterações foi obtido utilizando o Método das Potências até que $\max _{i}\left\{\pi^{(n)}(i)-\pi^{(n-1)}(i)\right\}<10^{-8}$. Os números mínimo e máximo de links iguais a 2 e 5 , respectivamente. Para o parâmetro $\alpha$, adotamos valores 0,85 e 0,99; simulações foram feitas em conjuntos de 500 até 710.000 páginas; em relação ao número de subconjuntos fechados, temos uma variação de 1 a 100 e a quantidade de nós pendentes foi proporcional ao número total de páginas: $\{0 ; 5 \% ; 50 \% ; 100 \% ; 200 \%\}$. Quando há páginas pertencentes ao grupo de ligação, fixou-se o tamanho deste em $10 \%$ do total de páginas dos grupos fechados e $10 \%$ de seus links destinam-se aos nós pendentes.

Para cada combinação de valores acima foram feitas 500 simulações e os dados apresentados são as médias dos resultados obtidos nestas 500 simulações.

As tabelas de resultados apresentam as seguintes informações: total de páginas (TP), quantidade de grupos fechados (QGF), total de páginas em cada conjunto fechado (TPGF), total de páginas do grupo de ligação (TPGL) e total de nós pendentes (TNP). Como resultado temos: número de iterações necessárias para a convergência ao utilizarmos $\alpha=0,85$ (NI com $\alpha=0,85$ ), número de iterações necessárias para a convergência ao utilizarmos $\alpha=0,99$ (NI com $\alpha=0,99$ ), número de páginas que apresentaram posições distintas ao utilizarmos $\alpha=0,85$ e $\alpha=0,99$ (NPD), média do deslocamento destas páginas diferentes (MedD) e máximo deslocamento que as páginas apresentaram (MaxD) sendo o deslocamento definido como $\left|\phi^{(0,99)}(i)-\phi^{(0,85)}(i)\right|$, onde $\phi^{(\alpha)}(i)$ é a 
posição da $i$-ésima página após a ordenação decrescente do vetor estacionário $\pi$, para determinado valor de $\alpha$.

De acordo com as Tabelas A.1 a A.6 parece que:

(i) A existência do grupo de ligação e a quantidade de nós pendentes não altera o número de iterações.

(ii) Quando o total de páginas compõem um único conjunto fechado, tanto para $\alpha=0,85$ como para $\alpha=0,99$, o número de iterações é baixo e seu comportamento é bastante diferente do mencionado na literatura ([1]) (para $\alpha=0,85,50$ a 100 iterações são necessárias para a convergência e para $\alpha=0,99$, este valor é muito mais elevado). Porém, tal comportamento é obtido quando se tem mais de um conjunto fechado.

(iii) Quando se fixa o número de grupos, variando-se o total de páginas do conjunto fechado, a medida que este número aumenta, o número de iterações decai. Por exemplo, um total de 1.000 páginas divididas em 5 grupos, sendo cada grupo com 200 páginas, apresenta um número de iterações em torno de 84 iterações, para um total de 10.000 páginas com mesma divisão, sendo cada grupo com 2.000 páginas, este número é em torno de 72 iterações e para um total de 100.000 páginas, sendo 20.000 páginas em cada grupo, são necessárias em torno de 59 iterações para a convergência.

(iv) Quando se fixa o total de páginas dos conjuntos fechados, variando-se o número e o tamanho dos grupos, a medida que o número de grupos aumenta e, consequentemente, a quantidade de páginas em cada grupo diminui, o número de iterações aumenta significantemente. Como não houve diferenças significativas com a existência do grupo de ligação e com a variação do número de nós pendentes, a partir daqui, as simulações foram feitas considerando a existência de um grupo de ligação, além do número de nós pendentes igual ao total de páginas dos conjuntos fechados.

Na Tabela A.7 foram feitas simulações com o tamanho de cada grupo fechado fixado em 1.000 e 10.000 páginas, variando-se o número de grupos. Além da obtenção das conclusões (ii) e (iii), perece que:

(v) A medida que o número de grupos fechados aumenta, com seus tamanhos mantidos fixos, o número de iterações necessárias para a convergência apresenta leve aumento.

Nas Tabelas A.8 e A.9, reforça-se as conclusões já obtidas em (ii), (iii) e (v).

Na Tabela A.10 são apresentados os resultados da simulações onde fixou-se o número total de páginas dos conjuntos fechados, variando-se o número de grupos e o tamanho destes, reforçando as conclusões já obtidas em (ii), (iv) e (v).

Nas Tabelas A.11 e A.12, além da obtenção das conclusões (ii) e (iii), parece que: 
(vi) O número de iterações aumenta a medida que o tamanho dos grupos se diferencia, ou seja, o número de iterações é maior quando temos juntos conjuntos de 50 e 500 páginas do que quando temos conjuntos de 450 e 500 páginas. Além disso, é possível verificar que o número de conjuntos de mesmo tamanho não influencia no número de iterações. Por exemplo, o número de iterações para 9 conjuntos fechados, sendo 8 destes de 50 páginas e 1 de 500 páginas é próximo do obtido no caso de 8 conjuntos de 500 páginas e 1 conjunto de 50 páginas.

De acordo com a Tabela A.13, além da conclusão (ii), parece que:

(vii) O número de iterações é governado pelo tamanho do menor conjunto fechado. Neste caso, como as páginas são divididas em grupos, quanto menor o tamanho do menor grupo, maior o número de iterações necessárias para a convergência. 

Apêndice A

Número Médio de Iterações 
Tabela A.1: Número médio de iterações para $\alpha=0,85$ e $\alpha=0,99$ e seus respectivos intervalos de confiança, variando o tamanho do grupo fechado, a existência do Grupo de Ligação e o número de Nós Pendentes, para um total de 1.000 páginas nos conjuntos fechados.

\begin{tabular}{|c|c|c|c|c|c|c|c|c|c|c|}
\hline$T P$ & $Q G F$ & $T P G F$ & $T P G L$ & $T N P$ & $\begin{array}{l}N I \mathrm{com} \\
\alpha=0,85\end{array}$ & $\begin{array}{l}\text { Limite } \\
\text { Inferior }\end{array}$ & $\begin{array}{c}\text { Limite } \\
\text { Superior }\end{array}$ & $\begin{array}{l}N I \text { com } \\
\alpha=0,99\end{array}$ & $\begin{array}{c}\text { Limite } \\
\text { Inferior }\end{array}$ & $\begin{array}{c}\text { Limite } \\
\text { Superior }\end{array}$ \\
\hline 1.000 & 1 & 1.000 & 0 & 0 & 24,86 & 24,78 & 24,94 & 31,17 & 31,05 & 31,30 \\
\hline 1.100 & 1 & 1.000 & 100 & 0 & 24,84 & 24,76 & 24,92 & 31,15 & 31,03 & 31,28 \\
\hline 1.050 & 1 & 1.000 & 0 & 50 & 24,76 & 24,69 & 24,84 & 31,03 & 30,91 & 31,14 \\
\hline 1.150 & 1 & 1.000 & 100 & 50 & 24,77 & 24,70 & 24,85 & 31,08 & 30,95 & 31,21 \\
\hline 1.600 & 1 & 1.000 & 100 & 500 & 24,81 & 24,73 & 24,89 & 31,11 & 30,98 & 31,24 \\
\hline 2.100 & 1 & 1.000 & 100 & 1.000 & 24,84 & 24,77 & 24,92 & 31,09 & 30,97 & 31,21 \\
\hline 3.100 & 1 & 1.000 & 100 & 2.000 & 25,07 & 25,00 & 25,14 & 31,06 & 30,94 & 31,18 \\
\hline 1.000 & 2 & 500 & 0 & 0 & 77,44 & 77,35 & 77,52 & 959,90 & 958,64 & 961,16 \\
\hline 1.100 & 2 & 500 & 100 & 0 & 77,36 & 77,28 & 77,45 & 959,02 & 957,72 & 960,31 \\
\hline 1.050 & 2 & 500 & 0 & 50 & 77,36 & 77,28 & 77,44 & 958,93 & 957,68 & 960,19 \\
\hline 1.150 & 2 & 500 & 100 & 50 & 77,37 & 77,29 & 77,45 & 959,10 & 957,87 & 960,33 \\
\hline 1.600 & 2 & 500 & 100 & 500 & 77,39 & 77,32 & 77,47 & 959,12 & 957,94 & 960,30 \\
\hline 2.100 & 2 & 500 & 100 & 1.000 & 77,39 & 77,31 & 77,47 & 959,04 & 957,81 & 960,28 \\
\hline 3.100 & 2 & 500 & 100 & 2.000 & 77,43 & 77,35 & 77,51 & 960,19 & 958,99 & 961,40 \\
\hline 1.000 & 5 & 200 & 0 & 0 & 84,29 & 84,20 & 84,39 & $1.071,15$ & $1.069,69$ & $1.072,61$ \\
\hline 1.100 & 5 & 200 & 100 & 0 & 84,41 & 84,32 & 84,51 & $1.072,19$ & $1.070,77$ & $1.073,62$ \\
\hline 1.050 & 5 & 200 & 0 & 50 & 84,33 & 84,23 & 84,43 & $1.071,63$ & $1.070,06$ & $1.073,21$ \\
\hline 1.150 & 5 & 200 & 100 & 50 & 84,39 & 84,30 & 84,49 & $1.072,25$ & $1.070,70$ & $1.073,80$ \\
\hline 1.600 & 5 & 200 & 100 & 500 & 84,36 & 84,26 & 84,45 & $1.071,81$ & $1.070,32$ & $1.073,30$ \\
\hline 2.100 & 5 & 200 & 100 & 1.000 & 84,38 & 84,28 & 84,47 & $1.071,91$ & $1.070,36$ & $1.073,46$ \\
\hline 3.100 & 5 & 200 & 100 & 2.000 & 84,32 & 84,22 & 84,41 & $1.071,40$ & $1.069,91$ & $1.072,89$ \\
\hline 1.000 & 10 & 100 & 0 & 0 & 88,13 & 88,04 & 88,22 & $1.132,88$ & $1.131,46$ & $1.134,30$ \\
\hline 1.100 & 10 & 100 & 100 & 0 & 88,17 & 88,09 & 88,26 & $1.133,77$ & $1.132,42$ & $1.135,11$ \\
\hline 1.050 & 10 & 100 & 0 & 50 & 88,17 & 88,07 & 88,26 & $1.133,51$ & $1.132,03$ & $1.135,00$ \\
\hline 1.150 & 10 & 100 & 100 & 50 & 88,23 & 88,13 & 88,33 & $1.134,70$ & $1.133,12$ & $1.136,28$ \\
\hline 1.600 & 10 & 100 & 100 & 500 & 88,13 & 88,03 & 88,22 & $1.133,24$ & $1.131,81$ & $1.134,67$ \\
\hline 2.100 & 10 & 100 & 100 & 1.000 & 88,17 & 88,07 & 88,27 & $1.133,55$ & $1.132,03$ & $1.135,08$ \\
\hline 3.100 & 10 & 100 & 100 & 2.000 & 88,15 & 88,06 & 88,25 & $1.133,22$ & $1.131,70$ & $1.134,75$ \\
\hline 1.000 & 50 & 20 & 0 & 0 & 93,82 & 93,75 & 93,89 & $1.224,62$ & $1.223,57$ & $1.225,67$ \\
\hline 1.100 & 50 & 20 & 100 & 0 & 93,80 & 93,73 & 93,87 & $1.224,90$ & $1.223,88$ & $1.225,92$ \\
\hline 1.050 & 50 & 20 & 0 & 50 & 93,82 & 93,75 & 93,89 & $1.224,74$ & $1.223,74$ & $1.225,74$ \\
\hline 1.150 & 50 & 20 & 100 & 50 & 93,82 & 93,75 & 93,88 & $1.224,91$ & $1.223,91$ & $1.225,91$ \\
\hline 1.600 & 50 & 20 & 100 & 500 & 93,83 & 93,76 & 93,90 & $1.224,91$ & $1.223,90$ & $1.225,93$ \\
\hline 2.100 & 50 & 20 & 100 & 1.000 & 93,77 & 93,70 & 93,84 & $1.224,22$ & $1.223,24$ & $1.225,20$ \\
\hline 3.100 & 50 & 20 & 100 & 2.000 & 93,84 & 93,77 & 93,90 & $1.225,35$ & $1.224,33$ & $1.226,37$ \\
\hline
\end{tabular}


Tabela A.2: Número médio de iterações para $\alpha=0,85$ e $\alpha=0,99$ e seus respectivos intervalos de confiança, variando o tamanho do grupo fechado, a existência do Grupo de Ligação e o número de Nós Pendentes, para um total de 10.000 páginas nos conjuntos fechados.

\begin{tabular}{|c|c|c|c|c|c|c|c|c|c|c|}
\hline$T P$ & $Q G F$ & $T P G F$ & $T P G L$ & $T N P$ & $\begin{array}{l}N I \text { com } \\
\alpha=0,85\end{array}$ & $\begin{array}{c}\text { Limite } \\
\text { Inferior }\end{array}$ & $\begin{array}{c}\text { Limite } \\
\text { Superior }\end{array}$ & $\begin{array}{l}N I \text { com } \\
\alpha=0,99\end{array}$ & $\begin{array}{c}\text { Limite } \\
\text { Inferior }\end{array}$ & $\begin{array}{c}\text { Limite } \\
\text { Superior }\end{array}$ \\
\hline 10.000 & 1 & 10.000 & 0 & 0 & 23,81 & 23,76 & 23,85 & 29,73 & 29,67 & 29,78 \\
\hline 11.000 & 1 & 10.000 & 1.000 & 0 & 23,79 & 23,74 & 23,83 & 29,71 & 29,65 & 29,77 \\
\hline 10.500 & 1 & 10.000 & 0 & 500 & 23,80 & 23,75 & 23,84 & 29,68 & 29,63 & 29,73 \\
\hline 11.500 & 1 & 10.000 & 1.000 & 500 & 23,80 & 23,75 & 23,84 & 29,66 & 29,60 & 29,71 \\
\hline 16.000 & 1 & 10.000 & 1.000 & 5.000 & 23,81 & 23,77 & 23,85 & 29,70 & 29,64 & 29,76 \\
\hline 21.000 & 1 & 10.000 & 1.000 & 10.000 & 23,74 & 23,69 & 23,79 & 29,68 & 29,62 & 29,73 \\
\hline 31.000 & 1 & 10.000 & 1.000 & 20.000 & 23,82 & 23,77 & 23,86 & 29,72 & 29,67 & 29,78 \\
\hline 10.000 & 2 & 5.000 & 0 & 0 & 64,91 & 64,84 & 64,97 & 757,23 & 756,27 & 758,18 \\
\hline 11.000 & 2 & 5.000 & 1.000 & 0 & 64,98 & 64,92 & 65,05 & 757,95 & 757,01 & 758,90 \\
\hline 10.500 & 2 & 5.000 & 0 & 500 & 64,96 & 64,89 & 65,02 & 758,38 & 757,43 & 759,33 \\
\hline 11.500 & 2 & 5.000 & 1.000 & 500 & 64,96 & 64,90 & 65,02 & 758,34 & 757,39 & 759,29 \\
\hline 16.000 & 2 & 5.000 & 1.000 & 5.000 & 64,90 & 64,84 & 64,96 & 757,28 & 756,39 & 758,16 \\
\hline 21.000 & 2 & 5.000 & 1.000 & 10.000 & 64,96 & 64,89 & 65,02 & 758,05 & 757,12 & 758,99 \\
\hline 31.000 & 2 & 5.000 & 1.000 & 20.000 & 64,96 & 64,90 & 65,03 & 758,24 & 757,30 & 759,18 \\
\hline 10.000 & 5 & 2.000 & 0 & 0 & 72,43 & 72,36 & 72,50 & 879,45 & 878,31 & 880,59 \\
\hline 11.000 & 5 & 2.000 & 1.000 & 0 & 72,45 & 72,37 & 72,52 & 879,40 & 878,30 & 880,50 \\
\hline 10.500 & 5 & 2.000 & 0 & 500 & 72,50 & 72,42 & 72,58 & 880,14 & 878,91 & 881,38 \\
\hline 11.500 & 5 & 2.000 & 1.000 & 500 & 72,47 & 72,39 & 72,54 & 879,74 & 878,65 & 880,84 \\
\hline 16.000 & 5 & 2.000 & 1.000 & 5.000 & 72,48 & 72,40 & 72,56 & 879,65 & 878,46 & 880,84 \\
\hline 21.000 & 5 & 2.000 & 1.000 & 10.000 & 72,45 & 72,37 & 72,52 & 879,36 & 878,21 & 880,51 \\
\hline 31.000 & 5 & 2.000 & 1.000 & 20.000 & 72,47 & 72,39 & 72,54 & 879,64 & 878,52 & 880,75 \\
\hline 10.000 & 10 & 1.000 & 0 & 0 & 76,90 & 76,81 & 76,98 & 951,36 & 950,05 & 952,66 \\
\hline 11.000 & 10 & 1.000 & 1.000 & 0 & 76,85 & 76,77 & 76,94 & 950,68 & 949,40 & 951,95 \\
\hline 10.500 & 10 & 1.000 & 0 & 500 & 76,84 & 76,77 & 76,92 & 950,09 & 948,93 & 951,24 \\
\hline 11.500 & 10 & 1.000 & 1.000 & 500 & 76,87 & 76,79 & 76,95 & 950,80 & 949,61 & 951,99 \\
\hline 16.000 & 10 & 1.000 & 1.000 & 5.000 & 76,82 & 76,74 & 76,90 & 950,06 & 948,81 & 951,31 \\
\hline 21.000 & 10 & 1.000 & 1.000 & 10.000 & 76,94 & 76,86 & 77,02 & 951,73 & 950,48 & 952,97 \\
\hline 31.000 & 10 & 1.000 & 1.000 & 20.000 & 76,95 & 76,87 & 77,03 & 951,99 & 950,78 & 953,21 \\
\hline 10.000 & 50 & 200 & 0 & 0 & 85,55 & 85,46 & 85,65 & $1.091,35$ & $1.089,89$ & $1.092,82$ \\
\hline 11.000 & 50 & 200 & 1.000 & 0 & 85,60 & 85,51 & 85,69 & $1.092,06$ & $1.090,64$ & $1.093,48$ \\
\hline 10.500 & 50 & 200 & 0 & 500 & 85,56 & 85,47 & 85,66 & $1.091,23$ & $1.089,78$ & $1.092,68$ \\
\hline 11.500 & 50 & 200 & 1.000 & 500 & 85,52 & 85,42 & 85,61 & $1.090,54$ & $1.089,13$ & $1.091,94$ \\
\hline 16.000 & 50 & 200 & 1.000 & 5.000 & 85,54 & 85,44 & 85,63 & $1.091,00$ & $1.089,50$ & $1.092,49$ \\
\hline 21.000 & 50 & 200 & 1.000 & 10.000 & 85,60 & 85,51 & 85,70 & $1.092,02$ & $1.090,54$ & $1.093,50$ \\
\hline 31.000 & 50 & 200 & 1.000 & 20.000 & 85,53 & 85,44 & 85,63 & $1.090,87$ & $1.089,40$ & $1.092,34$ \\
\hline
\end{tabular}


Tabela A.3: Número médio de iterações para $\alpha=0,85$ e $\alpha=0,99$ e seus respectivos intervalos de confiança, variando o tamanho do grupo fechado, a existência do Grupo de Ligação e o número de Nós Pendentes, para um total de 100.000 páginas nos conjuntos fechados.

\begin{tabular}{|c|c|c|c|c|c|c|c|c|c|c|}
\hline$T P$ & $Q G F$ & $T P G F$ & $T P G L$ & $T N P$ & $\begin{array}{l}N I \text { com } \\
\alpha=0,85\end{array}$ & $\begin{array}{c}\text { Limite } \\
\text { Inferior }\end{array}$ & $\begin{array}{c}\text { Limite } \\
\text { Superior }\end{array}$ & $\begin{array}{l}N I \text { com } \\
\alpha=0,99\end{array}$ & $\begin{array}{l}\text { Limite } \\
\text { Inferior }\end{array}$ & $\begin{array}{c}\text { Limite } \\
\text { Superior }\end{array}$ \\
\hline 100.000 & 1 & 100.000 & 0 & 0 & 22,54 & 22,50 & 22,59 & 28,16 & 28,12 & 28,20 \\
\hline 110.000 & 1 & 100.000 & 10.000 & 0 & 22,52 & 22,48 & 22,57 & 28,14 & 28,10 & 28,18 \\
\hline 105.000 & 1 & 100.000 & 0 & 5.000 & 22,49 & 22,45 & 22,53 & 28,14 & 28,09 & 28,18 \\
\hline 115.000 & 1 & 100.000 & 10.000 & 5.000 & 22,54 & 22,50 & 22,58 & 28,18 & 28,14 & 28,23 \\
\hline 160.000 & 1 & 100.000 & 10.000 & 50.000 & 22,52 & 22,48 & 22,56 & 28,16 & 28,12 & 28,21 \\
\hline 210.000 & 1 & 100.000 & 10.000 & 100.000 & 22,55 & 22,50 & 22,59 & 28,16 & 28,12 & 28,20 \\
\hline 310.000 & 1 & 100.000 & 10.000 & 200.000 & 22,50 & 22,46 & 22,55 & 28,15 & 28,11 & 28,19 \\
\hline 100.000 & 2 & 50.000 & 0 & 0 & 51,89 & 51,84 & 51,94 & 546,62 & 545,94 & 547,30 \\
\hline 110.000 & 2 & 50.000 & 10.000 & 0 & 51,92 & 51,87 & 51,97 & 547,17 & 546,45 & 547,89 \\
\hline 105.000 & 2 & 50.000 & 0 & 5.000 & 51,89 & 51,84 & 51,95 & 546,82 & 546,05 & 547,59 \\
\hline 115.000 & 2 & 50.000 & 10.000 & 5.000 & 51,92 & 51,87 & 51,98 & 547,25 & 546,52 & 547,98 \\
\hline 160.000 & 2 & 50.000 & 10.000 & 50.000 & 51,94 & 51,89 & 51,99 & 547,03 & 546,29 & 547,77 \\
\hline 210.000 & 2 & 50.000 & 10.000 & 100.000 & 51,92 & 51,87 & 51,97 & 547,06 & 546,35 & 547,78 \\
\hline 310.000 & 2 & 50.000 & 10.000 & 200.000 & 51,90 & 51,85 & 51,95 & 547,01 & 546,31 & 547,71 \\
\hline 100.000 & 5 & 20.000 & 0 & 0 & 59,73 & 59,67 & 59,79 & 673,75 & 672,85 & 674,66 \\
\hline 110.000 & 5 & 20.000 & 10.000 & 0 & 59,68 & 59,62 & 59,74 & 673,28 & 672,41 & 674,14 \\
\hline 105.000 & 5 & 20.000 & 0 & 5.000 & 59,68 & 59,62 & 59,74 & 672,80 & 671,94 & 673,67 \\
\hline 115.000 & 5 & 20.000 & 10.000 & 5.000 & 59,67 & 59,62 & 59,73 & 672,60 & 671,81 & 673,39 \\
\hline 160.000 & 5 & 20.000 & 10.000 & 50.000 & 59,63 & 59,57 & 59,69 & 672,11 & 671,28 & 672,93 \\
\hline 210.000 & 5 & 20.000 & 10.000 & 100.000 & 59,67 & 59,61 & 59,73 & 672,56 & 671,68 & 673,44 \\
\hline 310.000 & 5 & 20.000 & 10.000 & 200.000 & 59,67 & 59,61 & 59,73 & 672,53 & 671,71 & 673,36 \\
\hline 100.000 & 10 & 10.000 & 0 & 0 & 64,30 & 64,24 & 64,36 & 747,59 & 746,67 & 748,52 \\
\hline 110.000 & 10 & 10.000 & 10.000 & 0 & 64,32 & 64,25 & 64,38 & 747,53 & 746,62 & 748,43 \\
\hline 105.000 & 10 & 10.000 & 0 & 5.000 & 64,25 & 64,19 & 64,31 & 747,02 & 746,13 & 747,92 \\
\hline 115.000 & 10 & 10.000 & 10.000 & 5.000 & 64,36 & 64,30 & 64,42 & 748,04 & 747,09 & 748,99 \\
\hline 160.000 & 10 & 10.000 & 10.000 & 50.000 & 64,38 & 64,32 & 64,44 & 748,77 & 747,89 & 749,66 \\
\hline 210.000 & 10 & 10.000 & 10.000 & 100.000 & 64,32 & 64,26 & 64,38 & 748,10 & 747,22 & 748,97 \\
\hline 310.000 & 10 & 10.000 & 10.000 & 200.000 & 64,23 & 64,16 & 64,29 & 746,76 & 745,82 & 747,70 \\
\hline 100.000 & 50 & 2.000 & 0 & 0 & 73,69 & 73,61 & 73,76 & 899,10 & 897,95 & 900,24 \\
\hline 110.000 & 50 & 2.000 & 10.000 & 0 & 73,74 & 73,67 & 73,82 & 900,05 & 898,94 & 901,16 \\
\hline 105.000 & 50 & 2.000 & 0 & 5.000 & 73,71 & 73,64 & 73,79 & 899,91 & 898,75 & 901,06 \\
\hline 115.000 & 50 & 2.000 & 10.000 & 5.000 & 73,68 & 73,61 & 73,75 & 899,30 & 898,23 & 900,37 \\
\hline 160.000 & 50 & 2.000 & 10.000 & 50.000 & 73,71 & 73,63 & 73,78 & 899,47 & 898,39 & 900,55 \\
\hline 210.000 & 50 & 2.000 & 10.000 & 100.000 & 73,74 & 73,67 & 73,82 & 900,11 & 898,99 & 901,22 \\
\hline 310.000 & 50 & 2.000 & 10.000 & 200.000 & 73,70 & 73,63 & 73,77 & 899,29 & 898,17 & 900,42 \\
\hline
\end{tabular}


Tabela A.4: Número médio de iterações para $\alpha=0,85$ e $\alpha=0,99$ e seus respectivos intervalos de confiança, variando o tamanho do grupo fechado, a existência do Grupo de Ligação e o número de Nós Pendentes, para grupos fechados com até 750 páginas.

\begin{tabular}{|c|c|c|c|c|c|c|c|c|c|c|}
\hline$T P$ & $Q G F$ & $\overline{T P G F}$ & $\overline{T P G L}$ & $T N P$ & $\begin{array}{l}\text { NI com } \\
\alpha=0,85\end{array}$ & $\begin{array}{c}\text { Limite } \\
\text { Inferior }\end{array}$ & $\begin{array}{c}\text { Limite } \\
\text { Superior }\end{array}$ & $\begin{array}{l}\text { NI com } \\
\alpha=0,99\end{array}$ & $\begin{array}{c}\text { Limite } \\
\text { Inferior }\end{array}$ & $\begin{array}{c}\text { Limite } \\
\text { Superior }\end{array}$ \\
\hline 500 & 5 & 100 & 0 & 0 & 87,51 & 87,42 & 87,60 & $1.123,09$ & $1.121,65$ & $1.124,53$ \\
\hline 550 & 5 & 100 & 50 & 0 & 87,48 & 87,39 & 87,57 & $1.122,08$ & $1.120,59$ & $1.123,57$ \\
\hline 525 & 5 & 100 & 0 & 25 & 87,50 & 87,41 & 87,60 & $1.122,63$ & $1.121,09$ & $1.124,17$ \\
\hline 575 & 5 & 100 & 50 & 25 & 87,61 & 87,52 & 87,71 & $1.124,46$ & $1.122,93$ & $1.126,00$ \\
\hline 800 & 5 & 100 & 50 & 250 & 87,43 & 87,33 & 87,53 & $1.121,43$ & $1.119,89$ & $1.122,98$ \\
\hline 1.050 & 5 & 100 & 50 & 500 & 87,51 & 87,42 & 87,61 & $1.123,20$ & $1.121,71$ & $1.124,69$ \\
\hline 1.550 & 5 & 100 & 50 & 1.000 & 87,51 & 87,41 & 87,61 & $1.122,89$ & $1.121,34$ & $1.124,44$ \\
\hline 500 & 2 & 250 & 0 & 0 & 80,87 & 80,79 & 80,96 & $1.015,60$ & $1.014,34$ & $1.016,86$ \\
\hline 550 & 2 & 250 & 50 & 0 & 80,91 & 80,82 & 80,99 & $1.016,40$ & $1.015,16$ & $1.017,63$ \\
\hline 525 & 2 & 250 & 0 & 25 & 80,90 & 80,82 & 80,99 & $1.016,05$ & $1.014,70$ & $1.017,40$ \\
\hline 575 & 2 & 250 & 50 & 25 & 80,97 & 80,89 & 81,06 & $1.017,15$ & $1.015,85$ & $1.018,44$ \\
\hline 800 & 2 & 250 & 50 & 250 & 81,00 & 80,91 & 81,08 & $1.017,34$ & $1.016,01$ & $1.018,66$ \\
\hline 1.050 & 2 & 250 & 50 & 500 & 80,91 & 80,83 & 81,00 & $1.016,40$ & $1.015,05$ & $1.017,75$ \\
\hline 1.550 & 2 & 250 & 50 & 1.000 & 81,01 & 80,92 & 81,10 & $1.017,49$ & $1.016,14$ & $1.018,85$ \\
\hline 1.750 & 5 & 350 & 0 & 0 & 81,66 & 81,56 & 81,75 & $1.027,72$ & $1.026,29$ & $1.029,16$ \\
\hline 1.925 & 5 & 350 & 175 & 0 & 81,53 & 81,44 & 81,62 & $1.026,38$ & $1.024,99$ & $1.027,77$ \\
\hline 1.838 & 5 & 350 & 0 & 88 & 81,57 & 81,48 & 81,65 & $1.026,53$ & $1.025,16$ & $1.027,91$ \\
\hline 2.013 & 5 & 350 & 175 & 88 & 81,55 & 81,45 & 81,64 & $1.026,65$ & $1.025,23$ & $1.028,06$ \\
\hline 2.800 & 5 & 350 & 175 & 875 & 81,59 & 81,50 & 81,68 & $1.027,16$ & $1.025,74$ & $1.028,57$ \\
\hline 3.675 & 5 & 350 & 175 & 1.750 & 81,54 & 81,45 & 81,63 & $1.026,30$ & $1.024,85$ & $1.027,74$ \\
\hline 5.425 & 5 & 350 & 175 & 3.500 & 81,53 & 81,44 & 81,62 & $1.026,11$ & $1.024,73$ & $1.027,48$ \\
\hline 1.500 & 2 & 750 & 0 & 0 & 75,30 & 75,22 & 75,38 & 925,48 & 924,24 & 926,71 \\
\hline 1.650 & 2 & 750 & 150 & 0 & 75,28 & 75,21 & 75,36 & 925,12 & 923,95 & 926,29 \\
\hline 1.575 & 2 & 750 & 0 & 75 & 75,32 & 75,25 & 75,40 & 925,68 & 924,49 & 926,86 \\
\hline 1.725 & 2 & 750 & 150 & 75 & 75,26 & 75,18 & 75,34 & 925,00 & 923,79 & 926,22 \\
\hline 2.400 & 2 & 750 & 150 & 750 & 75,29 & 75,21 & 75,37 & 925,50 & 924,25 & 926,75 \\
\hline 3.150 & 2 & 750 & 150 & 1.500 & 75,28 & 75,21 & 75,36 & 925,06 & 923,88 & 926,23 \\
\hline 4.650 & 2 & 750 & 150 & 3.000 & 75,31 & 75,24 & 75,39 & 925,48 & 924,33 & 926,62 \\
\hline 2.000 & 2 & $250 ; 750$ & 0 & 0 & 82,86 & 82,77 & 82,95 & $1.047,44$ & $1.045,98$ & $1.048,90$ \\
\hline 2.100 & 2 & $250 ; 750$ & 100 & 0 & 82,93 & 82,84 & 83,03 & $1.048,75$ & $1.047,22$ & $1.050,28$ \\
\hline 2.050 & 2 & $250 ; 750$ & 0 & 50 & 82,78 & 82,69 & 82,88 & $1.046,91$ & $1.045,47$ & $1.048,36$ \\
\hline 2.150 & 2 & $250 ; 750$ & 100 & 50 & 82,90 & 82,81 & 83,00 & $1.048,53$ & $1.047,08$ & $1.049,97$ \\
\hline 2.600 & 2 & $250 ; 750$ & 100 & 500 & 82,85 & 82,75 & 82,94 & $1.047,53$ & $1.046,15$ & $1.048,91$ \\
\hline 3.100 & 2 & $250 ; 750$ & 100 & 1.000 & 82,79 & 82,70 & 82,88 & $1.046,66$ & $1.045,29$ & $1.048,03$ \\
\hline 4.100 & 2 & $250 ; 750$ & 100 & 2.000 & 82,89 & 82,79 & 82,99 & $1.047,91$ & $1.046,40$ & $1.049,42$ \\
\hline 5.000 & 5 & $3 \times 100 ; 2 \times 350$ & 0 & 0 & 88,14 & 88,04 & 88,24 & $1.133,36$ & $1.131,81$ & $1.134,92$ \\
\hline 5.100 & 5 & $3 \times 100 ; 2 \times 350$ & 100 & 0 & 88,19 & 88,09 & 88,29 & $1.133,87$ & $1.132,37$ & $1.135,36$ \\
\hline 5.050 & 5 & $3 \times 100 ; 2 \times 350$ & 0 & 50 & 88,20 & 88,10 & 88,29 & $1.133,84$ & $1.132,31$ & $1.135,37$ \\
\hline 5.150 & 5 & $3 \times 100 ; 2 \times 350$ & 100 & 50 & 88,23 & 88,13 & 88,33 & $1.134,47$ & $1.132,89$ & $1.136,05$ \\
\hline 5.600 & 5 & $3 \times 100 ; 2 \times 350$ & 100 & 500 & 88,21 & 88,11 & 88,31 & $1.134,04$ & $1.132,56$ & $1.135,51$ \\
\hline 6.100 & 5 & $3 \times 100 ; 2 \times 350$ & 100 & 1.000 & 88,24 & 88,15 & 88,33 & $1.134,50$ & $1.133,06$ & $1.135,93$ \\
\hline 7.100 & 5 & $3 \times 100 ; 2 \times 350$ & 100 & 2.000 & 88,21 & 88,11 & 88,31 & $1.134,35$ & $1.132,80$ & $1.135,90$ \\
\hline
\end{tabular}


Tabela A.5: Número médio de iterações para $\alpha=0,85$ e $\alpha=0,99$ e seus respectivos intervalos de confiança, variando o tamanho do grupo fechado, a existência do Grupo de Ligação e o número de Nós Pendentes, , para grupos fechados com até 7.500 páginas.

\begin{tabular}{|c|c|c|c|c|c|c|c|c|c|c|}
\hline$T P$ & $Q G F$ & $T P G F$ & $T P G L$ & $T N P$ & $\begin{array}{l}\text { NI com } \\
\alpha=0,85\end{array}$ & $\begin{array}{c}\text { Limite } \\
\text { Inferior }\end{array}$ & $\begin{array}{c}\text { Limite } \\
\text { Superior }\end{array}$ & $\begin{array}{l}\text { NI com } \\
\alpha=0,99\end{array}$ & $\begin{array}{c}\text { Limite } \\
\text { Inferior }\end{array}$ & $\begin{array}{c}\text { Limite } \\
\text { Superior }\end{array}$ \\
\hline 5.000 & 5 & 1.000 & 0 & 0 & 76,18 & 76,09 & 76,26 & 939,62 & 938,33 & 940,91 \\
\hline 5.500 & 5 & 1.000 & 500 & 0 & 76,17 & 76,09 & 76,24 & 939,65 & 938,45 & 940,85 \\
\hline 5.250 & 5 & 1.000 & 0 & 250 & 76,11 & 76,03 & 76,19 & 938,71 & 937,49 & 939,94 \\
\hline 5.750 & 5 & 1.000 & 500 & 250 & 76,25 & 76,16 & 76,33 & 940,36 & 939,06 & 941,67 \\
\hline 8.000 & 5 & 1.000 & 500 & 2.500 & 76,11 & 76,03 & 76,19 & 938,49 & 937,31 & 939,67 \\
\hline 10.500 & 5 & 1.000 & 500 & 5.000 & 76,24 & 76,16 & 76,32 & 940,58 & 939,34 & 941,83 \\
\hline 15.500 & 5 & 1.000 & 500 & 10.000 & 76,21 & 76,12 & 76,30 & 940,01 & 938,69 & 941,34 \\
\hline 5.000 & 2 & 2.500 & 0 & 0 & 68,79 & 68,72 & 68,85 & 819,89 & 818,90 & 820,88 \\
\hline 5.500 & 2 & 2.500 & 500 & 0 & 68,78 & 68,71 & 68,85 & 819,77 & 818,68 & 820,86 \\
\hline 5.250 & 2 & 2.500 & 0 & 250 & 68,82 & 68,76 & 68,89 & 820,51 & 819,53 & 821,48 \\
\hline 5.750 & 2 & 2.500 & 500 & 250 & 68,78 & 68,72 & 68,85 & 819,83 & 818,85 & 820,81 \\
\hline 8.000 & 2 & 2.500 & 500 & 2.500 & 68,81 & 68,75 & 68,88 & 820,47 & 819,45 & 821,48 \\
\hline 10.500 & 2 & 2.500 & 500 & 5.000 & 68,83 & 68,76 & 68,90 & 820,98 & 819,91 & 822,04 \\
\hline 15.500 & 2 & 2.500 & 500 & 10.000 & 68,81 & 68,75 & 68,88 & 820,39 & 819,34 & 821,44 \\
\hline 17.500 & 5 & 3.500 & 0 & 0 & 69,41 & 69,34 & 69,47 & 830,18 & 829,17 & 831,19 \\
\hline 19.250 & 5 & 3.500 & 1.750 & 0 & 69,42 & 69,34 & 69,49 & 830,21 & 829,12 & 831,29 \\
\hline 18.375 & 5 & 3.500 & 0 & 875 & 69,45 & 69,38 & 69,52 & 830,68 & 829,59 & 831,77 \\
\hline 20.125 & 5 & 3.500 & 1.750 & 875 & 69,35 & 69,29 & 69,42 & 829,15 & 828,17 & 830,14 \\
\hline 28.000 & 5 & 3.500 & 1.750 & 8.750 & 69,36 & 69,29 & 69,43 & 829,30 & 828,27 & 830,34 \\
\hline 36.750 & 5 & 3.500 & 1.750 & 17.500 & 69,37 & 69,30 & 69,44 & 829,41 & 828,34 & 830,48 \\
\hline 54.250 & 5 & 3.500 & 1.750 & 35.000 & 69,14 & 69,02 & 69,25 & 825,84 & 824,04 & 827,64 \\
\hline 15.000 & 2 & 7.500 & 0 & 0 & 62,64 & 62,59 & 62,70 & 720,91 & 720,08 & 721,75 \\
\hline 16.500 & 2 & 7.500 & 1.500 & 0 & 62,64 & 62,58 & 62,71 & 720,94 & 720,03 & 721,85 \\
\hline 15.750 & 2 & 7.500 & 0 & 750 & 62,67 & 62,61 & 62,73 & 721,30 & 720,41 & 722,19 \\
\hline 17.250 & 2 & 7.500 & 1.500 & 750 & 62,69 & 62,63 & 62,75 & 721,28 & 720,40 & 722,16 \\
\hline 24.000 & 2 & 7.500 & 1.500 & 7.500 & 62,65 & 62,59 & 62,71 & 720,93 & 720,10 & 721,76 \\
\hline 31.500 & 2 & 7.500 & 1.500 & 15.000 & 62,64 & 62,57 & 62,70 & 720,93 & 720,01 & 721,85 \\
\hline 46.500 & 2 & 7.500 & 1.500 & 30.000 & 62,67 & 62,61 & 62,73 & 721,30 & 720,44 & 722,16 \\
\hline 20.000 & 2 & $2500 ; 7500$ & 0 & 0 & 70,88 & 70,81 & 70,96 & 854,20 & 853,05 & 855,35 \\
\hline 21.000 & 2 & $2500 ; 7500$ & 1.000 & 0 & 70,80 & 70,73 & 70,88 & 852,79 & 851,70 & 853,87 \\
\hline 20.500 & 2 & $2500 ; 7500$ & 0 & 500 & 70,85 & 70,78 & 70,92 & 853,31 & 852,25 & 854,37 \\
\hline 21.500 & 2 & $2500 ; 7500$ & 1.000 & 500 & 70,84 & 70,77 & 70,91 & 853,42 & 852,32 & 854,51 \\
\hline 26.000 & 2 & $2500 ; 7500$ & 1.000 & 5.000 & 70,86 & 70,79 & 70,94 & 853,88 & 852,78 & 854,98 \\
\hline 31.000 & 2 & $2500 ; 7500$ & 1.000 & 10.000 & 70,83 & 70,76 & 70,90 & 853,25 & 852,17 & 854,33 \\
\hline 41.000 & 2 & $2500 ; 7500$ & 1.000 & 20.000 & 70,85 & 70,78 & 70,93 & 853,32 & 852,19 & 854,45 \\
\hline 50.000 & 5 & $3 \times 1000 ; 2 \times 3500$ & 0 & 0 & 76,88 & 76,79 & 76,96 & 950,84 & 949,55 & 952,14 \\
\hline 51.000 & 5 & $3 \times 1000 ; 2 \times 3500$ & 1.000 & 0 & 76,81 & 76,74 & 76,89 & 950,15 & 948,98 & 951,33 \\
\hline 50.500 & 5 & $3 \times 1000 ; 2 \times 3500$ & 0 & 500 & 76,88 & 76,80 & 76,96 & 951,57 & 950,33 & 952,81 \\
\hline 51.500 & 5 & $3 \times 1000 ; 2 \times 3500$ & 1.000 & 500 & 76,97 & 76,89 & 77,05 & 951,73 & 950,49 & 952,97 \\
\hline 56.000 & 5 & $3 \times 1000 ; 2 \times 3500$ & 1.000 & 5.000 & 76,90 & 76,82 & 76,98 & 951,22 & 949,98 & 952,46 \\
\hline 61.000 & 5 & $3 \times 1000 ; 2 \times 3500$ & 1.000 & 10.000 & 76,85 & 76,76 & 76,93 & 950,44 & 949,16 & 951,71 \\
\hline 71.000 & 5 & $3 \times 1000 ; 2 \times 3500$ & 1.000 & 20.000 & 76,90 & 76,82 & 76,98 & 951,31 & 950,08 & 952,54 \\
\hline
\end{tabular}


Tabela A.6: Número médio de iterações para $\alpha=0,85$ e $\alpha=0,99$ e seus respectivos intervalos de confiança, variando o tamanho do grupo fechado, a existência do Grupo de Ligação e o número de Nós Pendentes, , para grupos fechados com até 75.000 páginas.

\begin{tabular}{|c|c|c|c|c|c|c|c|c|c|c|}
\hline$T P$ & $Q G F$ & $T P G F$ & $T P G L$ & $T N P$ & $\begin{array}{l}\text { NI com } \\
\alpha=0,85\end{array}$ & $\begin{array}{c}\text { Limite } \\
\text { Inferior }\end{array}$ & $\begin{array}{c}\text { Limite } \\
\text { Superior }\end{array}$ & $\begin{array}{l}\text { NI com } \\
\alpha=0,99\end{array}$ & $\begin{array}{c}\text { Limite } \\
\text { Inferior }\end{array}$ & $\begin{array}{c}\text { Limite } \\
\text { Superior }\end{array}$ \\
\hline 50.000 & 5 & 10.000 & 0 & 0 & 63,62 & 63,55 & 63,69 & 736,35 & 735,32 & 737,38 \\
\hline 55.000 & 5 & 10.000 & 5000 & 0 & 63,60 & 63,54 & 63,66 & 736,08 & 735,15 & 737,01 \\
\hline 52.500 & 5 & 10.000 & 0 & 2500 & 63,59 & 63,52 & 63,65 & 736,00 & 735,06 & 736,95 \\
\hline 57.500 & 5 & 10.000 & 5000 & 2500 & 63,55 & 63,49 & 63,61 & 735,57 & 734,72 & 736,42 \\
\hline 80.000 & 5 & 10.000 & 5000 & 25000 & 63,56 & 63,50 & 63,62 & 735,53 & 734,60 & 736,47 \\
\hline 105.000 & 5 & 10.000 & 5000 & 50000 & 63,50 & 63,44 & 63,56 & 734,91 & 734,01 & 735,81 \\
\hline 155.000 & 5 & 10.000 & 5000 & 100000 & 63,53 & 63,46 & 63,59 & 735,40 & 734,49 & 736,30 \\
\hline 50.000 & 2 & 25.000 & 0 & 0 & 55,83 & 55,78 & 55,89 & 610,81 & 610,06 & 611,57 \\
\hline 55.000 & 2 & 25.000 & 5000 & 0 & 55,87 & 55,81 & 55,93 & 611,22 & 610,40 & 612,03 \\
\hline 52.500 & 2 & 25.000 & 0 & 2500 & 55,83 & 55,78 & 55,88 & 610,99 & 610,25 & 611,73 \\
\hline 57.500 & 2 & 25.000 & 5000 & 2500 & 55,89 & 55,84 & 55,95 & 612,06 & 611,27 & 612,85 \\
\hline 80.000 & 2 & 25.000 & 5000 & 25000 & 55,86 & 55,81 & 55,91 & 610,61 & 609,85 & 611,38 \\
\hline 105.000 & 2 & 25.000 & 5000 & 50000 & 55,85 & 55,79 & 55,91 & 610,70 & 609,92 & 611,48 \\
\hline 155.000 & 2 & 25.000 & 5000 & 100000 & 55,88 & 55,83 & 55,94 & 611,46 & 610,66 & 612,27 \\
\hline 175.000 & 5 & 35.000 & 0 & 0 & 56,52 & 56,47 & 56,57 & 621,67 & 620,92 & 622,42 \\
\hline 192.500 & 5 & 35.000 & 17500 & 0 & 56,49 & 56,44 & 56,54 & 621,13 & 620,34 & 621,91 \\
\hline 183.750 & 5 & 35.000 & 0 & 8750 & 56,46 & 56,41 & 56,52 & 620,95 & 620,17 & 621,73 \\
\hline 201.250 & 5 & 35.000 & 17500 & 8750 & 56,46 & 56,40 & 56,52 & 621,04 & 620,23 & 621,86 \\
\hline 280.000 & 5 & 35.000 & 17500 & 87500 & 56,54 & 56,48 & 56,59 & 621,75 & 620,94 & 622,56 \\
\hline 367.500 & 5 & 35.000 & 17500 & 175000 & 56,49 & 56,44 & 56,55 & 621,97 & 621,17 & 622,77 \\
\hline 542.500 & 5 & 35.000 & 17500 & 350000 & 56,50 & 56,44 & 56,55 & 621,70 & 620,92 & 622,48 \\
\hline 150.000 & 2 & 75.000 & 0 & 0 & 49,53 & 49,48 & 49,58 & 509,11 & 508,42 & 509,79 \\
\hline 165.000 & 2 & 75.000 & 15000 & 0 & 49,53 & 49,48 & 49,58 & 509,28 & 508,59 & 509,97 \\
\hline 157.500 & 2 & 75.000 & 0 & 7500 & 49,53 & 49,48 & 49,58 & 508,94 & 508,30 & 509,58 \\
\hline 172.500 & 2 & 75.000 & 15000 & 7500 & 49,55 & 49,50 & 49,60 & 509,26 & 508,55 & 509,96 \\
\hline 240.000 & 2 & 75.000 & 15000 & 75000 & 49,57 & 49,52 & 49,62 & 509,48 & 508,77 & 510,19 \\
\hline 315.000 & 2 & 75.000 & 15000 & 150000 & 49,51 & 49,46 & 49,57 & 509,08 & 508,38 & 509,79 \\
\hline 465.000 & 2 & 75.000 & 15000 & 300000 & 49,60 & 49,55 & 49,65 & 509,93 & 509,24 & 510,63 \\
\hline 200.000 & 2 & $25000 ; 75000$ & 0 & 0 & 58,03 & 57,97 & 58,09 & 646,09 & 645,21 & 646,96 \\
\hline 210.000 & 2 & $25000 ; 75000$ & 10000 & 0 & 58,05 & 57,99 & 58,10 & 646,04 & 645,22 & 646,87 \\
\hline 205.000 & 2 & $25000 ; 75000$ & 0 & 5000 & 58,02 & 57,96 & 58,07 & 645,92 & 645,13 & 646,71 \\
\hline 215.000 & 2 & $25000 ; 75000$ & 10000 & 5000 & 58,01 & 57,95 & 58,07 & 645,72 & 644,92 & 646,52 \\
\hline 260.000 & 2 & $25000 ; 75000$ & 10000 & 50000 & 58,06 & 58,00 & 58,12 & 646,66 & 645,81 & 647,52 \\
\hline 310.000 & 2 & $25000 ; 75000$ & 10000 & 100000 & 58,03 & 57,97 & 58,08 & 646,19 & 645,41 & 646,98 \\
\hline 410.000 & 2 & $25000 ; 75000$ & 10000 & 200000 & 58,04 & 57,98 & 58,09 & 646,11 & 645,29 & 646,94 \\
\hline 500.000 & 5 & $3 \times 10000 ; 2 \times 35000$ & 0 & 0 & 64,28 & 64,22 & 64,34 & 747,30 & 746,43 & 748,16 \\
\hline 510.000 & 5 & $3 \times 10000 ; 2 \times 35000$ & 10000 & 0 & 64,35 & 64,28 & 64,41 & 747,86 & 746,92 & 748,81 \\
\hline 505.000 & 5 & $3 \times 10000 ; 2 \times 35000$ & 0 & 5000 & 64,33 & 64,27 & 64,39 & 748,06 & 747,14 & 748,98 \\
\hline 515.000 & 5 & $3 \times 10000 ; 2 \times 35000$ & 10000 & 5000 & 64,33 & 64,26 & 64,39 & 747,87 & 746,90 & 748,83 \\
\hline 560.000 & 5 & $3 \times 10000 ; 2 \times 35000$ & 10000 & 50000 & 64,34 & 64,28 & 64,40 & 747,95 & 747,02 & 748,88 \\
\hline 610.000 & 5 & $3 \times 10000 ; 2 \times 35000$ & 10000 & 100000 & 64,34 & 64,28 & 64,40 & 747,81 & 746,88 & 748,73 \\
\hline 710.000 & 5 & $3 \times 10000 ; 2 \times 35000$ & 10000 & 200000 & 64,35 & 64,28 & 64,41 & 748,28 & 747,34 & 749,22 \\
\hline
\end{tabular}


Tabela A.7: Número médio de iterações para $\alpha=0,85$ e $\alpha=0,99$ e seus respectivos intervalos de confiança, variando o tamanho do grupo fechado, para grupos fechados de 1.000 e 10.000 páginas.

\begin{tabular}{ccccc|ccc|ccc}
\hline TP & QGF & TPGF & TPGL & TNP & $\begin{array}{c}\text { NI com } \\
\alpha=0,85\end{array}$ & $\begin{array}{c}\text { Limite } \\
\text { Inferior }\end{array}$ & $\begin{array}{c}\text { Limite } \\
\text { Superior }\end{array}$ & $\begin{array}{c}\text { NI com } \\
\alpha=0,99\end{array}$ & $\begin{array}{c}\text { Limite } \\
\text { Inferior }\end{array}$ & $\begin{array}{c}\text { Limite } \\
\text { Superior }\end{array}$ \\
\hline 2.100 & 1 & 1.000 & 100 & 1.000 & 24,84 & 24,77 & 24,92 & 31,09 & 30,97 & 31,21 \\
4.200 & 2 & 1.000 & 200 & 2.000 & 73,74 & 73,66 & 73,82 & 900,48 & 899,28 & 901,69 \\
6.300 & 3 & 1.000 & 300 & 3.000 & 75,07 & 74,98 & 75,15 & 921,95 & 920,61 & 923,29 \\
8.400 & 4 & 1.000 & 400 & 4.000 & 75,72 & 75,64 & 75,80 & 932,42 & 931,21 & 933,63 \\
10.500 & 5 & 1.000 & 500 & 5.000 & 76,24 & 76,16 & 76,32 & 940,58 & 939,34 & 941,83 \\
21.000 & 10 & 1.000 & 1.000 & 10.000 & 76,94 & 76,86 & 77,02 & 951,73 & 950,48 & 952,97 \\
31.500 & 15 & 1.000 & 1.500 & 15.000 & 77,17 & 77,09 & 77,24 & 955,52 & 954,39 & 956,66 \\
42.000 & 20 & 1.000 & 2.000 & 20.000 & 77,20 & 77,12 & 77,28 & 956,01 & 954,79 & 957,23 \\
\hline 21.000 & 1 & 10.000 & 1.000 & 10.000 & 23,74 & 23,69 & 23,79 & 29,68 & 29,62 & 29,73 \\
42.000 & 2 & 10.000 & 2.000 & 20.000 & 61,07 & 61,02 & 61,13 & 695,25 & 694,41 & 696,09 \\
63.000 & 3 & 10.000 & 3.000 & 30.000 & 62,41 & 62,35 & 62,47 & 717,43 & 716,50 & 718,36 \\
84.000 & 4 & 10.000 & 4.000 & 40.000 & 63,21 & 63,15 & 63,27 & 729,80 & 728,83 & 730,77 \\
105.000 & 5 & 10.000 & 5.000 & 50.000 & 63,50 & 63,44 & 63,56 & 734,91 & 734,01 & 735,81 \\
210.000 & 10 & 10.000 & 10.000 & 100.000 & 64,32 & 64,26 & 64,38 & 748,10 & 747,22 & 748,97 \\
315.000 & 15 & 10.000 & 15.000 & 150.000 & 64,51 & 64,45 & 64,58 & 750,96 & 749,99 & 751,94 \\
420.000 & 20 & 10.000 & 20.000 & 200.000 & 64,61 & 64,55 & 64,68 & 752,83 & 751,92 & 753,74 \\
\hline
\end{tabular}


Tabela A.8: Número médio de iterações para $\alpha=0,85$ e $\alpha=0,99$ e seus respectivos intervalos de confiança, variando o tamanho do grupo fechado, para grupos fechados de 500 a 2.000 páginas.

\begin{tabular}{|c|c|c|c|c|c|c|c|c|c|c|}
\hline$T P$ & $Q G F$ & $T P G F$ & $T P G L$ & $T N P$ & $\begin{array}{l}\text { NI com } \\
\alpha=0,85\end{array}$ & $\begin{array}{c}\text { Limite } \\
\text { Inferior }\end{array}$ & $\begin{array}{c}\text { Limite } \\
\text { Superior }\end{array}$ & $\begin{array}{l}\text { NI com } \\
\alpha=0,99\end{array}$ & $\begin{array}{l}\text { Limite } \\
\text { Inferior }\end{array}$ & $\begin{array}{c}\text { Limite } \\
\text { Superior }\end{array}$ \\
\hline 1.050 & 1 & 500 & 50 & 500 & 25,07 & 24,97 & 25,17 & 31,52 & 31,34 & 31,69 \\
\hline 2.100 & 1 & 1.000 & 100 & 1.000 & 24,84 & 24,77 & 24,92 & 31,09 & 30,97 & 31,21 \\
\hline 3.150 & 1 & 1.500 & 150 & 1.500 & 24,65 & 24,58 & 24,72 & 30,88 & 30,78 & 30,98 \\
\hline 4.200 & 1 & 2.000 & 200 & 2.000 & 24,53 & 24,48 & 24,59 & 30,70 & 30,62 & 30,78 \\
\hline 2.100 & 2 & 500 & 100 & 1.000 & 77,39 & 77,31 & 77,47 & 959,04 & 957,81 & 960,28 \\
\hline 4.200 & 2 & 1.000 & 200 & 2.000 & 73,74 & 73,66 & 73,82 & 900,48 & 899,28 & 901,69 \\
\hline 6.300 & 2 & 1.500 & 300 & 3.000 & 71,60 & 71,52 & 71,67 & 865,52 & 864,42 & 866,62 \\
\hline 8.400 & 2 & 2.000 & 400 & 4.000 & 70,00 & 69,93 & 70,07 & 839,44 & 838,37 & 840,51 \\
\hline 3.150 & 3 & 500 & 150 & 1.500 & 78,58 & 78,49 & 78,66 & 978,66 & 977,38 & 979,94 \\
\hline 6.300 & 3 & 1.000 & 300 & 3.000 & 75,07 & 74,98 & 75,15 & 921,95 & 920,61 & 923,29 \\
\hline 9.450 & 3 & 1.500 & 450 & 4.500 & 72,89 & 72,81 & 72,97 & 886,52 & 885,30 & 887,73 \\
\hline 12.600 & 3 & 2.000 & 600 & 6.000 & 71,34 & 71,27 & 71,42 & 861,60 & 860,44 & 862,76 \\
\hline 4.200 & 4 & 500 & 200 & 2.000 & 79,38 & 79,29 & 79,46 & 991,11 & 989,77 & 992,45 \\
\hline 8.400 & 4 & 1.000 & 400 & 4.000 & 75,72 & 75,64 & 75,80 & 932,42 & 931,21 & 933,63 \\
\hline 12.600 & 4 & 1.500 & 600 & 6.000 & 73,59 & 73,52 & 73,67 & 897,90 & 896,74 & 899,06 \\
\hline 16.800 & 4 & 2.000 & 800 & 8.000 & 72,07 & 72,00 & 72,14 & 872,84 & 871,67 & 874,02 \\
\hline 5.250 & 5 & 500 & 250 & 2.500 & 79,79 & 79,69 & 79,88 & 998,24 & 996,82 & 999,65 \\
\hline 10.500 & 5 & 1.000 & 500 & 5.000 & 76,24 & 76,16 & 76,32 & 940,58 & 939,34 & 941,83 \\
\hline 15.750 & 5 & 1.500 & 750 & 7.500 & 74,06 & 73,98 & 74,13 & 905,22 & 904,06 & 906,38 \\
\hline 21.000 & 5 & 2.000 & 1.000 & 10.000 & 72,45 & 72,37 & 72,52 & 879,36 & 878,21 & 880,51 \\
\hline 6.300 & 6 & 500 & 300 & 3.000 & 79,95 & 79,86 & 80,03 & $1.000,88$ & 999,58 & $1.002,18$ \\
\hline 12.600 & 6 & 1.000 & 600 & 6.000 & 76,41 & 76,34 & 76,49 & 943,23 & 942,08 & 944,39 \\
\hline 18.900 & 6 & 1.500 & 900 & 9.000 & 74,19 & 74,11 & 74,27 & 907,69 & 906,49 & 908,88 \\
\hline 25.200 & 6 & 2.000 & 1.200 & 12.000 & 72,73 & 72,65 & 72,80 & 884,10 & 882,94 & 885,27 \\
\hline 10.500 & 10 & 500 & 500 & 5.000 & 80,50 & 80,41 & 80,59 & $1.009,39$ & $1.008,00$ & $1.010,78$ \\
\hline 21.000 & 10 & 1.000 & 1.000 & 10.000 & 76,94 & 76,86 & 77,02 & 951,73 & 950,48 & 952,97 \\
\hline 31.500 & 10 & 1.500 & 1.500 & 15.000 & 74,74 & 74,66 & 74,82 & 916,26 & 915,07 & 917,46 \\
\hline 42.000 & 10 & 2.000 & 2.000 & 20.000 & 73,18 & 73,11 & 73,25 & 891,13 & 890,04 & 892,22 \\
\hline
\end{tabular}


Tabela A.9: Número médio de iterações para $\alpha=0,85$ e $\alpha=0,99$ e seus respectivos intervalos de confiança, variando o tamanho do grupo fechado, para grupos fechados de 5.000 a 20.000 páginas.

\begin{tabular}{|c|c|c|c|c|c|c|c|c|c|c|}
\hline$T P$ & $Q G F$ & $T P G F$ & $T P G L$ & $T N P$ & $\begin{array}{l}\text { NI com } \\
\alpha=0,85\end{array}$ & $\begin{array}{c}\text { Limite } \\
\text { Inferior }\end{array}$ & $\begin{array}{c}\text { Limite } \\
\text { Superior }\end{array}$ & $\begin{array}{l}\text { NI com } \\
\alpha=0,99\end{array}$ & $\begin{array}{c}\text { Limite } \\
\text { Inferior }\end{array}$ & $\begin{array}{c}\text { Limite } \\
\text { Superior }\end{array}$ \\
\hline 10.500 & 1 & 5.000 & 500 & 5.000 & 24,14 & 24,10 & 24,19 & 30,16 & 30,09 & 30,23 \\
\hline 21.000 & 1 & 10.000 & 1.000 & 10.000 & 23,74 & 23,69 & 23,79 & 29,68 & 29,62 & 29,73 \\
\hline 31.500 & 1 & 15.000 & 1.500 & 15.000 & 23,54 & 23,49 & 23,58 & 29,42 & 29,37 & 29,47 \\
\hline 42.000 & 1 & 20.000 & 2.000 & 20.000 & 23,44 & 23,39 & 23,48 & 29,27 & 29,23 & 29,32 \\
\hline 21.000 & 2 & 5.000 & 1.000 & 10.000 & 64,96 & 64,89 & 65,02 & 758,05 & 757,12 & 758,99 \\
\hline 42.000 & 2 & 10.000 & 2.000 & 20.000 & 61,07 & 61,02 & 61,13 & 695,25 & 694,41 & 696,09 \\
\hline 63.000 & 2 & 15.000 & 3.000 & 30.000 & 58,77 & 58,71 & 58,83 & 658,15 & 657,31 & 658,99 \\
\hline 84.000 & 2 & 20.000 & 4.000 & 40.000 & 57,14 & 57,08 & 57,19 & 631,46 & 630,65 & 632,28 \\
\hline 31.500 & 3 & 5.000 & 1.500 & 15.000 & 66,37 & 66,30 & 66,44 & 781,04 & 780,00 & 782,08 \\
\hline 63.000 & 3 & 10.000 & 3.000 & 30.000 & 62,41 & 62,35 & 62,47 & 717,43 & 716,50 & 718,36 \\
\hline 94.500 & 3 & 15.000 & 4.500 & 45.000 & 60,14 & 60,08 & 60,20 & 680,06 & 679,19 & 680,93 \\
\hline 126.000 & 3 & 20.000 & 6.000 & 60.000 & 58,50 & 58,44 & 58,56 & 653,70 & 652,86 & 654,54 \\
\hline 42.000 & 4 & 5.000 & 2.000 & 20.000 & 67,07 & 67,00 & 67,13 & 792,30 & 791,36 & 793,25 \\
\hline 84.000 & 4 & 10.000 & 4.000 & 40.000 & 63,21 & 63,15 & 63,27 & 729,80 & 728,83 & 730,77 \\
\hline 126.000 & 4 & 15.000 & 6.000 & 60.000 & 60,92 & 60,86 & 60,98 & 692,56 & 691,69 & 693,43 \\
\hline 168.000 & 4 & 20.000 & 8.000 & 80.000 & 59,30 & 59,24 & 59,36 & 666,66 & 665,80 & 667,52 \\
\hline 52.500 & 5 & 5.000 & 2.500 & 25.000 & 67,43 & 67,36 & 67,50 & 798,06 & 797,01 & 799,10 \\
\hline 105.000 & 5 & 10.000 & 5.000 & 50.000 & 63,50 & 63,44 & 63,56 & 734,91 & 734,01 & 735,81 \\
\hline 157.500 & 5 & 15.000 & 7.500 & 75.000 & 61,32 & 61,27 & 61,38 & 699,32 & 698,50 & 700,14 \\
\hline 210.000 & 5 & 20.000 & 10.000 & 100.000 & 59,67 & 59,61 & 59,73 & 672,56 & 671,68 & 673,44 \\
\hline 63.000 & 6 & 5.000 & 3.000 & 30.000 & 67,71 & 67,64 & 67,78 & 802,60 & 801,59 & 803,61 \\
\hline 126.000 & 6 & 10.000 & 6.000 & 60.000 & 63,82 & 63,76 & 63,89 & 739,71 & 738,80 & 740,62 \\
\hline 189.000 & 6 & 15.000 & 9.000 & 90.000 & 61,60 & 61,54 & 61,66 & 703,84 & 702,95 & 704,72 \\
\hline 252.000 & 6 & 20.000 & 12.000 & 120.000 & 59,93 & 59,87 & 59,99 & 676,79 & 675,88 & 677,70 \\
\hline 105.000 & 10 & 5.000 & 5.000 & 50.000 & 68,20 & 68,13 & 68,27 & 810,50 & 809,44 & 811,57 \\
\hline 210.000 & 10 & 10.000 & 10.000 & 100.000 & 64,32 & 64,26 & 64,38 & 748,10 & 747,22 & 748,97 \\
\hline 315.000 & 10 & 15.000 & 15.000 & 150.000 & 62,02 & 61,96 & 62,08 & 710,96 & 710,07 & 711,85 \\
\hline 420.000 & 10 & 20.000 & 20.000 & 200.000 & 60,39 & 60,33 & 60,45 & 684,65 & 683,78 & 685,52 \\
\hline
\end{tabular}


Tabela A.10: Número médio de iterações para $\alpha=0,85$ e $\alpha=0,99$ e seus respectivos intervalos de confiança, variando o tamanho do grupo fechado, para um total de 500, 5.000 e 50.000 páginas nos conjuntos fechados.

\begin{tabular}{ccccc|ccc|ccc}
\hline$T P$ & QGF & TPGF & TPGL & TNP & $\begin{array}{c}\text { NI com } \\
\alpha=0,85\end{array}$ & $\begin{array}{c}\text { Limite } \\
\text { Inferior }\end{array}$ & $\begin{array}{c}\text { Limite } \\
\text { Superior }\end{array}$ & $\begin{array}{c}\text { NI com } \\
\alpha=0,99\end{array}$ & $\begin{array}{c}\text { Limite } \\
\text { Inferior }\end{array}$ & $\begin{array}{c}\text { Limite } \\
\text { Superior }\end{array}$ \\
\hline 1.050 & 1 & 500 & 50 & 500 & 25,07 & 24,97 & 25,17 & 31,52 & 31,34 & 31,69 \\
1.050 & 2 & 250 & 50 & 500 & 80,91 & 80,83 & 81,00 & $1.016,40$ & $1.015,05$ & $1.017,75$ \\
1.050 & 5 & 100 & 50 & 500 & 87,51 & 87,42 & 87,61 & $1.123,20$ & $1.121,71$ & $1.124,69$ \\
1.054 & 8 & 63 & 50 & 504 & 89,85 & 89,76 & 89,95 & $1.161,05$ & $1.159,52$ & $1.162,58$ \\
1.050 & 10 & 50 & 50 & 500 & 90,94 & 90,86 & 91,03 & $1.178,54$ & $1.177,18$ & $1.179,90$ \\
1.050 & 20 & 25 & 50 & 500 & 93,27 & 93,20 & 93,34 & $1.215,89$ & $1.214,87$ & $1.216,91$ \\
1.050 & 50 & 10 & 50 & 500 & 94,25 & 94,18 & 94,32 & $1.231,72$ & $1.230,74$ & $1.232,70$ \\
\hline 10.500 & 1 & 5.000 & 500 & 5.000 & 24,16 & 24,12 & 24,20 & 30,13 & 30,07 & 30,19 \\
10.500 & 2 & 2.500 & 500 & 5.000 & 68,79 & 68,72 & 68,87 & 820,08 & 819,01 & 821,15 \\
10.500 & 5 & 1.000 & 500 & 5.000 & 76,24 & 76,16 & 76,32 & 940,58 & 939,34 & 941,83 \\
10.500 & 8 & 625 & 500 & 5.000 & 79,22 & 79,13 & 79,31 & 988,81 & 987,44 & 990,19 \\
10.500 & 10 & 500 & 500 & 5.000 & 80,49 & 80,40 & 80,57 & $1.009,35$ & $1.008,04$ & $1.010,66$ \\
10.500 & 20 & 250 & 500 & 5.000 & 84,38 & 84,29 & 84,47 & $1.072,09$ & $1.070,71$ & $1.073,46$ \\
10.500 & 50 & 100 & 500 & 5.000 & 88,64 & 88,55 & 88,73 & $1.141,16$ & $1.139,72$ & $1.142,61$ \\
10.580 & 80 & 63 & 500 & 5.040 & 90,67 & 90,57 & 90,76 & $1.174,02$ & $1.172,51$ & $1.175,53$ \\
10.500 & 100 & 50 & 500 & 5.000 & 91,58 & 91,49 & 91,67 & $1.188,65$ & $1.187,27$ & $1.190,04$ \\
\hline 105.000 & 1 & 50.000 & 5.000 & 50.000 & 22,96 & 22,93 & 23,00 & 28,60 & 28,55 & 28,65 \\
105.000 & 2 & 25.000 & 5.000 & 50.000 & 55,85 & 55,79 & 55,90 & 610,93 & 610,16 & 611,69 \\
105.000 & 5 & 10.000 & 5.000 & 50.000 & 63,50 & 63,44 & 63,56 & 734,91 & 734,01 & 735,81 \\
105.000 & 8 & 6.250 & 5.000 & 50.000 & 66,72 & 66,65 & 66,78 & 787,15 & 786,17 & 788,12 \\
105.000 & 10 & 5.000 & 5.000 & 50.000 & 68,20 & 68,13 & 68,27 & 810,50 & 809,44 & 811,57 \\
105.000 & 20 & 2.500 & 5.000 & 50.000 & 72,29 & 72,21 & 72,36 & 876,43 & 875,35 & 877,52 \\
105.000 & 50 & 1.000 & 5.000 & 50.000 & 77,43 & 77,34 & 77,51 & 959,70 & 958,47 & 960,94 \\
105.000 & 80 & 625 & 5.000 & 50.000 & 79,91 & 79,83 & 80,00 & 999,87 & 998,60 & $1.001,15$ \\
105.000 & 100 & 500 & 5.000 & 50.000 & 81,00 & 80,92 & 81,08 & $1.017,86$ & $1.016,53$ & $1.019,20$ \\
\hline
\end{tabular}


Tabela A.11: Número médio de iterações para $\alpha=0,85$ e $\alpha=0,99$ e seus respectivos intervalos de confiança, variando o tamanho do grupo fechado, para combinações de grupos fechados de 50 e 500 páginas e 450 e 500 páginas.

\begin{tabular}{|c|c|c|c|c|c|c|c|c|c|c|}
\hline$T P$ & $Q G F$ & $T P G F$ & $T P G L$ & $T N P$ & $\begin{array}{l}\text { NI com } \\
\alpha=0,85\end{array}$ & $\begin{array}{l}\text { Limite } \\
\text { Inferior }\end{array}$ & $\begin{array}{c}\text { Limite } \\
\text { Superior }\end{array}$ & $\begin{array}{l}\text { NI com } \\
\alpha=0,99\end{array}$ & $\begin{array}{c}\text { Limite } \\
\text { Inferior }\end{array}$ & $\begin{array}{c}\text { Limite } \\
\text { Superior }\end{array}$ \\
\hline 1.155 & 2 & $1 \times 50 ; 1 \times 500$ & 55 & 550 & 91,04 & 90,95 & 91,13 & $1.179,89$ & $1.178,49$ & $1.181,29$ \\
\hline 1.995 & 2 & $1 \times 450 ; 1 \times 500$ & 95 & 950 & 78,14 & 78,06 & 78,22 & 971,22 & 969,95 & 972,49 \\
\hline 2.205 & 3 & $1 \times 50 ; 2 \times 500$ & 105 & 1.050 & 91,36 & 91,27 & 91,45 & $1.185,29$ & $1.183,87$ & $1.186,70$ \\
\hline 3.045 & 3 & $1 \times 450 ; 2 \times 500$ & 145 & 1.450 & 79,42 & 79,33 & 79,51 & 992,47 & 991,09 & 993,86 \\
\hline 1.260 & 3 & $2 \times 50 ; 1 \times 500$ & 60 & 600 & 91,07 & 90,98 & 91,15 & $1.180,12$ & $1.178,77$ & $1.181,47$ \\
\hline 2.940 & 3 & $2 \times 450 ; 1 \times 500$ & 140 & 1.400 & 79,30 & 79,21 & 79,39 & 990,40 & 988,99 & 991,81 \\
\hline 2.310 & 4 & $2 \times 50 ; 2 \times 500$ & 110 & 1.100 & 91,44 & 91,35 & 91,53 & $1.186,27$ & $1.184,95$ & $1.187,58$ \\
\hline 3.990 & 4 & $2 \times 450 ; 2 \times 500$ & 190 & 1.900 & 80,02 & 79,92 & 80,11 & $1.001,45$ & $1.000,01$ & $1.002,89$ \\
\hline 4.305 & 5 & $1 \times 50 ; 4 \times 500$ & 205 & 2.050 & 91,48 & 91,39 & 91,57 & $1.187,23$ & $1.185,88$ & $1.188,59$ \\
\hline 5.145 & 5 & $1 \times 450 ; 4 \times 500$ & 245 & 2.450 & 80,39 & 80,30 & 80,48 & $1.008,16$ & $1.006,81$ & $1.009,50$ \\
\hline 1.470 & 5 & $4 \times 50 ; 1 \times 500$ & 70 & 700 & 91,24 & 91,15 & 91,32 & $1.183,12$ & $1.181,76$ & $1.184,48$ \\
\hline 4.830 & 5 & $4 \times 450 ; 1 \times 500$ & 230 & 2.300 & 80,39 & 80,30 & 80,48 & $1.008,02$ & $1.006,57$ & $1.009,47$ \\
\hline 4.620 & 8 & $4 \times 50 ; 4 \times 500$ & 220 & 2.200 & 91,40 & 91,30 & 91,49 & $1.185,91$ & $1.184,46$ & $1.187,35$ \\
\hline 7.980 & 8 & $4 \times 450 ; 4 \times 500$ & 380 & 3.800 & 80,89 & 80,81 & 80,98 & $1.015,60$ & $1.014,27$ & $1.016,92$ \\
\hline 8.505 & 9 & $1 \times 50 ; 8 \times 500$ & 405 & 4.050 & 91,56 & 91,47 & 91,65 & $1.188,42$ & $1.187,02$ & $1.189,83$ \\
\hline 9.345 & 9 & $1 \times 450 ; 8 \times 500$ & 445 & 4.450 & 81,05 & 80,97 & 81,14 & $1.018,37$ & $1.017,05$ & $1.019,69$ \\
\hline 6.615 & 9 & $3 \times 50 ; 6 \times 500$ & 315 & 3.150 & 91,54 & 91,46 & 91,63 & $1.188,21$ & $1.186,85$ & $1.189,57$ \\
\hline 9.135 & 9 & $3 \times 450 ; 6 \times 500$ & 435 & 4.350 & 81,04 & 80,95 & 81,13 & $1.018,36$ & $1.016,99$ & $1.019,73$ \\
\hline 1.890 & 9 & $8 \times 50 ; 1 \times 500$ & 90 & 900 & 91,24 & 91,15 & 91,33 & $1.182,90$ & $1.181,52$ & $1.184,28$ \\
\hline 8.610 & 9 & $8 \times 450 ; 1 \times 500$ & 410 & 4.100 & 81,06 & 80,96 & 81,15 & $1.018,57$ & $1.017,17$ & $1.019,98$ \\
\hline 3.780 & 9 & $6 \times 50 ; 3 \times 500$ & 180 & 1.800 & 91,34 & 91,25 & 91,43 & $1.185,11$ & $1.183,78$ & $1.186,44$ \\
\hline 8.820 & 9 & $6 \times 450 ; 3 \times 500$ & 420 & 4.200 & 81,01 & 80,92 & 81,09 & $1.017,31$ & $1.015,95$ & $1.018,68$ \\
\hline 8.085 & 14 & $7 \times 50 ; 7 \times 500$ & 385 & 3.850 & 91,64 & 91,55 & 91,74 & $1.189,69$ & $1.188,26$ & $1.191,11$ \\
\hline 13.965 & 14 & $7 \times 450 ; 7 \times 500$ & 665 & 6.650 & 81,24 & 81,16 & 81,33 & $1.021,46$ & $1.020,09$ & $1.022,82$ \\
\hline 11.550 & 20 & $10 \times 50 ; 10 \times 500$ & 550 & 5.500 & 91,63 & 91,54 & 91,72 & $1.189,29$ & $1.187,92$ & $1.190,67$ \\
\hline 19.950 & 20 & $10 \times 450 ; 10 \times 500$ & 950 & 9.500 & 81,36 & 81,27 & 81,45 & $1.023,54$ & $1.022,18$ & $1.024,89$ \\
\hline
\end{tabular}


Tabela A.12: Número médio de iterações para $\alpha=0,85$ e $\alpha=0,99$ e seus respectivos intervalos de confiança, variando o tamanho do grupo fechado, para combinações de grupos fechados de 500 e 5.000 páginas e 4.500 e $\mathbf{5 . 0 0 0}$ páginas.

\begin{tabular}{|c|c|c|c|c|c|c|c|c|c|c|}
\hline$T P$ & $Q G F$ & $T P G F$ & $T P G L$ & $T N P$ & $\begin{array}{l}\text { NI com } \\
\alpha=0,85\end{array}$ & $\begin{array}{l}\text { Limite } \\
\text { Inferior }\end{array}$ & $\begin{array}{c}\text { Limite } \\
\text { Superior }\end{array}$ & $\begin{array}{l}\text { NI com } \\
\alpha=0,99 \\
\end{array}$ & $\begin{array}{l}\text { Limite } \\
\text { Inferior }\end{array}$ & $\begin{array}{c}\text { Limite } \\
\text { Superior }\end{array}$ \\
\hline 11.550 & 2 & $1 \times 500 ; 1 \times 5000$ & 550 & 5.500 & 80,59 & 80,50 & 80,67 & $1.010,74$ & $1.009,38$ & $1.012,10$ \\
\hline 19.950 & 2 & $1 \times 4500 ; 1 \times 5000$ & 950 & 9.500 & 65,60 & 65,54 & 65,66 & 768,60 & 767,68 & 769,53 \\
\hline 22.050 & 3 & $1 \times 500 ; 2 \times 5000$ & 1.050 & 10.500 & 80,83 & 80,75 & 80,92 & $1.014,67$ & $1.013,37$ & $1.015,97$ \\
\hline 30.450 & 3 & $1 \times 4500 ; 2 \times 5000$ & 1.450 & 14.500 & 67,14 & 67,07 & 67,21 & 793,15 & 792,14 & 794,17 \\
\hline 12.600 & 3 & $2 \times 500 ; 1 \times 5000$ & 600 & 6.000 & 80,68 & 80,59 & 80,77 & $1.012,28$ & $1.010,83$ & $1.013,72$ \\
\hline 29.400 & 3 & $2 \times 4500 ; 1 \times 5000$ & 1.400 & 14.000 & 67,02 & 66,96 & 67,09 & 791,58 & 790,58 & 792,58 \\
\hline 23.100 & 4 & $2 \times 500 ; 2 \times 5000$ & 1.100 & 11.000 & 80,86 & 80,77 & 80,95 & $1.015,23$ & $1.013,84$ & $1.016,62$ \\
\hline 39.900 & 4 & $2 \times 4500 ; 2 \times 5000$ & 1.900 & 19.000 & 67,65 & 67,59 & 67,72 & 801,64 & 800,65 & 802,63 \\
\hline 43.050 & 5 & $1 \times 500 ; 4 \times 5000$ & 2.050 & 20.500 & 81,04 & 80,95 & 81,13 & $1.018,02$ & $1.016,70$ & $1.019,33$ \\
\hline 51.450 & 5 & $1 \times 4500 ; 4 \times 5000$ & 2.450 & 24.500 & 68,15 & 68,08 & 68,21 & 809,69 & 808,72 & 810,65 \\
\hline 14.700 & 5 & $4 \times 500 ; 1 \times$ & 700 & 7.000 & 80,67 & 80,59 & 80,76 & $1.012,52$ & $1.011,23$ & $1.013,82$ \\
\hline 48.300 & 5 & $4 \times 4500 ; 1 \times 5000$ & 2.300 & 23.000 & 68,09 & 68,02 & 68,16 & 808,91 & 807,84 & 809,97 \\
\hline 46.200 & 8 & $4 \times 500 ; 4 \times 5000$ & 2.200 & 22.000 & 81,04 & 80,96 & 81,12 & $1.018,12$ & $1.016,80$ & $1.019,4$ \\
\hline 79.800 & 8 & $4 \times 4500 ; 4 \times 5000$ & 3.800 & 38.000 & 68,60 & 68,53 & 68,67 & 817,16 & 816,18 & 818,14 \\
\hline 85.050 & 9 & $1 \times 500 ; 8 \times 5000$ & 4.050 & 40.500 & 81,14 & 81,05 & 81,23 & $1.019,49$ & $1.018,08$ & $1.020,9$ \\
\hline 93.450 & 9 & $1 \times 4500 ; 8 \times 5000$ & 4.450 & 44.500 & 68,74 & 68,67 & 68,81 & 819,10 & 818,05 & 820,16 \\
\hline 66.150 & 9 & $3 \times 500 ; 6 \times 5000$ & 3.150 & 31.500 & 80,99 & 80,91 & 81,08 & $1.017,65$ & $1.016,35$ & $1.018,9$ \\
\hline 91.350 & 9 & $3 \times 4500 ; 6 \times 5000$ & 4.350 & 43.500 & 68,66 & 68,59 & 68,73 & 817,89 & 816,89 & 818,89 \\
\hline 18.900 & 9 & $8 \times 500 ; 1 \times 5000$ & 900 & 9.000 & 80,81 & 80,72 & 80,90 & $1.014,50$ & $1.013,16$ & $1.015,8$ \\
\hline 86.100 & 9 & $8 \times 4500 ; 1 \times 5000$ & 4.100 & 41.000 & 68,70 & 68,63 & 68,76 & 818,56 & 817,54 & 819,58 \\
\hline 37.800 & 9 & $6 \times 500 ; 3 \times 5000$ & 1.800 & 18.000 & 81,00 & 80,91 & 81,09 & $1.017,45$ & $1.016,07$ & 1.018, \\
\hline 88.200 & 9 & $6 \times 4500 ; 3 \times 5000$ & 4.200 & 42.000 & 68,69 & 68,62 & 68,76 & 818,65 & 817,64 & 819,65 \\
\hline 80.850 & 14 & $7 \times 500 ; 7 \times 5000$ & 3.850 & 38.500 & 81,08 & 80,99 & 81,16 & $1.018,49$ & $1.017,15$ & $1.019,8$ \\
\hline 139.650 & 14 & $7 \times 4500 ; 7 \times 5000$ & 6.650 & 66.500 & 68,97 & 68,90 & 69,04 & 823,32 & 822,27 & 824,36 \\
\hline 115.500 & 20 & $10 \times 500 ; 10 \times 5000$ & 5.500 & 55.000 & 81,16 & 81,07 & 81,25 & $1.020,18$ & $1.018,75$ & 1.021, \\
\hline 199.500 & 20 & $100 \times 4500 ; 100 \times 5000$ & 9.500 & 95.000 & 69,07 & 69,00 & 69,14 & 824,75 & 823,71 & 825,78 \\
\hline
\end{tabular}


Tabela A.13: Número médio de iterações para $\alpha=0,85$ e $\alpha=0,99$ e seus respectivos intervalos de confiança, variando o tamanho do grupo fechado, para combinações de grupos fechados de diversos tamanhos.

\begin{tabular}{|c|c|c|c|c|c|c|c|c|c|c|}
\hline$T P$ & $Q G F$ & $T P G F$ & $T P G L$ & $T N P$ & $\begin{array}{l}\text { NI com } \\
\alpha=0,85\end{array}$ & $\begin{array}{c}\text { Limite } \\
\text { Inferior }\end{array}$ & $\begin{array}{c}\text { Limite } \\
\text { Superior }\end{array}$ & $\begin{array}{l}\text { NI com } \\
\alpha=0,99\end{array}$ & $\begin{array}{c}\text { Limite } \\
\text { Inferior }\end{array}$ & $\begin{array}{r}\text { Limi } \\
\text { Super }\end{array}$ \\
\hline 1050 & 1 & 500 & 50 & 500 & 25,02 & 24,91 & 25,13 & 31,43 & 31,25 & 31 \\
\hline 1050 & 2 & $20 ; 480$ & 50 & 500 & 93,66 & 93,59 & 93,72 & $1.222,73$ & $1.221,76$ & 1.22 \\
\hline 1050 & 2 & $200 ; 300$ & 50 & 500 & 82,56 & 82,48 & 82,65 & $1.042,62$ & $1.041,23$ & 1.04 \\
\hline 1050 & 2 & 250 & 50 & 500 & 80,93 & 80,85 & 81,01 & $1.016,73$ & $1.015,46$ & 1.01 \\
\hline 1050 & 3 & $10 ; 190 ; 300$ & 50 & 500 & 94,30 & 94,23 & 94,37 & $1.232,36$ & $1.231,36$ & 1.2 \\
\hline 1050 & 3 & $2 \times 10 ; 480$ & 50 & 500 & 94,25 & 94,18 & 94,32 & $1.231,61$ & $1.230,65$ & 1.2 \\
\hline 1050 & 4 & $20 ; 2 \times 120 ; 240$ & 50 & 500 & 93,71 & 93,65 & 93,78 & $1.223,10$ & $1.222,10$ & 1.22 \\
\hline 1050 & 4 & $3 \times 100 ; 200$ & 50 & 500 & 87,50 & 87,41 & 87,60 & $1.122,61$ & $1.121,14$ & 1.1 \\
\hline 1050 & 4 & $20 ; 100 ; 180 ; 200$ & 50 & 500 & 93,61 & 93,54 & 93,68 & $1.221,79$ & $1.220,75$ & 1.2 \\
\hline 1050 & 5 & $20 ; 4 \times 120$ & 50 & 500 & 93,73 & 93,66 & 93,79 & $1.223,30$ & $1.222,28$ & 1.2 \\
\hline 1050 & 7 & $5 \times 10 ; 150 ; 300$ & 50 & 500 & 94,28 & 94,21 & 94,35 & $1.232,26$ & $1.231,22$ & 1.2 \\
\hline 10500 & 1 & 5000 & 500 & 5000 & 24,16 & 24,11 & 24,21 & 30,19 & 30,12 & \\
\hline 10500 & 2 & $200 ; 4800$ & 500 & 5000 & 85,37 & 85,27 & 85,47 & $1.088,63$ & $1.087,11$ & 1.0 \\
\hline 10500 & 2 & $2000 ; 3000$ & 500 & 5000 & 70,65 & 70,58 & 70,73 & 850,35 & 849,16 & \\
\hline 10500 & 2 & 2.500 & 500 & 5000 & 68,76 & 68,69 & 68,83 & 819,74 & 818,71 & 82 \\
\hline 10500 & 3 & $100 ; 1900 ; 3000$ & 500 & 5000 & 88,74 & 88,65 & 88,83 & $1.142,52$ & $1.141,09$ & 1.1 \\
\hline 10500 & 3 & $2 \times 100 ; 4800$ & 500 & 5000 & 88,72 & 88,62 & 88,82 & $1.142,67$ & $1.141,14$ & 1.14 \\
\hline 10500 & 4 & $200 ; 2 \times 1200 ; 2400$ & 500 & 5000 & 85,47 & 85,37 & 85,56 & $1.089,68$ & $1.088,24$ & 1.0 \\
\hline 10500 & 4 & $3 \times 1000 ; 2000$ & 500 & 5000 & 76,16 & 76,08 & 76,24 & 939,40 & 938,16 & \\
\hline 10500 & 4 & $200 ; 1000 ; 1800 ; 2000$ & 500 & 5000 & 85,52 & 85,42 & 85,61 & $1.090,36$ & $1.088,81$ & 1.0 \\
\hline 10500 & 5 & $4 \times 50 ; 4800$ & 500 & 5000 & 91,55 & 91,47 & 91,64 & $1.188,23$ & $1.186,90$ & 1.1 \\
\hline 10500 & 5 & $200 ; 4 \times 1200$ & 500 & 5000 & 85,45 & 85,35 & 85,55 & $1.089,51$ & $1.088,01$ & 1.0 \\
\hline 10500 & 7 & $5 \times 100 ; 1500 ; 3000$ & 500 & 5000 & 88,77 & 88,67 & 88,87 & $1.142,90$ & $1.141,39$ & 1.14 \\
\hline 105000 & 1 & 50000 & 5000 & 50000 & 23,00 & 22,97 & 23,04 & 28,63 & 28,58 & \\
\hline 105000 & 2 & $2000 ; 48000$ & 5000 & 50000 & 73,53 & 73,46 & 73,60 & 896,57 & 895,49 & \\
\hline 105000 & 2 & $20000 ; 30000$ & 5000 & 50000 & 57,96 & 57,90 & 58,02 & 645,03 & 644,10 & \\
\hline 105000 & 2 & 25.000 & 5000 & 50000 & 55,85 & 55,79 & 55,90 & 610,93 & 610,16 & \\
\hline 105000 & 3 & 1000;19000;30000 & 5000 & 50000 & 77,50 & 77,41 & 77,58 & 960,63 & 959,29 & \\
\hline 105000 & 3 & $2 \times 1000 ; 48000$ & 5000 & 50000 & 77,46 & 77,38 & 77,54 & 960,53 & 959,29 & \\
\hline 105000 & 4 & $2000 ; 2 \times 12000 ; 24000$ & 5000 & 50000 & 73,60 & 73,52 & 73,67 & 898,01 & 896,85 & 89 \\
\hline 105000 & 4 & $3 \times 10000 ; 20000$ & 5000 & 50000 & 63,59 & 63,53 & 63,65 & 735,81 & 734,88 & 73 \\
\hline 105000 & 4 & $2000 ; 10000 ; 18000 ; 20000$ & 5000 & 50000 & 73,65 & 73,58 & 73,73 & 898,67 & 897,53 & 89 \\
\hline 105000 & 5 & $4 \times 500 ; 48000$ & 5000 & 50000 & 81,16 & 81,07 & 81,25 & $1.020,13$ & $1.018,74$ & 1.02 \\
\hline 105000 & 5 & $2000 ; 4 \times 12000$ & 5000 & 50000 & 73,57 & 73,50 & 73,64 & 897,00 & 895,90 & 89 \\
\hline 105000 & 7 & $5 \times 1000 ; 15000 ; 30000$ & 5000 & 50000 & 77,38 & 77,29 & 77,46 & 959,12 & 957,81 & \\
\hline
\end{tabular}


Apêndice B

Comparação entre $\alpha=0,85$ e $\alpha=0,99$ 
Tabela B.1: Número médio de iterações para $\alpha=0,85$ e $\alpha=0,99$, número médio de páginas com diferentes posições, média do Desvio Médio e média do Desvio Máximo, variando o tamanho do grupo fechado, a existência do Grupo de Ligação e o número de Nós Pendentes, para um total de 1.000 páginas nos conjuntos fechados.

\begin{tabular}{|c|c|c|c|c|c|c|c|c|c|}
\hline$T P$ & $Q G F$ & $T P G F$ & $T P G L$ & $T N P$ & $\begin{array}{l}\text { NI com } \\
\alpha=0,85\end{array}$ & $\begin{array}{l}N I \text { com } \\
\alpha=0,99\end{array}$ & $N P D$ & $M e d D$ & $\operatorname{MaxD}$ \\
\hline 1.000 & 1 & 1.000 & 0 & 0 & 24,86 & 31,17 & 958,25 & 16,35 & 480,04 \\
\hline 1.100 & 1 & 1.000 & 100 & 0 & 24,84 & 31,15 & 955,77 & 14,27 & 474,87 \\
\hline 1.050 & 1 & 1.000 & 0 & 50 & 24,76 & 31,03 & 956,56 & 15,50 & 479,78 \\
\hline 1.150 & 1 & 1.000 & 100 & 50 & 24,77 & 31,08 & 972,62 & 14,12 & 480,99 \\
\hline 1.600 & 1 & 1.000 & 100 & 500 & 24,81 & 31,11 & 988,10 & 10,40 & 485,42 \\
\hline 2.100 & 1 & 1.000 & 100 & 1.000 & 24,84 & 31,09 & 987,66 & 8,00 & 488,17 \\
\hline 3.100 & 1 & 1.000 & 100 & 2.000 & 25,07 & 31,06 & 988,27 & 5,38 & 481,17 \\
\hline 1.000 & 2 & 500 & 0 & 0 & 77,44 & 959,90 & 957,62 & 16,26 & 481,05 \\
\hline 1.100 & 2 & 500 & 100 & 0 & 77,36 & 959,02 & 957,33 & 14,35 & 476,07 \\
\hline 1.050 & 2 & 500 & 0 & 50 & 77,36 & 958,93 & 957,30 & 15,47 & 475,82 \\
\hline 1.150 & 2 & 500 & 100 & 50 & 77,37 & 959,10 & 972,06 & 14,10 & 478,73 \\
\hline 1.600 & 2 & 500 & 100 & 500 & 77,39 & 959,12 & 987,44 & 10,45 & 479,26 \\
\hline 2.100 & 2 & 500 & 100 & 1.000 & 77,39 & 959,04 & 987,35 & 7,90 & 483,56 \\
\hline 3.100 & 2 & 500 & 100 & 2.000 & 77,43 & 960,19 & 989,07 & 5,42 & 483,67 \\
\hline 1.000 & 5 & 200 & 0 & 0 & 84,29 & $1.071,15$ & 959,58 & 17,26 & 488,50 \\
\hline 1.100 & 5 & 200 & 100 & 0 & 84,41 & $1.072,19$ & 958,80 & 15,31 & 481,20 \\
\hline 1.050 & 5 & 200 & 0 & 50 & 84,33 & $1.071,63$ & 959,76 & 16,49 & 482,04 \\
\hline 1.150 & 5 & 200 & 100 & 50 & 84,39 & $1.072,25$ & 974,69 & 14,99 & 483,66 \\
\hline 1.600 & 5 & 200 & 100 & 500 & 84,36 & $1.071,81$ & 990,01 & 11,13 & 495,20 \\
\hline 2.100 & 5 & 200 & 100 & 1.000 & 84,38 & $1.071,91$ & 990,22 & 8,42 & 496,79 \\
\hline 3.100 & 5 & 200 & 100 & 2.000 & 84,32 & $1.071,40$ & 990,57 & 5,73 & 493,01 \\
\hline 1.000 & 10 & 100 & 0 & 0 & 88,13 & $1.132,88$ & 965,01 & 20,83 & 504,67 \\
\hline 1.100 & 10 & 100 & 100 & 0 & 88,17 & $1.133,77$ & 964,80 & 18,55 & 499,21 \\
\hline 1.050 & 10 & 100 & 0 & 50 & 88,17 & $1.133,51$ & 965,77 & 20,12 & 502,71 \\
\hline 1.150 & 10 & 100 & 100 & 50 & 88,23 & $1.134,70$ & 978,66 & 18,34 & 506,76 \\
\hline 1.600 & 10 & 100 & 100 & 500 & 88,13 & $1.133,24$ & 993,28 & 13,32 & 510,46 \\
\hline 2.100 & 10 & 100 & 100 & 1.000 & 88,17 & $1.133,55$ & 994,49 & 10,29 & 511,62 \\
\hline 3.100 & 10 & 100 & 100 & 2.000 & 88,15 & $1.133,22$ & 994,88 & 6,88 & 509,45 \\
\hline 1.000 & 50 & 20 & 0 & 0 & 93,82 & $1.224,62$ & 975,36 & 51,64 & 385,01 \\
\hline 1.100 & 50 & 20 & 100 & 0 & 93,80 & $1.224,90$ & 975,98 & 46,76 & 382,46 \\
\hline 1.050 & 50 & 20 & 0 & 50 & 93,82 & $1.224,74$ & 975,12 & 49,11 & 385,68 \\
\hline 1.150 & 50 & 20 & 100 & 50 & 93,82 & $1.224,91$ & 986,26 & 46,17 & 389,68 \\
\hline 1.600 & 50 & 20 & 100 & 500 & 93,83 & $1.224,91$ & 995,27 & 33,34 & 393,66 \\
\hline 2.100 & 50 & 20 & 100 & 1.000 & 93,77 & $1.224,22$ & 995,95 & 25,42 & 393,59 \\
\hline 3.100 & 50 & 20 & 100 & 2.000 & 93,84 & $1.225,35$ & 996,48 & 17,24 & 394,11 \\
\hline
\end{tabular}


Tabela B.2: Número médio de iterações para $\alpha=0,85$ e $\alpha=0,99$, número médio de páginas com diferentes posições, média do Desvio Médio e média do Desvio Máximo, variando o tamanho do grupo fechado, a existência do Grupo de Ligação e o número de Nós Pendentes, para um total de 10.000 páginas nos conjuntos fechados.

\begin{tabular}{|c|c|c|c|c|c|c|c|c|c|}
\hline$\overline{T P}$ & $Q G F$ & $T P G F$ & $T P G L$ & $\overline{T N P}$ & $\begin{array}{l}N I \text { com } \\
\alpha=0,85\end{array}$ & $\begin{array}{l}N I \text { com } \\
\alpha=0,99\end{array}$ & $N P D$ & $M e d D$ & $\operatorname{MaxD}$ \\
\hline 10.000 & 1 & 10.000 & 0 & 0 & 23,81 & 29,73 & $9.944,96$ & 161,28 & $5.693,60$ \\
\hline 11.000 & 1 & 10.000 & 1.000 & 0 & 23,79 & 29,71 & $9.942,89$ & 140,88 & $5.661,49$ \\
\hline 10.500 & 1 & 10.000 & 0 & 500 & 23,80 & 29,68 & $9.945,22$ & 152,64 & $5.682,97$ \\
\hline 11.500 & 1 & 10.000 & 1.000 & 500 & 23,80 & 29,66 & $10.053,41$ & 138,60 & $5.730,55$ \\
\hline 16.000 & 1 & 10.000 & 1.000 & 5.000 & 23,81 & 29,70 & $10.146,94$ & 102,15 & $5.769,71$ \\
\hline 21.000 & 1 & 10.000 & 1.000 & 10.000 & 23,74 & 29,68 & $10.154,91$ & 78,34 & $5.782,42$ \\
\hline 31.000 & 1 & 10.000 & 1.000 & 20.000 & 23,82 & 29,72 & $10.158,12$ & 53,04 & $5.791,22$ \\
\hline 10.000 & 2 & 5.000 & 0 & 0 & 64,91 & 757,23 & $9.945,86$ & 160,85 & $5.694,35$ \\
\hline 11.000 & 2 & 5.000 & 1.000 & 0 & 64,98 & 757,95 & $9.944,27$ & 141,03 & $5.667,54$ \\
\hline 10.500 & 2 & 5.000 & 0 & 500 & 64,96 & 758,38 & $9.946,36$ & 153,55 & $5.694,32$ \\
\hline 11.500 & 2 & 5.000 & 1.000 & 500 & 64,96 & 758,34 & $10.053,06$ & 138,73 & $5.719,91$ \\
\hline 16.000 & 2 & 5.000 & 1.000 & 5.000 & 64,90 & 757,28 & $10.149,08$ & 101,78 & $5.787,62$ \\
\hline 21.000 & 2 & 5.000 & 1.000 & 10.000 & 64,96 & 758,05 & $10.155,92$ & 78,40 & $5.792,53$ \\
\hline 31.000 & 2 & 5.000 & 1.000 & 20.000 & 64,96 & 758,24 & $10.158,72$ & 52,94 & $5.785,00$ \\
\hline 10.000 & 5 & 2.000 & 0 & 0 & 72,43 & 879,45 & $9.944,71$ & 161,32 & $5.695,80$ \\
\hline 11.000 & 5 & 2.000 & 1.000 & 0 & 72,45 & 879,40 & $9.944,71$ & 140,76 & $5.656,89$ \\
\hline 10.500 & 5 & 2.000 & 0 & 500 & 72,50 & 880,14 & $9.945,30$ & 152,88 & $5.683,67$ \\
\hline 11.500 & 5 & 2.000 & 1.000 & 500 & 72,47 & 879,74 & $10.054,01$ & 138,80 & $5.731,50$ \\
\hline 16.000 & 5 & 2.000 & 1.000 & 5.000 & 72,48 & 879,65 & $10.147,95$ & 102,58 & $5.776,58$ \\
\hline 21.000 & 5 & 2.000 & 1.000 & 10.000 & 72,45 & 879,36 & $10.154,73$ & 77,98 & $5.781,55$ \\
\hline 31.000 & 5 & 2.000 & 1.000 & 20.000 & 72,47 & 879,64 & $10.158,46$ & 53,00 & $5.779,22$ \\
\hline 10.000 & 10 & 1.000 & 0 & 0 & 76,90 & 951,36 & $9.944,53$ & 160,72 & $5.686,90$ \\
\hline 11.000 & 10 & 1.000 & 1.000 & 0 & 76,85 & 950,68 & $9.943,78$ & 140,63 & $5.659,48$ \\
\hline 10.500 & 10 & 1.000 & 0 & 500 & 76,84 & 950,09 & $9.945,90$ & 153,77 & $5.688,29$ \\
\hline 11.500 & 10 & 1.000 & 1.000 & 500 & 76,87 & 950,80 & $10.053,70$ & 139,44 & $5.734,11$ \\
\hline 16.000 & 10 & 1.000 & 1.000 & 5.000 & 76,82 & 950,06 & $10.148,74$ & 102,74 & $5.769,61$ \\
\hline 21.000 & 10 & 1.000 & 1.000 & 10.000 & 76,94 & 951,73 & $10.154,12$ & 78,46 & $5.772,22$ \\
\hline 31.000 & 10 & 1.000 & 1.000 & 20.000 & 76,95 & 951,99 & $10.158,05$ & 52,93 & $5.774,74$ \\
\hline 10.000 & 50 & 200 & 0 & 0 & 85,55 & $1.091,35$ & $9.950,46$ & 172,25 & $5.661,89$ \\
\hline 11.000 & 50 & 200 & 1.000 & 0 & 85,60 & $1.092,06$ & $9.949,76$ & 152,21 & $5.652,80$ \\
\hline 10.500 & 50 & 200 & 0 & 500 & 85,56 & $1.091,23$ & $9.950,15$ & 164,31 & $5.673,37$ \\
\hline 11.500 & 50 & 200 & 1.000 & 500 & 85,52 & $1.090,54$ & $10.054,78$ & 149,56 & $5.708,53$ \\
\hline 16.000 & 50 & 200 & 1.000 & 5.000 & 85,54 & $1.091,00$ & $10.150,18$ & 110,10 & $5.773,30$ \\
\hline 21.000 & 50 & 200 & 1.000 & 10.000 & 85,60 & $1.092,02$ & $10.157,26$ & 83,52 & $5.763,02$ \\
\hline 31.000 & 50 & 200 & 1.000 & 20.000 & 85,53 & $1.090,87$ & $10.160,37$ & 56,95 & $5.762,59$ \\
\hline
\end{tabular}


Tabela B.3: Número médio de iterações para $\alpha=0,85$ e $\alpha=0,99$, número médio de páginas com diferentes posições, média do Desvio Médio e média do Desvio Máximo, variando o tamanho do grupo fechado, a existência do Grupo de Ligação e o número de Nós Pendentes, para um total de 100.000 páginas nos conjuntos fechados.

\begin{tabular}{|c|c|c|c|c|c|c|c|c|c|}
\hline$T P$ & $Q G F$ & $T P G F$ & $T P G L$ & $T N P$ & $\begin{array}{l}N I \text { com } \\
\alpha=0,85\end{array}$ & $\begin{array}{l}\text { NI com } \\
\alpha=0,99\end{array}$ & $N P D$ & $M e d D$ & MaxD \\
\hline 100.000 & 1 & 100.000 & 0 & 0 & 22,54 & 28,16 & $99.934,26$ & $1.607,94$ & $8.992,56$ \\
\hline 110.000 & 1 & 100.000 & 0.000 & 0 & 22,52 & 28,14 & $99.932,24$ & $1.406,57$ & $8.820,88$ \\
\hline 105.000 & 1 & 100.000 & 0 & 5.000 & 22,49 & 28,14 & $99.932,37$ & $1.532,50$ & $59.027,85$ \\
\hline 115.000 & 1 & 100.000 & 10.000 & 5.000 & 22,54 & 28 & $100.919,39$ & $1.386,93$ & $59.329,56$ \\
\hline 160.000 & 1 & 100.000 & 10.000 & 50.000 & 22,52 & 28,16 & $101.802,46$ & $1.020,49$ & $59.967,60$ \\
\hline 210.000 & 1 & 100.000 & 10.000 & 100.000 & 22,55 & 28,16 & $101.872,44$ & 780,76 & $59.913,79$ \\
\hline 310.000 & 1 & 100.000 & 10.000 & 200.000 & 22,50 & 28,15 & $101.906,25$ & 530,21 & $60.018,32$ \\
\hline 100.000 & 2 & 50.000 & 0 & 0 & 51,89 & 546,62 & $99.933,62$ & $1.610,38$ & $58.979,33$ \\
\hline 110.000 & 2 & 0 & .000 & 0 & 92 & $r$ & $9.932,29$ & $.405,89$ & $8.850,23$ \\
\hline 105.000 & 2 & 50.000 & 0 & 5.000 & 51,89 & 546,82 & $99.932,31$ & $1.533,16$ & $58.985,55$ \\
\hline 115.000 & 2 & 50.000 & 10.000 & 5.000 & 51,92 & 547,25 & $100.920,10$ & $1.387,36$ & $59.310,04$ \\
\hline 160.000 & 2 & 50.000 & .000 & 50.000 & 51,94 & 547 & $101.802,02$ & $1.020,98$ & $9.990,11$ \\
\hline 210.000 & 2 & 50.000 & 10.000 & 100.000 & 51,92 & 547,06 & $101.868,20$ & 779,70 & $59.964,12$ \\
\hline 310.000 & 2 & 50.0 & 10.000 & 200.000 & 51,90 & 547 & 7,27 & 529 & 22,32 \\
\hline 100.0 & 5 & 0 & 0 & 0 & 59,73 & 673 & 31,84 & $1.606,24$ & $59.003,72$ \\
\hline 110.000 & 5 & 20.000 & 10.000 & 0 & 59,68 & 673 & $99.931,25$ & $1.406,60$ & $58.859,38$ \\
\hline 105.000 & 5 & 20.000 & 0 & 5.000 & 59,68 & 672 & $99.933,10$ & $1.532,58$ & $58.998,52$ \\
\hline .000 & 5 & 20.000 & .000 & 5.000 & 59,67 & 672 & $100.918,62$ & $1.387,60$ & $59.398,06$ \\
\hline 00 & 5 & 0 & 00 & 50.0 & 59 , & 672 & 58 & $1.020,93$ & 0,98 \\
\hline 210.0 & 5 & 0 & 10.000 & 100.000 & 59,67 & 672 & 84 & 78 & $59.896,49$ \\
\hline 310.000 & 5 & 20.000 & 10.000 & 200.000 & 59,67 & 672, & $101.904,39$ & 529,89 & $59.995,64$ \\
\hline 100.000 & 10 & 10.000 & ( & 0 & 64,30 & 747 & $99.932,89$ & $1.610,23$ & $59.035,10$ \\
\hline 110.00 & 10 & 10.000 & 10.000 & 0 & 64,32 & 747 & $99.931,99$ & $1.407,53$ & $58.788,41$ \\
\hline 105.00 & 10 & 10.000 & 0 & 5.000 & 64,25 & 747 & 33,44 & $1.531,10$ & $59.012,24$ \\
\hline 115.0 & 10 & 10.000 & 0.000 & 5.000 & 64,36 & 748 & $100.920,47$ & $1.385,22$ & $59.360,08$ \\
\hline 0.00 & 10 & & .000 & 50.000 & 64,38 & 748 & $101.797,47$ & $1.020,92$ & $59.985,20$ \\
\hline 210.000 & 10 & 10.000 & 10.000 & 100.000 & 64,32 & 748 & $101.871,98$ & 780,22 & $59.944,88$ \\
\hline 310.000 & 10 & 10.000 & 10.000 & 200.000 & 64,23 & 746,76 & $101.904,63$ & 529,78 & $59.971,46$ \\
\hline 100.000 & 50 & 2.0 & $\Omega$ & 0 & 73,69 & 899 & $99.932,02$ & $1.612,07$ & $58.971,20$ \\
\hline 110.000 & 50 & 2.000 & 0.000 & 0 & 73,74 & 900,05 & $99.930,28$ & $1.407,28$ & $58.780,48$ \\
\hline & 50 & 2.000 & 0 & 5.000 & 73,71 & 899 & $99.932,94$ & $1.531,88$ & $58.977,45$ \\
\hline 115.000 & 50 & 2.000 & 0.000 & 5.000 & 73,68 & 899,30 & $100.920,85$ & $1.388,28$ & $59.380,82$ \\
\hline 160.000 & 50 & 2.000 & 10.000 & 50.000 & 73,71 & 899,47 & $101.803,62$ & $1.020,48$ & $60.014,74$ \\
\hline & 50 & 2.000 & 10.000 & 100.000 & 73,74 & 900,11 & $101.870,33$ & 780,14 & $59.961,21$ \\
\hline 310.000 & 50 & 2.000 & 10.000 & 200.000 & 73,70 & 899,29 & $101.900,82$ & 529,09 & $59.934,74$ \\
\hline
\end{tabular}


Tabela B.4: Número médio de iterações para $\alpha=0,85$ e $\alpha=0,99$, número médio de páginas com diferentes posições, média do Desvio Médio e média do Desvio Máximo, variando o tamanho do grupo fechado, a existência do Grupo de Ligação e o número de Nós Pendentes, para grupos fechados com até 750 páginas.

\begin{tabular}{|c|c|c|c|c|c|c|c|c|c|}
\hline$T P$ & $Q G F$ & $T P G F$ & $T P G L$ & $T N P$ & $\begin{array}{l}N I \text { com } \\
\alpha=0,85\end{array}$ & $\begin{array}{l}\text { NI com } \\
\alpha=0,99\end{array}$ & $N P D$ & MedD & $\operatorname{Max} D$ \\
\hline 500 & 5 & 100 & 0 & 0 & 87,51 & $1.123,09$ & 466,55 & 10,44 & 234,65 \\
\hline 550 & 5 & 100 & 50 & 0 & 87,48 & $1.122,08$ & 466,47 & 9,50 & 232,26 \\
\hline 525 & 5 & 100 & 0 & 25 & 87,50 & $1.122,63$ & 466,83 & 9,90 & 232,54 \\
\hline 575 & 5 & 100 & 50 & 25 & 87,61 & $1.124,46$ & 474,18 & 9,25 & 236,20 \\
\hline 800 & 5 & 100 & 50 & 250 & 87,43 & $1.121,43$ & 482,67 & 6,80 & 236,83 \\
\hline 1.050 & 5 & 100 & 50 & 500 & 87,51 & $1.123,20$ & 482,63 & 5,11 & 233,04 \\
\hline 1.550 & 5 & 100 & 50 & 1000 & 87,51 & $1.122,89$ & 482,90 & 3,45 & 232,68 \\
\hline 500 & 2 & 250 & 0 & 0 & 80,87 & $1.015,60$ & 462,34 & 8,51 & 217,86 \\
\hline 550 & 2 & 250 & 50 & 0 & 80,91 & $1.016,40$ & 460,87 & 7,44 & 213,39 \\
\hline 525 & 2 & 250 & 0 & 25 & 80,90 & $1.016,05$ & 461,42 & 7,99 & 218,42 \\
\hline 575 & 2 & 250 & 50 & 25 & 80,97 & $1.017,15$ & 469,69 & 7,47 & 220,31 \\
\hline 800 & 2 & 250 & 50 & 250 & 81,00 & $1.017,34$ & 477,38 & 5,38 & 218,84 \\
\hline 1.050 & 2 & 250 & 50 & 500 & 80,91 & $1.016,40$ & 477,09 & 4,07 & 213,80 \\
\hline 1.550 & 2 & 250 & 50 & 1000 & 81,01 & $1.017,49$ & 477,85 & 2,78 & 216,64 \\
\hline 1.750 & 5 & 350 & 0 & 0 & 81,66 & $1.027,72$ & $1.705,06$ & 28,90 & 900,01 \\
\hline 1.925 & 5 & 350 & 175 & 0 & 81,53 & $1.026,38$ & $1.704,27$ & 25,32 & 890,58 \\
\hline 1.838 & 5 & 350 & 0 & 88 & 81,57 & $1.026,53$ & $1.705,00$ & 27,63 & 899,52 \\
\hline 2.013 & 5 & 350 & 175 & 88 & 81,55 & $1.026,65$ & $1.730,21$ & 24,94 & 898,41 \\
\hline 2.800 & 5 & 350 & 175 & 875 & 81,59 & $1.027,16$ & $1.752,89$ & 18,35 & 919,10 \\
\hline 3.675 & 5 & 350 & 175 & 1750 & 81,54 & $1.026,30$ & $1.753,66$ & 13,93 & 907,55 \\
\hline 5.425 & 5 & 350 & 175 & 3500 & 81,53 & $1.026,11$ & $1.755,17$ & 9,60 & 919,72 \\
\hline 1.500 & 2 & 750 & 0 & 0 & 75,30 & 925,48 & $1.455,78$ & 24,27 & 761,66 \\
\hline 1.650 & 2 & 750 & 150 & 0 & 75,28 & 925,12 & $1.454,40$ & 21,37 & 746,55 \\
\hline 1.575 & 2 & 750 & 0 & 75 & 75,32 & 925,68 & $1.454,42$ & 22,84 & 748,74 \\
\hline 1.725 & 2 & 750 & 150 & 75 & 75,26 & 925,00 & $1.477,78$ & 20,68 & 752,73 \\
\hline 2.400 & 2 & 750 & 150 & 750 & 75,29 & 925,50 & $1.498,58$ & 15,46 & 767,07 \\
\hline 3.150 & 2 & 750 & 150 & 1500 & 75,28 & 925,06 & $1.499,12$ & 11,82 & 764,33 \\
\hline 4.650 & 2 & 750 & 150 & 3000 & 75,31 & 925,48 & $1.499,45$ & 8,04 & 775,44 \\
\hline 2.000 & 2 & $250 ; 750$ & 0 & 0 & 82,86 & $1.047,44$ & 958,28 & 16,37 & 480,32 \\
\hline 2.100 & 2 & $250 ; 750$ & 100 & 0 & 82,93 & $1.048,75$ & 956,39 & 14,30 & 473,98 \\
\hline 2.050 & 2 & $250 ; 750$ & 0 & 50 & 82,78 & $1.046,91$ & 956,63 & 15,64 & 478,86 \\
\hline 2.150 & 2 & $250 ; 750$ & 100 & 50 & 82,90 & $1.048,53$ & 973,28 & 14,17 & 478,55 \\
\hline 2.600 & 2 & $250 ; 750$ & 100 & 500 & 82,85 & $1.047,53$ & 987,84 & 10,52 & 484,24 \\
\hline 3.100 & 2 & $250 ; 750$ & 100 & 1000 & 82,79 & $1.046,66$ & 988,24 & 7,94 & 484,03 \\
\hline 4.100 & 2 & $250 ; 750$ & 100 & 2000 & 82,89 & $1.047,91$ & 989,03 & 5,41 & 487,98 \\
\hline 5.000 & 5 & $3 \times 100 ; 2 \times 350$ & 0 & 0 & 88,14 & $1.133,36$ & 961,31 & 17,76 & 492,76 \\
\hline 5.100 & 5 & $3 \times 100 ; 2 \times 350$ & 100 & 0 & 88,19 & $1.133,87$ & 959,45 & 15,75 & 492,06 \\
\hline 5.050 & 5 & $3 \times 100 ; 2 \times 350$ & 0 & 50 & 88,20 & $1.133,84$ & 961,36 & 16,93 & 489,17 \\
\hline 5.150 & 5 & $3 \times 100 ; 2 \times 350$ & 100 & 50 & 88,23 & $1.134,47$ & 976,18 & 15,56 & 488,35 \\
\hline 5.600 & 5 & $3 \times 100 ; 2 \times 350$ & 100 & 500 & 88,21 & $1.134,04$ & 990,65 & 11,41 & 497,81 \\
\hline 6.100 & 5 & $3 \times 100 ; 2 \times 350$ & 100 & 1000 & 88,24 & $1.134,50$ & 991,81 & 8,77 & 500,90 \\
\hline 7.100 & 5 & $3 \times 100 ; 2 \times 350$ & 100 & 2000 & 88,21 & $1.134,35$ & 991,58 & 5,92 & 499,59 \\
\hline
\end{tabular}


Tabela B.5: Número médio de iterações para $\alpha=0,85$ e $\alpha=0,99$, número médio de páginas com diferentes posições, média do Desvio Médio e média do Desvio Máximo, variando o tamanho do grupo fechado, a existência do Grupo de Ligação e o número de Nós Pendentes, para grupos fechados com até 7.500 páginas.

\begin{tabular}{|c|c|c|c|c|c|c|c|c|c|}
\hline$T P$ & $Q G F$ & $T P G F$ & $T P G L$ & $\overline{T N P}$ & $\begin{array}{l}N I \text { com } \\
\alpha=0,85\end{array}$ & $\begin{array}{l}\text { NI com } \\
\alpha=0,99\end{array}$ & $N P D$ & $M e d D$ & $\operatorname{MaxD}$ \\
\hline 5.000 & 5 & 1.000 & 0 & 0 & 76,18 & 939,62 & $4.948,40$ & 80,69 & $2.781,66$ \\
\hline 5.500 & 5 & 1.000 & 500 & 0 & 76,17 & 939,65 & $4.947,63$ & 70,39 & $2.755,26$ \\
\hline 5.250 & 5 & 1.000 & 0 & 250 & 76,11 & 938,71 & $4.948,84$ & 76,73 & $2.776,33$ \\
\hline 5.750 & 5 & 1.000 & 500 & 250 & 76,25 & 940,36 & $5.009,78$ & 69,72 & $2.784,28$ \\
\hline 8.000 & 5 & 1.000 & 500 & 2.500 & 76,11 & 938,49 & $5.060,46$ & 51,15 & $2.814,57$ \\
\hline 10.500 & 5 & 1.000 & 500 & 5.000 & 76,24 & 940,58 & $5.063,88$ & 39,21 & $2.822,97$ \\
\hline 15.500 & 5 & 1.000 & 500 & 10.000 & 76,21 & 940,01 & $5.066,07$ & 26,61 & $2.821,51$ \\
\hline 5.000 & 2 & 2.500 & 0 & 0 & 68,79 & 819,89 & $4.947,78$ & 80,55 & $2.778,33$ \\
\hline 5.500 & 2 & 2.500 & 500 & 0 & 68,78 & 819,77 & $4.946,77$ & 70,61 & $2.760,13$ \\
\hline 5.250 & 2 & 2.500 & 0 & 250 & 68,82 & 820,51 & $4.948,26$ & 76,49 & $2.766,46$ \\
\hline 5.750 & 2 & 2.500 & 500 & 250 & 68,78 & 819,83 & $5.009,73$ & 69,51 & $2.792,30$ \\
\hline 8.000 & 2 & 2.500 & 500 & 2.500 & 68,81 & 820,47 & $5.060,29$ & 50,81 & $2.831,55$ \\
\hline 10.500 & 2 & 2.500 & 500 & 5.000 & 68,83 & 820,98 & $5.064,61$ & 39,02 & $2.818,56$ \\
\hline 15.500 & 2 & 2.500 & 500 & 10.000 & 68,81 & 820,39 & $5.065,36$ & 26,53 & $2.827,12$ \\
\hline 17.500 & 5 & 3.500 & 0 & 0 & 69,41 & 830,18 & $17.442,09$ & 281,24 & $10.067,94$ \\
\hline 19.250 & 5 & 3.500 & 1.750 & 0 & 69,42 & 830,21 & $17.439,70$ & 246,02 & $10.035,65$ \\
\hline 18.375 & 5 & 3.500 & 0 & 875 & 69,45 & 830,68 & $17.441,49$ & 267,88 & $10.056,75$ \\
\hline 20.125 & 5 & 3.500 & 1.750 & 875 & 69,35 & 829,15 & $17.622,41$ & 242,19 & $10.131,10$ \\
\hline 28.000 & 5 & 3.500 & 1.750 & 8.750 & 69,36 & 829,30 & $17.783,76$ & 178,71 & $10.232,23$ \\
\hline 36.750 & 5 & 3.500 & 1.750 & 17.500 & 69,37 & 829,41 & $17.795,01$ & 136,37 & $10.231,65$ \\
\hline 54.250 & 5 & 3.500 & 1.750 & 35.000 & 69,14 & 825,84 & $18.860,92$ & 98,53 & $10.861,53$ \\
\hline 15.000 & 2 & 7.500 & 0 & 0 & 62,64 & 720,91 & $14.942,77$ & 241,72 & $8.603,33$ \\
\hline 16.500 & 2 & 7.500 & 1.500 & 0 & 62,64 & 720,94 & $14.939,48$ & 210,38 & $8.575,21$ \\
\hline 15.750 & 2 & 7.500 & 0 & 750 & 62,67 & 721,30 & $14.943,19$ & 230,05 & $8.606,78$ \\
\hline 17.250 & 2 & 7.500 & 1.500 & 750 & 62,69 & 721,28 & $15.098,76$ & 208,11 & $8.657,14$ \\
\hline 24.000 & 2 & 7.500 & 1.500 & 7.500 & 62,65 & 720,93 & $15.236,79$ & 153,26 & $8.752,39$ \\
\hline 31.500 & 2 & 7.500 & 1.500 & 15.000 & 62,64 & 720,93 & $15.247,55$ & 116,85 & $8.760,36$ \\
\hline 46.500 & 2 & 7.500 & 1.500 & 30.000 & 62,67 & 721,30 & $15.253,57$ & 79,56 & $8.752,44$ \\
\hline 20.000 & 2 & $2.500 ; 7.500$ & 0 & 0 & 70,88 & 854,20 & $9.944,62$ & 160,80 & $5.691,33$ \\
\hline 21.000 & 2 & $2.500 ; 7.500$ & 1.000 & 0 & 70,80 & 852,79 & $9.943,49$ & 141,18 & $5.663,36$ \\
\hline 20.500 & 2 & $2.500 ; 7.500$ & 0 & 500 & 70,85 & 853,31 & $9.944,84$ & 152,95 & $5.687,03$ \\
\hline 21.500 & 2 & $2.500 ; 7.500$ & 1.000 & 500 & 70,84 & 853,42 & $10.054,25$ & 138,95 & $5.725,06$ \\
\hline 26.000 & 2 & $2.500 ; 7.500$ & 1.000 & 5.000 & 70,86 & 853,88 & $10.148,85$ & 102,50 & $5.770,10$ \\
\hline 31.000 & 2 & $2.500 ; 7.500$ & 1.000 & 10.000 & 70,83 & 853,25 & $10.156,33$ & 78,10 & $5.779,92$ \\
\hline 41.000 & 2 & $2.500 ; 7.500$ & 1.000 & 20.000 & 70,85 & 853,32 & $10.158,64$ & 52,88 & $5.786,28$ \\
\hline 50.000 & 5 & $3 \times 1.000 ; 2 \times 3.500$ & 0 & 0 & 76,88 & 950,84 & $9.945,23$ & 161,44 & $5.685,86$ \\
\hline 51.000 & 5 & $3 \times 1.000 ; 2 \times 3.500$ & 1.000 & 0 & 76,81 & 950,15 & $9.942,69$ & 141,05 & $5.670,84$ \\
\hline 50.500 & 5 & $3 \times 1.000 ; 2 \times 3.500$ & 0 & 500 & 76,88 & 951,57 & $9.944,18$ & 152,79 & $5.689,59$ \\
\hline 51.500 & 5 & $3 \times 1.000 ; 2 \times 3.500$ & 1.000 & 500 & 76,97 & 951,73 & $10.053,44$ & 138,80 & $5.739,68$ \\
\hline 56.000 & 5 & $3 \times 1.000 ; 2 \times 3.500$ & 1.000 & 5.000 & 76,90 & 951,22 & $10.148,80$ & 102,28 & $5.775,03$ \\
\hline 61.000 & 5 & $3 \times 1.000 ; 2 \times 3.500$ & 1.000 & 10.000 & 76,85 & 950,44 & $10.153,74$ & 78,39 & $5.783,92$ \\
\hline 71.000 & 5 & $3 \times 1.000 ; 2 \times 3.500$ & 1.000 & 20.000 & 76,90 & 951,31 & $10.157,98$ & 52,98 & $5.769,98$ \\
\hline
\end{tabular}


Tabela B.6: Número médio de iterações para $\alpha=0,85$ e $\alpha=0,99$, número médio de páginas com diferentes posições, média do Desvio Médio e média do Desvio Máximo, variando o tamanho do grupo fechado, a existência do Grupo de Ligação e o número de Nós Pendentes, para grupos fechados com até $\mathbf{7 5 . 0 0 0}$ páginas.

\begin{tabular}{|c|c|c|c|c|c|c|c|c|c|}
\hline$T P$ & $Q G F$ & $T P G F$ & $T P G L$ & $T N P$ & $\begin{array}{l}N I \text { com } \\
\alpha=0,85\end{array}$ & $\begin{array}{l}\text { NI com } \\
\alpha=0,99\end{array}$ & $N P D$ & $M e d D$ & MaxD \\
\hline 50.000 & 5 & 10.000 & 0 & 0 & 63,62 & 736,35 & $49.935,43$ & 804,67 & $29.239,04$ \\
\hline 55.000 & 5 & 10.000 & 5000 & 0 & 63,60 & 736,08 & $49.934,26$ & 704,39 & $29.125,52$ \\
\hline 52.500 & 5 & 10.000 & 0 & 2500 & 63,59 & 736,00 & $49.937,55$ & 767,05 & $29.220,75$ \\
\hline 57.500 & 5 & 10.000 & 5000 & 2500 & 63,55 & 735,57 & $50.431,99$ & 693,55 & $29.400,99$ \\
\hline 80.000 & 5 & 10.000 & 5000 & 25000 & 63,56 & 735,53 & $50.876,22$ & 509,92 & $29.708,88$ \\
\hline 105.000 & 5 & 10.000 & 5000 & 50000 & 63,50 & 734,91 & $50.911,21$ & 389,69 & $29.683,60$ \\
\hline 155.000 & 5 & 10.000 & 5000 & 100000 & 63,53 & 735,40 & $50.927,55$ & 264,50 & $29.680,78$ \\
\hline 50.000 & 2 & 25.000 & 0 & 0 & 55,83 & 610,81 & $49.935,75$ & 805,00 & $29.227,10$ \\
\hline 55.000 & 2 & 25.000 & 5000 & 0 & 55,87 & 611,22 & $49.935,05$ & 703,04 & $29.103,22$ \\
\hline 52.500 & 2 & 25.000 & 0 & 2500 & 55,83 & 610,99 & $49.936,53$ & 766,01 & $29.215,36$ \\
\hline 57.500 & 2 & 25.000 & 5000 & 2500 & 55,89 & 612,06 & $50.431,29$ & 694,06 & $29.384,95$ \\
\hline 80.000 & 2 & 25.000 & 5000 & 25000 & 55,86 & 610,61 & $50.876,99$ & 510,57 & $29.725,46$ \\
\hline 105.000 & 2 & 25.000 & 5000 & 50000 & 55,85 & 610,70 & $50.910,07$ & 390,28 & $29.709,57$ \\
\hline 155.000 & 2 & 25.000 & 5000 & 100000 & 55,88 & 611,46 & $50.928,19$ & 264,41 & $29.694,26$ \\
\hline 175.000 & 5 & 35.000 & 0 & 0 & 56,52 & 621,67 & $174.930,11$ & $2.817,37$ & $103.835,98$ \\
\hline 192.500 & 5 & 35.000 & 17500 & 0 & 56,49 & 621,13 & $174.928,58$ & $2.462,08$ & $103.595,33$ \\
\hline 183.750 & 5 & 35.000 & 0 & 8750 & 56,46 & 620,95 & $174.927,66$ & $2.682,83$ & $103.862,89$ \\
\hline 201.250 & 5 & 35.000 & 17500 & 8750 & 56,46 & 621,04 & $176.657,47$ & $2.426,61$ & $104.541,75$ \\
\hline 280.000 & 5 & 35.000 & 17500 & 87500 & 56,54 & 621,75 & $178.189,85$ & $1.787,37$ & $105.582,57$ \\
\hline 367.500 & 5 & 35.000 & 17500 & 175000 & 56,49 & 621,97 & $178.319,56$ & $1.366,88$ & $105.599,01$ \\
\hline 542.500 & 5 & 35.000 & 17500 & 350000 & 56,50 & 621,70 & $178.379,01$ & 926,76 & $105.569,21$ \\
\hline 150.000 & 2 & 75.000 & 0 & 0 & 49,53 & 509,11 & $149.930,62$ & $2.413,49$ & $88.885,03$ \\
\hline 165.000 & 2 & 75.000 & 15000 & 0 & 49,53 & 509,28 & $149.928,83$ & $2.111,27$ & $88.627,35$ \\
\hline 157.500 & 2 & 75.000 & 0 & 7500 & 49,53 & 508,94 & $149.930,83$ & $2.300,69$ & $88.922,02$ \\
\hline 172.500 & 2 & 75.000 & 15000 & 7500 & 49,55 & 509,26 & $151.413,44$ & $2.081,79$ & $89.456,62$ \\
\hline 240.000 & 2 & 75.000 & 15000 & 75000 & 49,57 & 509,48 & $152.729,66$ & $1.531,12$ & $90.488,05$ \\
\hline 315.000 & 2 & 75.000 & 15000 & 150000 & 49,51 & 509,08 & $152.830,63$ & $1.170,47$ & $90.365,92$ \\
\hline 465.000 & 2 & 75.000 & 15000 & 300000 & 49,60 & 509,93 & $152.885,75$ & 794,78 & $90.340,24$ \\
\hline 200.000 & 2 & $.000 ; 75.000$ & 0 & 0 & 58,03 & 646,09 & $99.932,91$ & $1.607,70$ & $59.058,58$ \\
\hline 210.000 & 2 & $25.000 ; 75.000$ & 10000 & 0 & 58,05 & 646,04 & $99.931,01$ & $1.406,23$ & $58.830,41$ \\
\hline 205.000 & 2 & $25.000 ; 75.000$ & 0 & 5000 & 58,02 & 645,92 & $99.932,05$ & $1.533,99$ & $58.997,24$ \\
\hline 215.000 & 2 & $25.000 ; 75.000$ & 10000 & 5000 & 58,01 & 645,72 & $100.920,93$ & $1.384,74$ & $59.309,36$ \\
\hline 260.000 & 2 & $25.000 ; 75.000$ & 10000 & 50000 & 58,06 & 646,66 & $101.799,47$ & $1.021,02$ & $59.993,84$ \\
\hline 310.000 & 2 & $25.000 ; 75.000$ & 10000 & 100000 & 58,03 & 646,19 & $101.868,66$ & 780,96 & $59.990,04$ \\
\hline 410.000 & 2 & $25.000 ; 75.000$ & 10000 & 200000 & 58,04 & 646,11 & $101.907,09$ & 530,04 & $59.995,46$ \\
\hline 500.000 & 5 & $\times 10000 ; 2 \times 35000$ & 0 & 0 & 64,28 & 747,30 & $99.933,72$ & $1.608,37$ & $58.944,76$ \\
\hline 510.000 & 5 & $3 \times 10000 ; 2 \times 35000$ & 10000 & 0 & 64,35 & 747,86 & $99.930,71$ & $1.405,76$ & $58.840,57$ \\
\hline 505.000 & 5 & $3 \times 10000 ; 2 \times 35000$ & 0 & 5000 & 64,33 & 748,06 & $99.933,96$ & $1.534,27$ & $59.009,25$ \\
\hline 515.000 & 5 & $3 \times 10000 ; 2 \times 35000$ & 10000 & 5000 & 64,33 & 747,87 & $100.921,82$ & $1.387,16$ & $59.333,12$ \\
\hline 560.000 & 5 & $3 \times 10000 ; 2 \times 35000$ & 10000 & 50000 & 64,34 & 747,95 & $101.803,40$ & $1.020,17$ & $59.987,98$ \\
\hline 610.000 & 5 & $3 \times 10000 ; 2 \times 35000$ & 10000 & 100000 & 64,34 & 747,81 & $101.873,99$ & 781,02 & $59.935,90$ \\
\hline 710.000 & 5 & $3 \times 10000 ; 2 \times 35000$ & 10000 & 200000 & 64,35 & 748,28 & $101.906,14$ & 529,52 & $59.949,97$ \\
\hline
\end{tabular}


Tabela B.7: Número médio de iterações para $\alpha=0,85$ e $\alpha=0,99$, número médio de páginas com diferentes posições, média do Desvio Médio e média do Desvio Máximo, variando o tamanho do grupo fechado, para grupos fechados de 1.000 e 10.000 páginas.

\begin{tabular}{cccccccccc}
\hline TP & QGF & TPGF & TPGL & TNP & $\begin{array}{c}\text { NI com } \\
\alpha=0,85\end{array}$ & $\begin{array}{c}\text { NI com } \\
\alpha=0,99\end{array}$ & NPD & MedD & MaxD \\
\hline 2.100 & 1 & 1.000 & 100 & 1.000 & 24,84 & 31,09 & 987,66 & 8,00 & 488,17 \\
4.200 & 2 & 1.000 & 200 & 2.000 & 73,74 & 900,48 & $2.008,91$ & 15,78 & $1.046,28$ \\
6.300 & 3 & 1.000 & 300 & 3.000 & 75,07 & 921,95 & $3.028,03$ & 23,60 & $1.635,75$ \\
8.400 & 4 & 1.000 & 400 & 4.000 & 75,72 & 932,42 & $4.046,09$ & 31,20 & $2.224,58$ \\
10.500 & 5 & 1.000 & 500 & 5.000 & 76,24 & 940,58 & $5.063,88$ & 39,21 & $2.822,97$ \\
21.000 & 10 & 1.000 & 1.000 & 10.000 & 76,94 & 951,73 & $10.154,12$ & 78,46 & $5.772,22$ \\
31.500 & 15 & 1.000 & 1.500 & 15.000 & 77,17 & 955,52 & $15.247,54$ & 117,12 & $8.741,97$ \\
42.000 & 20 & 1.000 & 2.000 & 20.000 & 77,20 & 956,01 & $20.341,31$ & 156,23 & $11.724,91$ \\
\hline 21.000 & 1 & 10.000 & 1.000 & 10.000 & 23,74 & 29,68 & $10.154,91$ & 78,34 & $5.782,42$ \\
42.000 & 2 & 10.000 & 2.000 & 20.000 & 61,07 & 695,25 & $20.341,58$ & 156,02 & $11.722,34$ \\
63.000 & 3 & 10.000 & 3.000 & 30.000 & 62,41 & 717,43 & $30.529,13$ & 233,66 & $17.704,65$ \\
84.000 & 4 & 10.000 & 4.000 & 40.000 & 63,21 & 729,80 & $40.720,49$ & 312,68 & $23.712,32$ \\
105.000 & 5 & 10.000 & 5.000 & 50.000 & 63,50 & 734,91 & $50.911,21$ & 389,69 & $29.683,60$ \\
210.000 & 10 & 10.000 & 10.000 & 100.000 & 64,32 & 748,10 & $101.871,98$ & 780,22 & $59.944,88$ \\
315.000 & 15 & 10.000 & 15.000 & 150.000 & 64,51 & 750,96 & $152.831,59$ & $1.171,05$ & $90.357,33$ \\
420.000 & 20 & 10.000 & 20.000 & 200.000 & 64,61 & 752,83 & $203.792,78$ & $1.560,39$ & $120.784,27$ \\
\hline
\end{tabular}


Tabela B.8: Número médio de iterações para $\alpha=0,85$ e $\alpha=0,99$, número médio de páginas com diferentes posições, média do Desvio Médio e média do Desvio Máximo, variando o tamanho do grupo fechado, para grupos fechados de 500 a 2.000 páginas.

\begin{tabular}{cccccccccc}
\hline$T P$ & QGF & TPGF & TPGL & TNP & NI com & NI com & NPD & MedD & MaxD \\
& & & & & $\alpha=0,85$ & $\alpha=0,99$ & & & \\
\hline 1.050 & 1 & 500 & 50 & 500 & 25,07 & 31,52 & 476,13 & 4,01 & 215,63 \\
2.100 & 1 & 1.000 & 100 & 1.000 & 24,84 & 31,09 & 987,66 & 8,00 & 488,17 \\
3.150 & 1 & 1.500 & 150 & 1.500 & 24,65 & 30,88 & $1.499,33$ & 11,94 & 764,90 \\
4.200 & 1 & 2.000 & 200 & 2.000 & 24,53 & 30,70 & $2.008,82$ & 15,66 & $1.051,56$ \\
\hline 2.100 & 2 & 500 & 100 & 1.000 & 77,39 & 959,04 & 987,35 & 7,90 & 483,56 \\
4.200 & 2 & 1.000 & 200 & 2.000 & 73,74 & 900,48 & $2.008,91$ & 15,78 & $1.046,28$ \\
6.300 & 2 & 1.500 & 300 & 3.000 & 71,60 & 865,52 & $3.027,42$ & 23,30 & $1.620,97$ \\
8.400 & 2 & 2.000 & 400 & 4.000 & 70,00 & 839,44 & $4.045,82$ & 31,15 & $2.219,05$ \\
\hline 3.150 & 3 & 500 & 150 & 1.500 & 78,58 & 978,66 & $1.498,94$ & 11,85 & 762,18 \\
6.300 & 3 & 1.000 & 300 & 3.000 & 75,07 & 921,95 & $3.028,03$ & 23,60 & $1.635,75$ \\
9.450 & 3 & 1.500 & 450 & 4.500 & 72,89 & 886,52 & $4.555,06$ & 35,16 & $2.522,63$ \\
12.600 & 3 & 2.000 & 600 & 6.000 & 71,34 & 861,60 & $6.081,23$ & 46,98 & $3.408,39$ \\
\hline 4.200 & 4 & 500 & 200 & 2.000 & 79,38 & 991,11 & $2.009,53$ & 15,88 & $1.056,96$ \\
8.400 & 4 & 1.000 & 400 & 4.000 & 75,72 & 932,42 & $4.046,09$ & 31,20 & $2.224,58$ \\
12.600 & 4 & 1.500 & 600 & 6.000 & 73,59 & 897,90 & $6.081,57$ & 46,86 & $3.415,63$ \\
16.800 & 4 & 2.000 & 800 & 8.000 & 72,07 & 872,84 & $8.119,07$ & 62,40 & $4.595,32$ \\
\hline 5.250 & 5 & 500 & 250 & 2.500 & 79,79 & 998,24 & $2.519,49$ & 19,65 & $1.347,61$ \\
10.500 & 5 & 1.000 & 500 & 5.000 & 76,24 & 940,58 & $5.063,88$ & 39,21 & $2.822,97$ \\
15.750 & 5 & 1.500 & 750 & 7.500 & 74,06 & 905,22 & $7.610,34$ & 58,54 & $4.316,64$ \\
21.000 & 5 & 2.000 & 1.000 & 10.000 & 72,45 & 879,36 & $10.154,73$ & 77,98 & $5.781,55$ \\
\hline 6.300 & 6 & 500 & 300 & 3.000 & 79,95 & $1.000,88$ & $3.027,82$ & 23,61 & $1.637,03$ \\
12.600 & 6 & 1.000 & 600 & 6.000 & 76,41 & 943,23 & $6.081,91$ & 46,94 & $3.419,15$ \\
18.900 & 6 & 1.500 & 900 & 9.000 & 74,19 & 907,69 & $9.136,86$ & 70,01 & $5.192,08$ \\
25.200 & 6 & 2.000 & 1.200 & 12.000 & 72,73 & 884,10 & $12.192,68$ & 93,80 & $6.974,97$ \\
\hline 10.500 & 10 & 500 & 500 & 5.000 & 80,50 & $1.009,39$ & $5.063,83$ & 39,61 & $2.820,89$ \\
21.000 & 10 & 1.000 & 1.000 & 10.000 & 76,94 & 951,73 & $10.154,12$ & 78,46 & $5.772,22$ \\
31.500 & 10 & 1.500 & 1.500 & 15.000 & 74,74 & 916,26 & $15.247,33$ & 117,14 & $8.738,01$ \\
42.000 & 10 & 2.000 & 2.000 & 20.000 & 73,18 & 891,13 & $20.340,87$ & 156,06 & $11.714,97$ \\
\hline & & & & & & & & &
\end{tabular}


Tabela B.9: Número médio de iterações para $\alpha=0,85$ e $\alpha=0,99$, número médio de páginas com diferentes posições, média do Desvio Médio e média do Desvio Máximo, variando o tamanho do grupo fechado, para grupos fechados de 5.000 a 20.000 páginas.

\begin{tabular}{|c|c|c|c|c|c|c|c|c|c|}
\hline$T P$ & $Q G F$ & $T P G F$ & $T P G L$ & TNP & $\begin{array}{l}\text { NI com } \\
\alpha=0,85\end{array}$ & $\begin{array}{l}\text { NI com } \\
\alpha=0,99\end{array}$ & $N P D$ & $M e d D$ & MaxD \\
\hline 10.500 & 1 & 5.000 & 500 & 5.000 & 24,14 & 30,16 & $5.063,79$ & 38,92 & $2.813,75$ \\
\hline 21.000 & 1 & 10.000 & 1.000 & 10.000 & 23,74 & 29,68 & $10.154,91$ & 78,34 & $5.782,42$ \\
\hline 31.500 & 1 & 15.000 & 1.500 & 15.000 & 23,54 & 29,42 & $15.247,13$ & 117,25 & $8.749,13$ \\
\hline 42.000 & 1 & 20.000 & 2.000 & 20.000 & 23,44 & 29,27 & $20.340,91$ & 155,75 & $11.722,12$ \\
\hline 21.000 & 2 & 5.000 & 1.000 & 10.000 & 64,96 & 758,05 & $10.155,92$ & 78,40 & $5.792,53$ \\
\hline 42.000 & 2 & 10.000 & 2.000 & 20.000 & 61,07 & 695,25 & $20.341,58$ & 156,02 & $11.722,34$ \\
\hline 63.000 & 2 & 15.000 & 3.000 & 30.000 & 58,77 & 658,15 & $30.531,00$ & 234,38 & $17.713,99$ \\
\hline 84.000 & 2 & 20.000 & 4.000 & 40.000 & 57,14 & 631,46 & $40.721,33$ & 312,00 & $23.683,56$ \\
\hline 31.500 & 3 & 5.000 & 1.500 & 15.000 & 66,37 & 781,04 & $15.246,88$ & 116,87 & $8.757,11$ \\
\hline 63.000 & 3 & 10.000 & 3.000 & 30.000 & 62,41 & 717,43 & $30.529,13$ & 233,66 & $17.704,65$ \\
\hline 94.500 & 3 & 15.000 & 4.500 & 45.000 & 60,14 & 680,06 & $45.815,00$ & 351,61 & $26.685,18$ \\
\hline 126.000 & 3 & 20.000 & 6.000 & 60.000 & 58,50 & 653,70 & $61.105,88$ & 468,40 & $35.819,19$ \\
\hline 42.000 & 4 & 5.000 & 2.000 & 20.000 & 67,07 & $\begin{array}{l}792,30 \\
\end{array}$ & $20.341,27$ & 156,23 & $11.741,09$ \\
\hline 84.000 & 4 & 10.000 & 4.000 & 40.000 & 63,21 & 729,80 & $40.720,49$ & 312,68 & $23.712,32$ \\
\hline 126.000 & 4 & 15.000 & 6.000 & 60.000 & 60,92 & 692,56 & $61.103,32$ & 467,90 & $35.716,34$ \\
\hline 168.000 & 4 & 20.000 & 8.000 & 80.000 & 59,30 & 666,66 & $81.488,28$ & 624,08 & $47.904,15$ \\
\hline 52.500 & 5 & 5.000 & 2.500 & 25.000 & 67,43 & 798,06 & $25.434,69$ & 194,71 & $14.684,69$ \\
\hline 105.000 & 5 & 10.000 & 5.000 & 50.000 & 63,50 & 734,91 & $50.911,21$ & 389,69 & $29.683,60$ \\
\hline 157.500 & 5 & 15.000 & 7.500 & 75.000 & 61,32 & 699,32 & $76.392,48$ & 585,69 & $44.805,54$ \\
\hline 210.000 & 5 & 20.000 & 10.000 & 100.000 & 59,67 & 672,56 & $101.870,84$ & 780,51 & $59.896,49$ \\
\hline 63.000 & 6 & 5.000 & 3.000 & 30.000 & 67,71 & 802,60 & $30.528,88$ & 234,28 & $17.672,37$ \\
\hline 126.000 & 6 & 10.000 & 6.000 & 60.000 & 63,82 & 739,71 & $61.102,11$ & 468,99 & $35.736,25$ \\
\hline 189.000 & 6 & 15.000 & 9.000 & 90.000 & 61,60 & 703,84 & $91.676,83$ & 702,87 & $53.899,11$ \\
\hline 252.000 & 6 & 20.000 & 12.000 & 120.000 & 59,93 & 676,79 & $122.260,37$ & 935,98 & $72.198,88$ \\
\hline 105.000 & 10 & 5.000 & 5.000 & 50.000 & 68,20 & 810,50 & $50.911,35$ & 389,44 & $29.724,16$ \\
\hline 210.000 & 10 & 10.000 & 10.000 & 100.000 & 64,32 & 748,10 & $101.871,98$ & 780,22 & $59.944,88$ \\
\hline 315.000 & 10 & 15.000 & 15.000 & 150.000 & 62,02 & 710,96 & $152.834,48$ & $1.169,93$ & $90.389,93$ \\
\hline 420.000 & 10 & 20.000 & 20.000 & 200.000 & 60,39 & 684,65 & $203.797,67$ & $1.558,98$ & $120.846,33$ \\
\hline
\end{tabular}


Tabela B.10: Número médio de iterações para $\alpha=0,85$ e $\alpha=0,99$, número médio de páginas com diferentes posições, média do Desvio Médio e média do Desvio Máximo, variando o tamanho do grupo fechado, para um total de 500, 5.000 e 50.000 páginas nos conjuntos fechados.

\begin{tabular}{cccccccccc}
\hline$T P$ & QGF & TPGF & TPGL & TNP & $\begin{array}{c}\text { NI com } \\
\alpha=0,85\end{array}$ & $\begin{array}{c}\text { NI com } \\
\alpha=0,99\end{array}$ & NPD & MedD & MaxD \\
\hline 1.050 & 1 & 500 & 50 & 500 & 25,07 & 31,52 & 476,13 & 4,01 & 215,63 \\
1.050 & 2 & 250 & 50 & 500 & 80,91 & $1.016,40$ & 477,09 & 4,07 & 213,80 \\
1.050 & 5 & 100 & 50 & 500 & 87,51 & $1.123,20$ & 482,63 & 5,11 & 233,04 \\
1.054 & 8 & 63 & 50 & 504 & 89,85 & $1.161,05$ & 489,35 & 6,82 & 252,30 \\
1.050 & 10 & 50 & 50 & 500 & 90,94 & $1.178,54$ & 485,31 & 7,85 & 246,75 \\
1.050 & 20 & 25 & 50 & 500 & 93,27 & $1.215,89$ & 487,24 & 12,20 & 220,80 \\
1.050 & 50 & 10 & 50 & 500 & 94,25 & $1.231,72$ & 485,18 & 5,49 & 103,94 \\
\hline 10.500 & 1 & 5.000 & 500 & 5.000 & 24,16 & 30,13 & $5.064,90$ & 39,32 & $2.815,07$ \\
10.500 & 2 & 2.500 & 500 & 5.000 & 68,79 & 820,08 & $5.064,75$ & 39,03 & $2.821,75$ \\
10.500 & 5 & 1.000 & 500 & 5.000 & 76,24 & 940,58 & $5.063,88$ & 39,21 & $2.822,97$ \\
10.500 & 8 & 625 & 500 & 5.000 & 79,22 & 988,81 & $5.063,59$ & 39,32 & $2.819,20$ \\
10.500 & 10 & 500 & 500 & 5.000 & 80,49 & $1.009,35$ & $5.064,25$ & 39,29 & $2.822,99$ \\
10.500 & 20 & 250 & 500 & 5.000 & 84,38 & $1.072,09$ & $5.065,83$ & 41,09 & $2.837,07$ \\
10.500 & 50 & 100 & 500 & 5.000 & 88,64 & $1.141,16$ & $5.068,32$ & 50,92 & $2.819,26$ \\
10.580 & 80 & 63 & 500 & 5.040 & 90,67 & $1.174,02$ & $5.108,55$ & 67,08 & $2.795,09$ \\
10.500 & 100 & 50 & 500 & 5.000 & 91,58 & $1.188,65$ & $5.067,52$ & 78,02 & $2.710,70$ \\
\hline 105.000 & 1 & 50.000 & 5.000 & 50.000 & 22,96 & 28,60 & $50.909,03$ & 389,94 & $29.741,41$ \\
105.000 & 2 & 25.000 & 5.000 & 50.000 & 55,85 & 610,93 & $50.910,59$ & 390,08 & $29.710,58$ \\
105.000 & 5 & 10.000 & 5.000 & 50.000 & 63,50 & 734,91 & $50.911,21$ & 389,69 & $29.683,60$ \\
105.000 & 8 & 6.250 & 5.000 & 50.000 & 66,72 & 787,15 & $50.910,63$ & 390,40 & $29.734,07$ \\
105.000 & 10 & 5.000 & 5.000 & 50.000 & 68,20 & 810,50 & $50.911,35$ & 389,44 & $29.724,16$ \\
105.000 & 20 & 2.500 & 5.000 & 50.000 & 72,29 & 876,43 & $50.911,26$ & 390,18 & $29.729,42$ \\
105.000 & 50 & 1.000 & 5.000 & 50.000 & 77,43 & 959,70 & $50.910,19$ & 391,30 & $29.693,48$ \\
105.000 & 80 & 625 & 5.000 & 50.000 & 79,91 & 999,87 & $50.912,57$ & 392,67 & $29.670,31$ \\
105.000 & 100 & 500 & 5.000 & 50.000 & 81,00 & $1.017,86$ & $50.913,14$ & 393,88 & $29.611,96$ \\
\hline
\end{tabular}


Tabela B.11: Número médio de iterações para $\alpha=0,85$ e $\alpha=0,99$, número médio de páginas com diferentes posições, média do Desvio Médio e média do Desvio Máximo, variando o tamanho do grupo fechado, para combinações de grupos fechados de 50 e 500 páginas e 450 e 500 páginas.

\begin{tabular}{|c|c|c|c|c|c|c|c|c|c|}
\hline$T P$ & $Q G F$ & $T P G F$ & $T P G L$ & $T N P$ & $\begin{array}{l}N I \text { com } \\
\alpha=0,85\end{array}$ & $\begin{array}{l}N I \text { com } \\
\alpha=0,99\end{array}$ & $N P D$ & $M e d D$ & $\operatorname{Max} D$ \\
\hline 1.155 & 2 & $1 \times 50 ; 1 \times 500$ & 55 & 550 & 91,04 & $1.179,89$ & 531,41 & 4,91 & 250,71 \\
\hline 1.995 & 2 & $1 \times 450 ; 1 \times 500$ & 95 & 950 & 78,14 & 971,22 & 937,45 & 7,58 & 460,10 \\
\hline 2.205 & 3 & $1 \times 50 ; 2 \times 500$ & 105 & 1.050 & 91,36 & $1.185,29$ & $1.040,97$ & 8,78 & 519,33 \\
\hline 3.045 & 3 & $1 \times 450 ; 2 \times 500$ & 145 & 1.450 & 79,42 & 992,47 & $1.448,13$ & 11,60 & 741,30 \\
\hline 1.260 & 3 & $2 \times 50 ; 1 \times 500$ & 60 & 600 & 91,07 & $1.180,12$ & 584,34 & 5,73 & 281,07 \\
\hline 2.940 & 3 & $2 \times 450 ; 1 \times 500$ & 140 & 1.400 & 79,30 & 990,40 & $1.396,13$ & 11,10 & 703,43 \\
\hline 2.310 & 4 & $2 \times 50 ; 2 \times 500$ & 110 & 1.100 & 91,44 & $1.186,27$ & $1.094,48$ & 9,58 & 556,31 \\
\hline 3.990 & 4 & $2 \times 450 ; 2 \times 500$ & 190 & 1.900 & 80,02 & $1.001,45$ & $1.907,18$ & 15,07 & 991,96 \\
\hline 4.305 & 5 & $1 \times 50 ; 4 \times 500$ & 205 & 2.050 & 91,48 & $1.187,23$ & $2.060,58$ & 16,65 & $1.088,27$ \\
\hline 5.145 & 5 & $1 \times 450 ; 4 \times 500$ & 245 & 2.450 & 80,39 & $1.008,16$ & $2.468,30$ & 19,48 & $1.319,88$ \\
\hline 1.470 & 5 & $4 \times 50 ; 1 \times 500$ & 70 & 700 & 91,24 & $1.183,12$ & 688,27 & 7,24 & 349,99 \\
\hline 4.830 & 5 & $4 \times 450 ; 1 \times 500$ & 230 & 2.300 & 80,39 & $1.008,02$ & $2.314,36$ & 18,13 & $1.222,66$ \\
\hline 4.620 & 8 & $4 \times 50 ; 4 \times 500$ & 220 & 2.200 & 91,40 & $1.185,91$ & $2.215,41$ & 19,12 & $1.194,62$ \\
\hline 7.980 & 8 & $4 \times 450 ; 4 \times 500$ & 380 & 3.800 & 80,89 & $1.015,60$ & $3.841,43$ & 29,91 & $2.104,04$ \\
\hline 8.505 & 9 & $1 \times 50 ; 8 \times 500$ & 405 & 4.050 & 91,56 & $1.188,42$ & $4.097,29$ & 32,51 & $2.255,10$ \\
\hline 9.345 & 9 & $1 \times 450 ; 8 \times 500$ & 445 & 4.450 & 81,05 & $1.018,37$ & $4.504,36$ & 34,98 & $2.498,70$ \\
\hline 6.615 & 9 & $3 \times 50 ; 6 \times 500$ & 315 & 3.150 & 91,54 & $1.188,21$ & $3.181,54$ & 26,02 & $1.735,57$ \\
\hline 9.135 & 9 & $3 \times 450 ; 6 \times 500$ & 435 & 4.350 & 81,04 & $1.018,36$ & $4.402,05$ & 34,31 & $2.440,41$ \\
\hline 1.890 & 9 & $8 \times 50 ; 1 \times 500$ & 90 & 900 & 91,24 & $1.182,90$ & 893,88 & 10,54 & 468,33 \\
\hline 8.610 & 9 & $8 \times 450 ; 1 \times 500$ & 410 & 4.100 & 81,06 & $1.018,57$ & $4.148,12$ & 32,37 & $2.276,47$ \\
\hline 3.780 & 9 & $6 \times 50 ; 3 \times 500$ & 180 & 1.800 & 91,34 & $1.185,11$ & $1.809,84$ & 17,01 & 971,12 \\
\hline 8.820 & 9 & $6 \times 450 ; 3 \times 500$ & 420 & 4.200 & 81,01 & $1.017,31$ & $4.249,82$ & 33,29 & $2.346,38$ \\
\hline 8.085 & 14 & $7 \times 50 ; 7 \times 500$ & 385 & 3.850 & 91,64 & $1.189,69$ & $3.895,84$ & 33,46 & $2.166,59$ \\
\hline 13.965 & 14 & $7 \times 450 ; 7 \times 500$ & 665 & 6.650 & 81,24 & $1.021,46$ & $6.743,40$ & 52,42 & $3.789,72$ \\
\hline 11.550 & 20 & $10 \times 50 ; 10 \times 500$ & 550 & 5.500 & 91,63 & $1.189,29$ & $5.576,07$ & 47,76 & $3.140,09$ \\
\hline 19.950 & 20 & $10 \times 450 ; 10 \times 500$ & 950 & 9.500 & 81,36 & $1.023,54$ & $9.646,71$ & 74,98 & $5.474,81$ \\
\hline
\end{tabular}


Tabela B.12: Número médio de iterações para $\alpha=0,85$ e $\alpha=0,99$, número médio de páginas com diferentes posições, média do Desvio Médio e média do Desvio Máximo, variando o tamanho do grupo fechado, para combinações de grupos fechados de 500 e 5.000 páginas e 4.500 e 5.000 páginas.

\begin{tabular}{|c|c|c|c|c|c|c|c|c|c|}
\hline$T P$ & $Q G F$ & $T P G F$ & $T P G L$ & $\overline{T N P}$ & $\begin{array}{l}\text { NI com } \\
\alpha=0,85\end{array}$ & $\begin{array}{l}\text { NI com } \\
\alpha=0,99\end{array}$ & $N P D$ & $M e d D$ & $\operatorname{MaxD}$ \\
\hline 11.550 & 2 & $1 \times 500 ; 1 \times 5000$ & 550 & 5.500 & 80,59 & $1.010,74$ & $5.573,38$ & 43,07 & $3.114,72$ \\
\hline 19.950 & 2 & $1 \times 4500 ; 1 \times 5000$ & 950 & 9.500 & 65,60 & 768,60 & $9.646,23$ & 73,98 & $5.487,08$ \\
\hline 22.050 & 3 & $1 \times 500 ; 2 \times 5000$ & 1.050 & 10.500 & 80,83 & $1.014,67$ & $10.664,84$ & 81,71 & $6.065,24$ \\
\hline 30.450 & 3 & $1 \times 4500 ; 2 \times 5000$ & 1.450 & 14.500 & 67,14 & 793,15 & $14.736,47$ & 113,11 & $8.448,03$ \\
\hline 12.600 & 3 & $2 \times 500 ; 1 \times 5000$ & 600 & 6.000 & 80,68 & $1.012,28$ & $6.081,47$ & 47,03 & $3.417,35$ \\
\hline 29.400 & 3 & $2 \times 4500 ; 1 \times 5000$ & 1.400 & 14.000 & 67,02 & 791,58 & $14.229,82$ & 109,21 & $8.150,65$ \\
\hline 23.100 & 4 & $2 \times 500 ; 2 \times 5000$ & 1.100 & 11.000 & 80,86 & $1.015,23$ & $11.174,14$ & 86,02 & $6.374,87$ \\
\hline 39.900 & 4 & $2 \times 4500 ; 2 \times 5000$ & 1.900 & 19.000 & 67,65 & 801,64 & $19.322,15$ & 147,99 & $11.122,88$ \\
\hline 43.050 & 5 & $1 \times 500 ; 4 \times 5000$ & 2.050 & 20.500 & 81,04 & $1.018,02$ & $20.851,71$ & 160,01 & $12.023,49$ \\
\hline 51.450 & 5 & $1 \times 4500 ; 4 \times 5000$ & 2.450 & 24.500 & 68,15 & 809,69 & $24.927,38$ & 191,05 & $14.422,38$ \\
\hline 14.700 & 5 & $4 \times 500 ; 1 \times 5000$ & 700 & 7.000 & 80,67 & $1.012,52$ & $7.100,75$ & 54,32 & $4.002,27$ \\
\hline 48.300 & 5 & $4 \times 4500 ; 1 \times 5000$ & 2.300 & 23.000 & 68,09 & 808,91 & $23.398,83$ & 179,46 & $13.518,07$ \\
\hline 46.200 & 8 & $4 \times 500 ; 4 \times 5000$ & 2.200 & 22.000 & 81,04 & $1.018,12$ & $22.380,02$ & 171,63 & $12.914,66$ \\
\hline 79.800 & 8 & $4 \times 4500 ; 4 \times 5000$ & 3.800 & 38.000 & 68,60 & 817,16 & $38.682,59$ & 296,38 & $22.468,89$ \\
\hline 85.050 & 9 & $1 \times 500 ; 8 \times 5000$ & 4.050 & 40.500 & 81,14 & $1.019,49$ & $41.227,37$ & 316,05 & $23.997,85$ \\
\hline 93.450 & 9 & $1 \times 4500 ; 8 \times 5000$ & 4.450 & 44.500 & 68,74 & 819,10 & $45.305,85$ & 346,98 & $26.385,51$ \\
\hline 66.150 & 9 & $3 \times 500 ; 6 \times 5000$ & 3.150 & 31.500 & 80,99 & $1.017,65$ & $32.057,70$ & 245,79 & $18.573,76$ \\
\hline 91.350 & 9 & $3 \times 4500 ; 6 \times 5000$ & 4.350 & 43.500 & 68,66 & 817,89 & $44.288,67$ & 338,74 & $25.763,32$ \\
\hline 18.900 & 9 & $8 \times 500 ; 1 \times 5000$ & 900 & 9.000 & 80,81 & $1.014,50$ & $9.137,19$ & 70,71 & $5.188,34$ \\
\hline 86.100 & 9 & $8 \times 4500 ; 1 \times 5000$ & 4.100 & 41.000 & 68,70 & 818,56 & $41.738,48$ & 319,41 & $24.302,71$ \\
\hline 37.800 & 9 & $6 \times 500 ; 3 \times 5000$ & 1.800 & 18.000 & 81,00 & $1.017,45$ & $18.303,97$ & 140,44 & $10.531,42$ \\
\hline 88.200 & 9 & $6 \times 4500 ; 3 \times 5000$ & 4.200 & 42.000 & 68,69 & 818,65 & $42.759,81$ & 327,76 & $24.920,97$ \\
\hline 80.850 & 14 & $7 \times 500 ; 7 \times 5000$ & 3.850 & 38.500 & 81,08 & $1.018,49$ & $39.192,59$ & 300,84 & $22.809,49$ \\
\hline 139.650 & 14 & $7 \times 4500 ; 7 \times 5000$ & 6.650 & 66.500 & 68,97 & 823,32 & $67.727,80$ & 518,64 & $39.671,48$ \\
\hline 115.500 & 20 & $10 \times 500 ; 10 \times 5000$ & 5.500 & 55.000 & 81,16 & $1.020,18$ & $56.006,28$ & 430,27 & $32.711,32$ \\
\hline 199.500 & 20 & $10 \times 4500 ; 10 \times 5000$ & 9.500 & 95.000 & 69,07 & 824,75 & $96.773,80$ & 741,63 & $56.934,36$ \\
\hline
\end{tabular}


Tabela B.13: Número médio de iterações para $\alpha=0,85$ e $\alpha=0,99$, número médio de páginas com diferentes posições, média do Desvio Médio e média do Desvio Máximo, variando o tamanho do grupo fechado, para combinações de grupos fechados de diversos tamanhos.

\begin{tabular}{|c|c|c|c|c|c|c|c|c|c|}
\hline$T P$ & $Q G F$ & $T P G F$ & $T P G L$ & $T N P$ & $\begin{array}{l}\text { NI com } \\
\alpha=0,85\end{array}$ & $\begin{array}{l}\text { NI com } \\
\alpha=0,99\end{array}$ & $N P D$ & $M e d D$ & MaxD \\
\hline 1.050 & 1 & 500 & 50 & 500 & 25,02 & 31,43 & 476,83 & 4,02 & 214,60 \\
\hline 1.050 & 2 & $20 ; 480$ & 50 & 500 & 93,66 & $1.222,73$ & 480,90 & 4,62 & 232,66 \\
\hline 1.050 & 2 & $200 ; 300$ & 50 & 500 & 82,56 & $1.042,62$ & 478,14 & 4,13 & 216,76 \\
\hline 1.050 & 2 & 250 & 50 & 500 & 80,93 & $1.016,73$ & 477,77 & 4,11 & 217,16 \\
\hline 1.050 & 3 & 10;190;300 & 50 & 500 & 94,30 & $1.232,36$ & 479,50 & 4,60 & 230,84 \\
\hline 1.050 & 3 & $2 \times 10 ; 480$ & 50 & 500 & 94,25 & $1.231,61$ & 478,87 & 4,85 & 234,78 \\
\hline 1.050 & 4 & $20 ; 2 \times 120 ; 240$ & 50 & 500 & 93,71 & $1.223,10$ & 482,05 & 5,00 & 235,04 \\
\hline 1.050 & 4 & $3 \times 100 ; 200$ & 50 & 500 & 87,50 & $1.122,61$ & 481,41 & 4,78 & 231,04 \\
\hline 1.050 & 4 & $20 ; 100 ; 180 ; 200$ & 50 & 500 & 93,61 & $1.221,79$ & 482,04 & 5,06 & 235,32 \\
\hline 1.050 & 5 & $20 ; 4 \times 120$ & 50 & 500 & 93,73 & $1.223,30$ & 482,59 & 5,32 & 239,55 \\
\hline 1.050 & 7 & $5 \times 10 ; 150 ; 300$ & 50 & 500 & 94,28 & $1.232,26$ & 481,84 & 6,13 & 238,35 \\
\hline 10.500 & 1 & 5.000 & 500 & 5000 & 24,16 & 30,19 & $5.065,42$ & 39,09 & $2.830,08$ \\
\hline 10.500 & 2 & $200 ; 4800$ & 500 & 5000 & 85,37 & $1.088,63$ & $5.064,18$ & 39,33 & $2.818,60$ \\
\hline 10.500 & 2 & $2000 ; 3000$ & 500 & 5000 & 70,65 & 850,35 & $5.064,65$ & 39,16 & $2.828,62$ \\
\hline 10.500 & 2 & 2500 & 500 & 5000 & 68,76 & 819,74 & $5.064,27$ & 39,17 & $2.827,18$ \\
\hline 10.500 & 3 & $100 ; 1900 ; 30$ & 500 & 5000 & 88,74 & $1.142,52$ & $5.064,42$ & 39,29 & $2.813,06$ \\
\hline 10.500 & 3 & $2 \times 100 ; 4800$ & 500 & 5000 & 88,72 & $1.142,67$ & $5.063,99$ & 39,59 & $2.811,23$ \\
\hline 10.500 & 4 & $200 ; 2 \times 1200 ; 2400$ & 500 & 5000 & 85,47 & $1.089,68$ & $5.063,72$ & 38,98 & $2.827,21$ \\
\hline 10.500 & 4 & $3 \times 1000 ; 2000$ & 500 & 5000 & 76,16 & 939,40 & $5.063,30$ & 39,04 & $2.821,04$ \\
\hline 10.500 & 4 & $200 ; 1000 ; 1800 ; 2000$ & 500 & 5000 & 85,52 & $1.090,36$ & $5.064,48$ & 39,13 & $2.819,96$ \\
\hline 10.500 & 5 & $4 \times 50 ; 4800$ & 500 & 5000 & 91,55 & $1.188,23$ & $5.065,01$ & 40,70 & $2.826,7$ \\
\hline 10.500 & 5 & $200 ; 4 \times 1200$ & 500 & 5000 & 85,45 & $1.089,51$ & $5.063,28$ & 39,06 & $2.814,89$ \\
\hline 10.500 & 7 & $5 \times 100 ; 1500 ; 3000$ & 500 & 5000 & 88,77 & $1.142,90$ & $5.063,65$ & 40,29 & $2.831,70$ \\
\hline 105.000 & 1 & 50000 & 5000 & 50000 & 23,00 & 28,63 & $50.909,94$ & 390,32 & $29.731,64$ \\
\hline 105.000 & 2 & $2000 ; 48000$ & 5000 & 50000 & 73,53 & 896,57 & $50.913,45$ & 390,50 & $29.730,3$ \\
\hline 105.000 & 2 & $20000 ; 30000$ & 5000 & 50000 & 57,96 & 645,03 & $50.911,98$ & 390,69 & $29.734,2$ \\
\hline 105.000 & 2 & 25000 & 5000 & 50000 & 55,85 & 610,93 & $50.910,59$ & 390,08 & $29.710,5$ \\
\hline 105.000 & 3 & $1000 ; 19000 ; 30000$ & 5000 & 50000 & 77,50 & 960,63 & $50.910,01$ & 389,89 & $29.666,4$ \\
\hline 105.000 & 3 & $2 \times 1000 ; 48000$ & 5000 & 50000 & 77,46 & 960,53 & $50.911,78$ & 390,16 & $29.707,8$ \\
\hline 105.000 & 4 & $2000 ; 2 \times 12000 ; 24000$ & 5000 & 50000 & 73,60 & 898,01 & $50.912,21$ & 390,25 & $29.698,2$ \\
\hline 105.000 & 4 & $3 \times 10000 ; 20000$ & 5000 & 50000 & 63,59 & 735,81 & $50.910,69$ & 390,02 & $29.735,5$ \\
\hline 105.000 & 4 & $2000 ; 10000 ; 18000 ; 20000$ & 5000 & 50000 & 73,65 & 898,67 & $50.912,60$ & 390,21 & $29.710,0$ \\
\hline 105.000 & 5 & $4 \times 500 ; 48000$ & 5000 & 50000 & 81,16 & $1.020,13$ & $50.908,85$ & 389,81 & $29.683,8$ \\
\hline 105.000 & 5 & $2000 ; 4 \times 12000$ & 5000 & 50000 & 73,57 & 897,00 & $50.912,83$ & 390,20 & $29.749,4$ \\
\hline 105.000 & 7 & $5 \times 1000 ; 15000 ; 30000$ & 5000 & 50000 & 77,38 & 959,12 & $50.911,72$ & 390,29 & $29.680,72$ \\
\hline
\end{tabular}




\section{Referências Bibliográficas}

[1] D. Austin, How Google Finds Your Needle in the Web's Haystack, American Mathematical Society Feature Column (Dec. 2006).

[2] K. Bryan, T. Leise, The \$ 25,000,000,000 Eigenvector the Linear Algebra Behind Google, SIAM Review (2006), vol. 48, no.3, 569-581.

[3] T.H. Haveliwala, S.D. Kamvar, The Second Eigenvalue of the Google Matrix, Stanford Publication - Technical Report (2003).

[4] R. Durrett, Essentials of Stochastic Processes, first ed., Springer-Verlag, New York, 1999.

[5] D.L. Isaacson, R.W. Madsen, Markov Chains Theory and Applications, second ed., John Wiley and Sons, Florida, 1985.

[6] G.R. Grimmett, D.R. Stirzaker, Probability and Random Processes, second ed., Oxford University Press, New York, 1992.

[7] A.R. Gourlay, G.A. Watson, Computational Methods for Matrix Eigenproblems, first ed., John Wiley and Sons, Florida, 1973.

[8] J.H. Wilkinson, The Algebraic Eigenvalue Problem, first ed., Oxford University Press, New York, 1965.

[9] E.A. Souza e Silva, R.R. Muntz, Métodos Computacionais de Solução de Cadeias de Markov: Aplicações a Sistemas de Computação e Comunicação, first ed., Inst.Informática da UFRGS, Porto Alegre, 1992. 